Universidade de São PaUlo

FFCLRP - DEPARTAMENTO DE FísiCA E MATEMÁTICA

Pós-GraduaÇão EM Física Aplicada À Medicina E Biologia

\title{
Ferramentas computacionais na análise da variabilidade da frequência cardíaca através do paradigma não extensivo no estudo de cardiopatias.
}

Luiz Eduardo Virgilio da Silva

Ribeirão Preto - SP

2010 


\section{LUIZ EDUARDO VIRGILIO DA SILVA}

\section{Ferramentas computacionais na análise da variabilidade da frequiência cardíaca através do paradigma não extensivo no estudo de cardiopatias.}

Dissertação apresentada à Faculdade de Filosofia, Ciências e Letras de Ribeirão Preto da Universidade de São Paulo, como parte das exigências para a obtenção do título de Mestre em Ciências.

Àrea de Concentração:

Física Aplicada à Medicina e Biologia.

Orientador:

Prof. Dr. Luiz Otavio Murta Junior

Ribeirão Preto - SP

2010 
Autorizo a reprodução e divulgação total ou parcial deste trabalho, por qualquer meio convencional ou eletrônico, para fins de estudo e pesquisa, desde que citada a fonte.

SILVA, LUIZ EDUARDO VIRGILIO.

Ferramentas computacionais na análise da variabilidade da freqüência cardíaca através do paradigma não extensivo no estudo de cardiopatias / Luiz Eduardo Virgilio da Silva; orientador Luiz Otavio Murta Junior. Ribeirão Preto, 2010.

$94 \mathrm{p}$.

Dissertação (Mestrado - Programa de Pós-Graduação em Física Aplicada à Medicina e Biologia) - Faculdade de Filosofia, Ciências e Letras de Ribeirão Preto da Universidade de São Paulo.

1. Variabilidade da frequência cardíaca. 2. Sistemas não lineares. 4. Caos determinístico. 5. Entropia. 6. Entropia não extensiva. 7. Transformada de Fourier. 


\section{Agradecimentos}

Em primeiro lugar, agradeço à Deus por tudo o que tenho, pela oportunidade de estudar, de crescer e trabalhar em meu próprio favor e em favor dos outros.

Agradeço ao professor Luiz Otávio Murta Junior pela paciência comigo e por me orientar nas atividades acadêmicas desde a graduação, e também à todos os outros professores que, direta ou indiretamente, contribuem nas nossas formações. Agradeço também à todos os colegas de laboratório pelas conversas de produção e descontração que vem nos motivando e fortalecendo nosso grupo.

Finalmente, agradeço aos meus pais, esposa, tias, tios e primos por todo o apoio moral e carinho que me oferecem, apesar de todos os meus defeitos, para estarmos sempre firmes e unidos diante das dificuldades, fortalecendo nosso ânimo e nossa fé em Deus para continuar buscando dar o melhor de nós em todas as nossas atividades.

À todos, meu sincero agradecimento! 
"Quanto mais sei, mais sei que nada sei." Sócrates

"Quem sabe pode muito, quem ama pode mais." Francisco Cândido Xavier 


\section{Resumo}

SILVA, L. E V. Ferramentas computacionais na análise da variabilidade da frequência cardíaca através do paradigma não extensivo no estudo de cardiopatias. 2010. 94f. Dissertação (Mestrado) - Faculdade de Filosofia, Ciências e Letras de Ribeirão Preto, Universidade de São Paulo, Ribeirão Preto, 2010.

Este trabalho teve por objetivo construir e avaliar ferramentas de quantificação e análise da variabilidade da freqüência cardíaca segundo o paradigma não extensivo de Tsallis na modelagem do sistema de regulação da freqüência cardíaca, e na discriminação de situação de normalidade e cardiopatias e apoio ao diagnóstico de cardiopatias. O sistema de regulação da frequiência cardíaca é reconhecidamente não linear. Este estudo explora esta característica, quantificando a complexidade através de uma família de entropias condicionais não extensivas e outras medidas de avaliação usualmente utilizadas na análise da variabilidade cardíaca. Foram utilizados dados reais de 15 indivíduos saudáveis, 23 indivíduos chagásicos e 19 indivíduos hipertensos, além de dados simulados computacionalmente para uma avaliação controlada das ferramentas estatísticas estudadas. Durante a avaliação foram gerados dados substitutos (surrogate data) para os testes de validade e intensidade da hipótese de não linearidade das séries. Os resultados mostraram que o parâmetro $q$ introduz uma forma diferente de quantificação da complexidade do sinal. Com o auxílio dos dados substitutos, foi possível identificar, para alguns sinais, a região de valores de $q$ onde o comportamento não linear é mais evidente. Os resultados obtidos indicam que a abordagem merece estudos mais aprofundados. 


\section{Abstract}

SILVA, L. E V. Computational tools for heart rate variability analysis through non-extensive paradigm in heart diseases. 2010. 94f. Dissertação (Mestrado) - Faculdade de Filosofia, Ciências e Letras de Ribeirão Preto, Universidade de São Paulo, Ribeirão Preto, 2010.

This study aimed to construct and evaluate tools for quantification and analysis of heart rate variability under Tsallis non-extensive statistical paradigm to model heart rate regulation system, and discrimination in situations of healthy conditions and support diagnosis of heart diseases. The heart rate regulation system is known to be nonlinear. This study explores this feature by quantifying the signal complexity through a family of non extensive conditional entropy and other evaluation measures commonly used in the analysis of heart rate variability. We used real data from 15 healthy subjects, 23 individuals with Chagas disease and 19 hypertensive individuals, in addition to simulated data to make a computationally controlled evaluation of the statistical tools studied. During the evaluation were generated surrogate data for tests of validity and strength of the time series non-linearity hypothesis. The results have shown that the $q$ parameter introduces a different way of quantifying the complexity of the signal. With the support of surrogate data, it was possible to identify a range of $q$ values that nonlinear behavior is more evident for some signals. The results indicate that the approach deserves further study. 


\section{Lista de Figuras}

2.1 Ilustração do mecanismo de regulação da frequência cardíaca. . . . . . . . . p. 15

2.2 Ilustração da geração de uma série de intervalos RR a partir de um ECG. . . . p. 17

3.1 Representação do pêndulo simples. . . . . . . . . . . . . . . . . p. 23

3.2 Diagrama de fases do pêndulo simples. . . . . . . . . . . . . . p. 24

3.3 Evolução e mapa de fases do mapa logístico em regime regular. . . . . . . . . p. 25

3.4 Diagrama representando as propriedades de aditividade e homogeneidade de sistemas lineares. . . . . . . . . . . . . . . . . p. 27

3.5 Mapas de fase do pêndulo forçado e amortecido. . . . . . . . . . . . . p. 30

3.6 Diagrama de bifurcações do pêndulo. . . . . . . . . . . . . p. 31

3.7 Diagrama de bifurcação do mapa logístico. . . . . . . . . . . . . . p. 32

3.8 Relação entre o diagrama de bifurcação e expoentes de Lyapunov do mapa

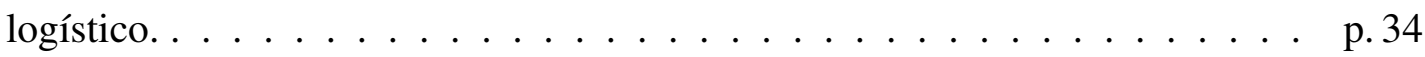

4.1 Convergência da entropia KS utilizando a equação de diferença (4.14). . . . . p. p.43

4.2 Exemplo de contagem de padrões da equação (4.18) . . . . . . . . . . . p. p.44

4.3 Exemplo de cálculo da entropia amostral para diferentes valores dos parâme-

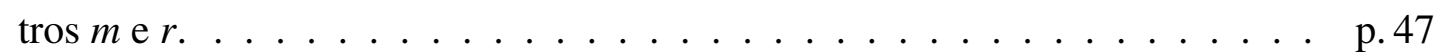

4.4 Ilustração da construção das séries em diferentes escalas. . . . . . . . . . . . p. 48

4.5 Exemplos de resultado da entropia multiescala. . . . . . . . . . . . . p. 48

4.6 Ilustração da função $\ln _{q}(x)$ em função de $x$ e $q . \ldots \ldots \ldots \ldots$ p. . . . . . . . . .

5.1 Protocolo de obtenção de dados no Laboratório de Fisiologia do Exercício da FMRP . . . . . . . . . . . . . . . . . . p. 53

6.1 Transformada q-Fourier para alguns valores de $q$ entre 1 e $3 . \ldots \ldots$ p. 62

6.2 Transformada q-Fourier para alguns valores de $q$ próximos de $1 . \ldots$. . . . p.63 
6.3 Entropia aproximada e amostral das séries de variabilidade cardíaca dos grupos normais, chagásicos e hipertensos. . . . . . . . . . . . . . p. 64

6.4 Diagrama de blocos indicando a ordem (classificação) de cada série RR de acordo com o valor da entropia amostral, para as siutações de repouso e tilt. . p.65

6.5 Resultado das entropias aproximada e amostral para os sinais simulados. . . . p. 66

6.6 Entropia aproximada e amostral das séries de variabilidade cardíaca. . . . . . p. 67

6.7 Diagrama de blocos indicando a ordem (classificação) de cada série RR de acordo com o valor da entropia amostral, para as siutações de repouso e tilt. . p.68

6.8 Resultado das entropias aproximada e amostral para os sinais simulados. . . . p. 69

6.9 Resultado da entropia multiescala (MSE) do ruído 1/f, utilizando a generalização da equação $(5.5) \ldots \ldots$. . . . . . . . . . . . . . . . . p.70

6.10 Resultado da entropia multiescala (MSE) do ruído 1/f e da mesma série RR utilizada anteriormente, utilizando a generalização da equação (5.7). . . . . . p. 71

6.11 Análise surrogate das séries RR, utilizando surrogates tipo 1. . . . . . . . . p.73

6.12 Análise surrogate dos sinais simulados, utilizando surrogates tipo 1. . . . . . p.74

6.13 Diagrama de blocos com a classificação de cada série RR em relação à diferença de entropia entre a série original e a entropia média das séries surrogates tipo 1, utilizando a generalização da entropia dada pela equação (5.5). p.75

6.14 Diagrama de blocos com a classificação de cada série $\mathrm{RR}$ em relação à diferença de entropia entre a série original e a entropia média das séries surrogates tipo 1, utilizando a generalização da entropia dada pela equação (5.7). . p.76

6.15 Diagrama de blocos com a classificação dos sinais simulados em relação à diferença de entropia entre a série original e a entropia média das séries surrogates tipo $1 \ldots \ldots \ldots \ldots \ldots \ldots$. . . . . . . . . . . . . . . . . . . . . . .

6.16 Análise surrogate das séries RR, utilizando surrogates tipo 2 . . . . . . . . . p.78

6.17 Análise dos sinais simulados, utilizando surrogates tipo $2 . \quad \ldots \ldots$. . . . . p. 79

6.18 Diagrama de blocos com a classificação de cada série RR em relação à diferença de entropia entre a série original e a entropia média das séries surrogates tipo 2, utilizando a generalização da entropia dada pela equação (5.5). . p.80 
6.19 Diagrama de blocos com a classificação de cada série RR em relação à diferença de entropia entre a série original e a entropia média das séries surrogates tipo 2, utilizando a generalização da entropia dada pela equação (5.7). p.81

6.20 Diagrama de blocos com a classificação dos sinais simulados em relação à diferença de entropia entre a série original e a entropia média das séries surrogates tipo $2 \ldots \ldots \ldots \ldots \ldots \ldots \ldots \ldots$. . . . . . . . . . . . . . . . .

6.21 Análise das séries RR utilizando surrogates tipo $3 . \quad \ldots \ldots \ldots$. . . . . . . 83

6.22 Análise dos sinais simulados utilizando surrogates tipo 3. . . . . . . . . . p. 84

6.23 Diagrama de blocos com a classificação de cada série em relação à diferença de entropia entre a série original e a entropia média das séries surrogates tipo 3, utilizando a generalização da entropia dada pela equação (5.5) . . . . . . . p. 85

6.24 Diagrama de blocos com a classificação de cada série em relação à diferença de entropia entre a série original e a entropia média das séries surrogates tipo 3, utilizando a generalização da entropia dada pela equação (5.7) . . . . . . . . p. 86

6.25 Diagrama de blocos com a classificação dos sinais simulados em relação à diferença de entropia entre a série original e a entropia média das séries sur-

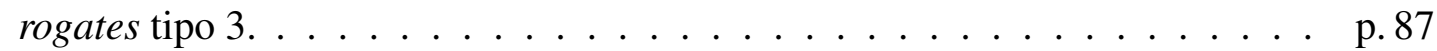

6.26 Estrutura de tabelas definida para o banco de dados do sistema. . . . . . . . p. 89

6.27 Screenshots de algumas telas da primeira versão do sistema. . . . . . . . . . p. 89 


\section{Lista de Tabelas}

5.1 Informações do grupo de pacientes saudáveis. . . . . . . . . . . . . . p.53

5.2 Informações do grupo de pacientes chagásicos. . . . . . . . . . . . . . p. 54

5.3 Informações do grupo de pacientes hipertensos. . . . . . . . . . . p. 55 


\section{Sumário}

1 Introdução $\quad$ p. 12

2 Variabilidade da Frequência Cardíaca $\quad$ p. 14

2.1 Modelos de Análise da VFC . . . . . . . . . . . . . . . . p. 17

3 Dinâmica Não Linear e Caos $\quad$ p. 21

3.1 Sistemas Dinâmicos . . . . . . . . . . . . . . . p. 22

3.2 Não Linearidades e o Caos . . . . . . . . . . . . . . . . . . p. 26

4 Entropia $\quad$ p. 36

4.1 Entropia de Kolmogorov-Sinai . . . . . . . . . . . . . . p. 40

4.2 Entropia para Séries Temporais . . . . . . . . . . . . . p. 42

4.3 Entropia Não Extensiva . . . . . . . . . . . . . . . . . . . p. 49

5 Metodologia $\quad$ p. 52

5.1 Dados Utilizados $\ldots \ldots \ldots \ldots \ldots \ldots$ p. . . . . . . . . . . . . . . . . .

5.2 Ferramentas Computacionais Utilizadas $\ldots \ldots \ldots \ldots$ p. . . . . . . . .

6 Resultados $\quad$ p. 61

6.1 Transformada de Fourier Generalizada $(q$-Fourier $) \ldots \ldots \ldots$. . . . . . . 61

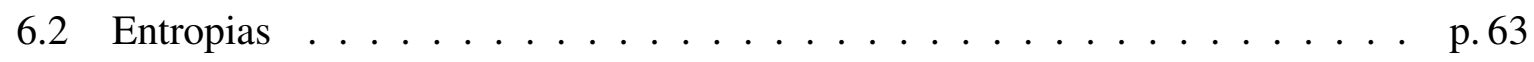

6.2.1 Entropia Aproximada e Amostral . . . . . . . . . . . p. 63

6.2 .2 Entropia Multiescala . . . . . . . . . . . . p. 70

6.2 .3 Análise Surrogate . . . . . . . . . . . . . . . p. 72 
6.3 Sistema Computacional . . . . . . . . . . . . . . . . p. 87

7 Conclusões e Perspectivas

p. 91

Referências Bibliográficas

p. 93 


\section{$1 \quad$ Introdução}

A dinâmica dos batimentos cardíacos deve se adaptar às mais adversas situações para suprir as necessidades de sangue por todos os órgãos e tecidos. Pensando na quantidade de possibilidades quase infinita de situações as quais um indivíduo pode se deparar na sua vida diária, o sistema cardiovascular deve ter um sistema de adaptação altamente complexo, capaz de prover a adaptação a estas possibilidades, e ao mesmo tempo simples para prover respostas rápidas diante das novas situações que são impostas ao corpo. A resposta evolutiva que a natureza deu a este problema foi criar um sistema de controle, através do sistema nervoso autônomo, para efetuar sobre o sistema cardiovascular um controle rápido e eficiente. Este sistema complexo de controle não linear pode ser observado através da dinâmica de batimentos, em termos de freqüência cardíaca facilmente mensurável, de maneira não invasiva, através da atividade elétrica detectável na superfície de pele.

Dentre as ferramentas computacionais de análise da dinâmica dos batimentos cardíacos (variabilidade da frequência cardíaca), as mais utilizadas atualmente, em sua maioria, são baseadas em modelos lineares, como é o caso da transformada de Fourier e modelo autorregressivo, que buscam identificar a contribuição das componentes de frequências presentes nas séries de intervalos entre batimentos cardíacos. Contudo, por apresentar características de não linearidade, a avaliação desta dinâmica com modelos lineares pode omitir características importantes que não são possíveis de serem detectadas com tais modelos; a utilização de modelos não lineares nestes casos pode ser muito útil, ainda mais se tais características estiverem ligadas às condições de saúde ou doença dos indivíduos. A literatura mostra que a eficácia destes métodos não lineares têm um impacto sobre a predição da morte súbita no período neonatal. Entretanto, há ainda uma lacuna no que concerne à exploração desta metodologia, no que se refere ao tipo de metodologia que se aplica a determinado conjunto de dados.

Neste contexto, o objetivo deste estudo é avaliar a proposta de uma entropia não extensiva, introduzida por Tsallis, aplicada a uma família de entropias condicionais (aproximada, amostral e escalonada), bem como a análise espectral generalizada, e compará-las às suas formulações clássicas, na identificação de padrões específicos de variabilidade da freqüência cardíaca. A 
entropia não extensiva é um conceito recente, que surgiu para descrever a entropia de sistemas que possuem correlações de longo alcance e memória de longo termo. O parâmetro de não extensividade $q$ da entropia de Tsallis será investigado quanto à sua influência na quantificação de complexidade das séries temporais de batimentos cardíacos.

As quantificações das entropias e da transformada generalizada serão obtidas em séries temporais dos intervalos R-R do sinal eletrocardiográfico convencional, adquiridas durante situações de repouso e manobra postural passiva, em condições de menor grau de estacionaridade. Os métodos propostos serão avaliadas também utilizados sinais simulados, tais comos ruídos e mapas bastante difundidos na literatura.

Este documento está organizado da seguinte maneira: no Capítulo 2 é feita uma introdução sobre as bases fisiológicas do sistema de regulação da freqüência cardíaca, bem como das análises computacionais mais conhecidas aplicadas neste contexto; no Capítulo 3 é feita uma breve descrição sobre sistemas dinâmicos com regimes não lineares, o surgimento do comportamento caótico em tais sistemas e algumas técnicas básicas para análise de séries temporais caóticas; em seguida, no Capítulo 4 é feita uma abordagem sobre o conceito de entropia, desde seu surgimento até sua interpretação como taxa de crescimento de informação em sistemas dinâmicos, descrevendo os três métodos de entropia que serão utilizados neste projeto, chegando finalmente ao conceito de entropia não extensiva; no Capítulo 5 são apresentados os detalhes da metodologia utilizada, tais como os dados utilizados, as equações generalizadas utilizadas e a metodologia de avaliação do parâmetro de não extensividade $q$; no Capítulo 6 todos os resultados serão apresentados, finalizando com o Capítulo 7 que descreve as conclusões obtidas e algumas perspectivas futuras. 


\section{Variabilidade da Frequência Cardíaca}

O organismo humano é constituído por um conjunto de órgãos e tecidos com estruturas e funções diversas. Para que todos esses órgãos e tecidos funcionem em harmonia com os demais (homeostase), o Sistema Nervoso exerce um papel fundamental nos mecanismos de regulação dos sistemas biológicos. O Sistema Nervoso pode ser dividido em duas partes principais: o Sistema Nervoso Central (SNC), representado pelo encéfalo e medula espinhal, e o Sistema Nervoso Periférico, que consiste de todas as outras estruturas nervosas. O Sistema Nervoso Periférico é ainda subdividido em duas outras partes: Sistema Nervoso Somático (ou voluntário) e Sistema Nervoso Autônomo (SNA). Este último é responsável pelas funções involuntárias das estruturas do organismo humano, e juntamente com o SNC, atua na regulação das diversas funções fisiológicas autonômicas, com por exemplo a pressão arterial, a mobilidade e secreção gastrointestinal, a temperatura corporal, entre outras.

O SNA, por sua vez, possui duas porções diferentes: Simpática e Parassimpática. A principal diferença entre elas está na função que cada uma exerce, atuando geralmente com efeitos antagônicos. Por exemplo, a porção simpática atua inibindo a salivação e acelerando a taxa de batimentos cardíacos enquanto que a porção parassimpática atua estimulando a salivação e reduzindo a taxa de batimentos cardíacos.

O SNA possui fibras nervosas eferentes (que vão do SNC aos órgãos, pele, grandes vasos, etc) e aferentes (que chegam destes ao SNC). Através das vias nervosas aferentes, as estruturas periféricas fornecem informações ao SNC a respeito da sua atividade, e este, combinando as informações recebidas dos vários órgão e tecidos, emite novos pulsos elétricos regulatórios para todo o organismo, através das vias eferentes. É neste mecanismo interativo de alta complexidade que o sistema nervoso trabalha, em busca de atingir a homeostase.

O funcionamento adequado do SNA permite ao homem se adaptar às mudanças súbitas em seu ambiente. Uma de suas mais impressionantes características é a rapidez e a intensidade com que ele pode induzir respostas às variáveis fisiológicas. Por exemplo, em 3 a 5 segundos, ele pode aumentar ou diminuir, de até duas vezes, a frequiência cardíaca em relação ao seu 
valor normal; por outro lado, em 10 a 15 segundos a pressão arterial pode dobrar seu valor; em contrapartida, a pressão arterial pode diminuir seus valores em apenas 4 ou 5 segundos [1], o que por si só aponta para a não linearidade dos sistemas de controle.

O coração é um dos órgãos mais importantes do corpo humano e o controle de seu funcionamento está diretamente ligado ao SNA. Sabe-se que os impulsos elétricos do coração, que originam as contrações músculares do batimento cardíaco, são gerados principalmente pelo nódulo sinusal (NS), uma região de células localizadas no átrio direito que possuem uma habilidade espontânea em gerar impulsos elétricos [2]. Contudo, a atividade deste nódulo está submetida à ação do SNA e o balanço das atividades simpática e parassimpática é decisivo para aumentar ou diminuir a frequência de geração dos impulsos elétricos do NS, e consequentemente da frequência cardíaca. Além disso, os barorreceptores (células nervosas especializadas na detecção de variações da pressão sanguínea), situados nas artérias carótidas e arco aórtico, atuam realimentando o SNC, auxiliando neste processo. A Figura 2.1 ilustra o mecanismo de regulação da frequência cardíaca.

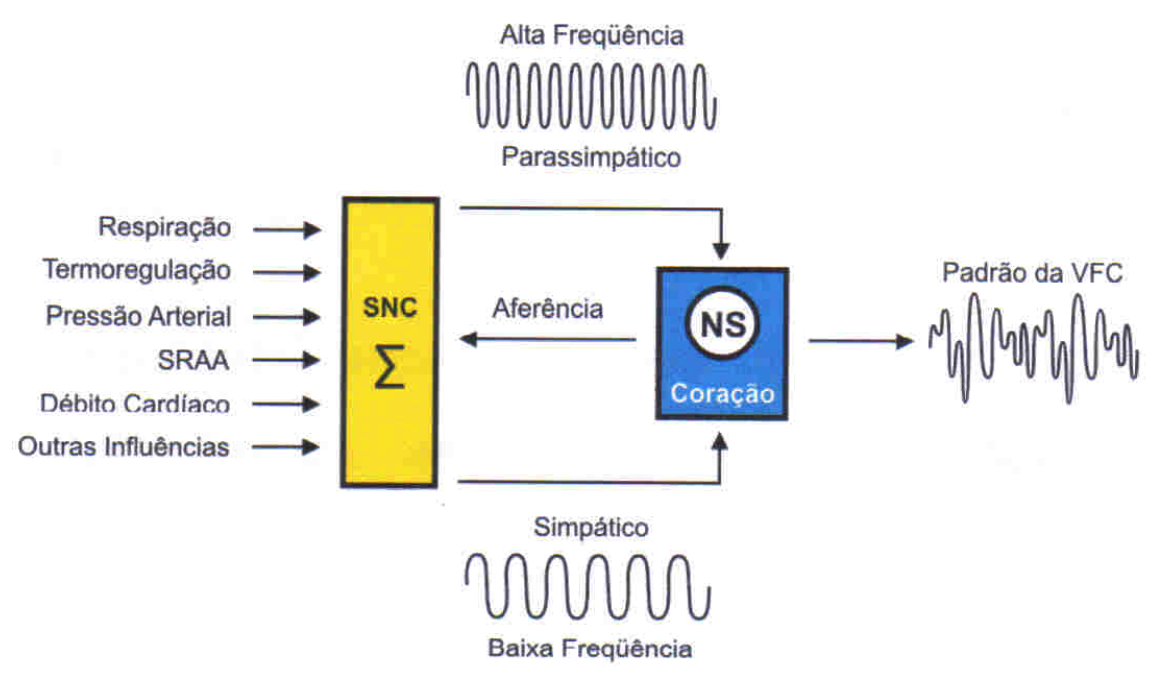

Figura 2.1: Ilustração do mecanismo de regulação da frequência cardíaca. O SNC recebe informações proveniente dos vários sistemas do corpo humano, gerando as componentes simpáticas e parassimpáticas que irão atuar, em conjunto, na regulação cardíaca. SRAA é a sigla de Sistema Renina-Angiotensina-Aldosterona e a via aferente representada ilustra a função dos barorreceptores. Extraído de [3].

As ramificações eferentes e aferentes do SNA chegam e saem do coração através do plexo cardíaco, um conjunto misto de fibras nervosas simpáticas e parassimpáticas que compõe a inervação do coração. As fibras parassimpáticas são todas ramificações do nervo vago enquanto que as fibras simpáticas são basicamente originárias dos ramos T1, T2, T3 e T4 da medula espinhal. As atividades simpática e vagal estão constantemente interagindo na regulação cardíaca, e atra- 
vés de vários estudos foi possível identificar características importantes sobre a atuação destes dois ramos do SNA na regulação cardíaca, bem como maneiras de se avaliar problemas no funcionamento de cada um $[4,5,6,7]$.

As anormalidades no SNA podem ocorrer espontaneamente ou em consequência de doenças sistêmicas, cardíacas ou neurológicas, assim como por efeito de medicações que modificam as concentrações dos mediadores químicos deste sistema. A localização de uma disfunção neste sistema pode ser detectada por meio de uma série de testes autonômicos, que buscam identificar as diferenças existentes entre as componentes eferentes simpática e parassimpática, e nos levar a localizar um dado defeito em um deles ou em ambos. A insuficiência autonômica tem como principal manifestação clínica a ocorrência de hipotensão postural, quando o paciente assume a posição vertical; nestas condições, ocorre o aparecimento de vários sintomas, como tontura, escurecimento da vista e até mesmo a síncope [8].

Sabe-se, por exemplo, que em condições de repouso há uma predominância da atividade vagal no controle da frequência cardíaca. No entanto, realizando um teste ortostático passivo (tilt), no qual uma pessoa que estava em posição horizontal é levada passivamente para a posição vertical, há um deslocamento do volume sanguíneo da região toráxica para as extremidades inferiores, e consequentemente uma diminuição da pressão arterial sistêmica. Isto gera uma ativação das vias eferentes simpáticas e diminuição da atividade vagal, aumentando a frequência cardíaca na busca por recuperar o equilíbrio. Outros exemplos de testes de avaliação do balanço simpato-vagal são:

- Manobra de Valsalva;

- Exercício físico;

- Imersão da face em água (esfriamento facial);

- Infusão venosa de angiotensina II;

- Hiperventilação;

- Massagem no seio carotídeo;

- Estresse mental.

A avaliação do SNA visa, então, determinar indiretamente o grau de inter-relação entre o sistema nervoso e o coração, dentro de uma visão interdisciplinar [9]. Em todos os testes, o objetivo básico é estimular os mecanismos de regulação dos ramos simpático e parassimpático 
do SNA com situações críticas, e observar suas respostas. Essas respostas do SNA refletem em mudanças de outras variáveis fisiológicas, como a frequência cardíaca e a pressão arterial. Devido a isso, a análise da variabilidade da frequência cardíaca (VFC) torna-se uma abordagem muito poderosa para se obter informações a respeito da atividade do SNA. Avaliando as variações da frequência cardíaca ao longo do tempo é possível ter uma idéia de sua atividade no período analisado.

As análises da VFC são feitas, geralmente, a partir de uma série temporal que contém os intervalos de tempos entre cada batimento cardíaco consecutivo. A partir de um eletrocardiograma (ECG), todos os batimentos são identificados (geralmente pelo pico R, por ser a parte do batimento com melhores características de detecção pelos algoritmos computacionais). Em seguida, uma nova série é criada contendo os intervalos de tempo entre cada batimento consecutivo. Esta série é conhecida como série de intervalos RR ou tacograma. A Figura 2.2 ilustra esta etapa.
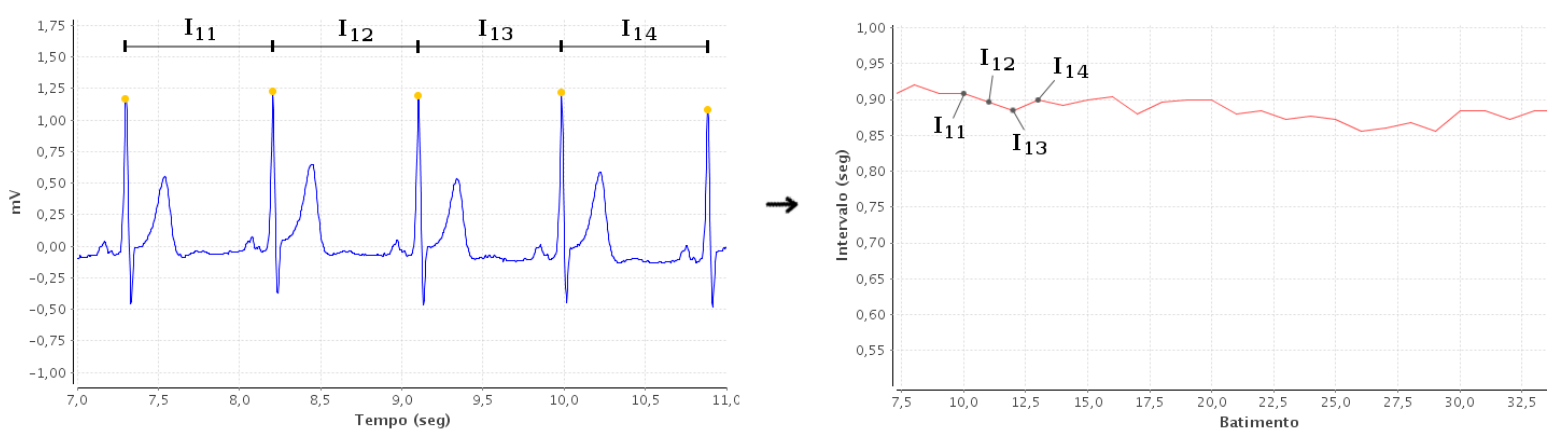

Figura 2.2: Ilustração da geração de uma série de intervalos RR a partir de um ECG. Primeiramente os picos R do ECG são identificados (esquerda) e em seguida a distância entre cada pico consecutivo é calculada e inserida em outra série (direita), que equivale à série de intervalos RR.

Além de ser uma série bastante simples de ser obtida, com métodos não invasivos e de baixo custo, a série de intervalos RR carrega informações importantes a respeito da dinâmica regulatória do sistema cardiovascular e da influência do SNA neste mecanismo. Para tentar extrair informações das séries RR, diversos modelos computacionais são utilizados. Alguns destes modelos serão discutidos na seção a seguir.

\subsection{Modelos de Análise da VFC}

Os modelos lineares clássicos de análise da VFC estão bem definidos e regulamentados por uma força-tarefa em variabilidade cardíaca [7]. Basicamente, esses métodos clássicos podem ser divididos em dois grupos: um grupo de medidas relacionadas ao domínio do tempo e outro 
ao domínio de frequência. No primeiro grupo destacamos as seguintes medidas:

- Histograma, contendo a distribuição dos pontos da série, geralmente com bins de tamanho $7.8125 \mathrm{~ms}$.

- Media, Desvio Padrão (SD, do inglês Standard Deviation) e Média Quadrática de SD (RMSSD, do inglês Root Mean Square of SD)

- Desvio Padrão das Médias (SDA, do inglês Standard Deviation of Averages), que consiste em calcular o desvio padrão das médias dos intervalos RR a cada 5 minutos.

- NN50: número de pontos (batimentos) consecutivos diferentes em mais de $50 \mathrm{~ms}$.

- pNN50: NN50 dividido pelo número total de batimentos.

- Índice Triangular: número total de todos os intervalos entre batimentos dividido pela quantidade de pontos do bin modal (altura do histograma).

Dentre essas medidas, quatros delas formam um grupo que é o mais recomendado para uso nas análises [7]: desvio padrão, índice triangular, desvio padrão das médias e RMSSD. As duas primeiras são estimativas a respeito da série como um todo; a terceira é uma estimativa das componentes de longo alcance, e a quarta, de curto alcance. Juntas, essas quatro medidas forncecem informações importantes sobre uma série RR, sendo desnecessário o uso de todas as medidas citadas, já que algumas delas estão correlacionadas. Apesar de úteis, a maioria dessas medidas no domínio do tempo são dependentes do tamanho da série, fato que inviabiliza a comparação de resultados.

No segundo grupo de medidas tem-se, basicamente, dois modelos: Transformada de Fourier e Modelo Autorregressivo. Ambos são utilizados para estimar a potência espectral da série, ou seja, a potência das componentes de frequência da série [10]. Esta análise no domínio da frequência é de grande importância e a mais utilizada na prática, por ser capaz de proporcionar uma boa idéia da atuação das componentes do SNA na série.

As componentes espectrais das séries RR possuem padrões bem estabelecidos, obtidos pelo esforço de vários pesquisadores, permitindo identificar as influências simpáticas e vagais. Seu espectro de potências pode ser dividido em quatro bandas de frequência principais:

- HF (do inglês High Frequency), banda de alta frequência que compreende os valores entre 0,15 e $0,40 \mathrm{~Hz}$. Suas componentes estão fortemente relacionadas com a atividade vagal. 
- LF (do inglês Low Frequency), banda de baixa frequência que compreende os valores entre 0,04 e $0,15 \mathrm{~Hz}$. A interpretação desta banda ainda gera algumas contrariedades, sendo afirmada por alguns autores como a representação da atividade simpática e por outros como da atividade de ambos os ramos simpático e vagal.

- VLF e ULF (do inglês Very Low Frequency e Ultra Low Frequency) são as bandas de frequências mais baixas do espectro. A primeira abrange a faixa que vai de 0,003 e 0,04 $\mathrm{Hz}$, e a segunda os valores $<0,003 \mathrm{~Hz}$. Contudo, a faixa ULF só existe quando a série RR utilizada é grande, geralmente obtida em um período de 24 horas. Em séries pequenas, por exemplo as obtidas em um período de 5 minutos, a banda ULF não existe e VLF é considerada nos valores de frequência $<0,04 \mathrm{~Hz}$. A interpretação fisiológica dessas bandas ainda não está bem estabelecida e requer mais estudos.

As bandas de frequências citadas podem ser calculadas em unidades absolutas (geralmente em $m s^{2}$ ) ou unidades normalizadas (u.n.). Em unidades normalizadas, as bandas LF e HF são calculadas como a porcentagem da potência total, desconsiderando a potência em VLF, ou seja:

$$
\begin{aligned}
& H F(\text { u.n. })=\frac{H F}{\text { Potência Total }-V L F} \times 100 \\
& L F \text { (u.n.) }=\frac{L F}{\text { Potência Total }-V L F} \times 100
\end{aligned}
$$

As diferentes interpretações da banda LF, como citado, podem ser entendidas pelos resultados do espectro de potências utilizando unidades absolutas e normalizadas. Em alguns casos, um aumento da atividade simpática pode gerar uma diminuição da potência absoluta de LF, contradizendo a afirmação de que essa banda representa a atividade simpática. Porém, a ativação simpática normalmente também ocasiona uma diminuição na potência total do espectro. Assim, ao analisar os efeitos de uma ativação simpática em unidades absolutas, a potência em LF pode não apresentar variações, ou até mesmo diminuir. Mas quando essa mesma ativação é analisada em unidades normalizadas, fica evidente o aumento da potência em LF, pois neste caso o que se mede é sua proporção em relação ao total presente em LF e HF.

As bandas LF e HF são, então, as bandas que mais fornecem informação para a análise da VFC, nas quais é possível inferir-se algo em relação ao funcionamento dos ramos do SNA. Por exemplo, sabe-se que ocorre um aumento na banda LF, em unidades normalizadas, durante a manobra postural passiva, estresse mental e exercício físico moderado, em pacientes saudáveis. Por outro lado, um aumento na banda HF ocorre quando a respiração é ativamente controlada, a face é imergida em água gelada e em situações de estímulo de rotação [7]. 
Apesar de proporcionar informações importantes para a análise da VFC, todas essas medidas clássicas citadas estão baseadas em modelos lineares. Por exemplo, a transformada de Fourier considera o sinal de VFC como uma soma ponderada (amplitudes diferentes) de senóides de diversas frequências. Porém, como citado no início do capítulo, algumas características da regulação da VFC apontam para a não linearidade do seu funcionamento, e com isso, ferramentas não lineares podem trazer informações importantes a respeito da dinâmica na VFC, informações talvez não obtidas com os modelos lineares.

Grande parte dos modelos não lineares de avaliação da VFC existentes são baseados em dimensões fractais e de correlação, índices de complexidade e entropias [11]. Porém, a quantidade de pesquisas envolvendo tais modelos tem crescido nos últimos anos [12], reflexo dos resultados que vem demonstrando que, além de não lineares, as relações dos sistemas biológicos nas regulação da VFC podem apresentar diferentes graus de complexidade [13]. Indivíduos saudáveis tendem a apresentar uma variabilidade mais complexa (mais caótica) do que indivíduos acometidos por alguma patologia. Essa característica pode ser intuitivamente explicada pelo fato de que indivíduos saudáveis possuem maior capacidade de se adaptar às adversidades que podem surgir no dia a dia, e isso é representado pelo alto grau de complexidade em sua série RR. Em indivíduos que não possuem essa capacidade de adaptação, as séries RR são mais preditivas, possuem maior regularidade, fatores altamente ligados ao conceito de caos, indicando a possibilidade de existência de uma forte relação entre complexidade e diferentes situações fisiológicas [14].

A presença de caos na dinâmica das séries RR é um ponto bastante interessante e que pode proporcionar ainda mais informações a respeito da VFC. É nesta linha de análise da complexidade das séries RR que este projeto está baseado, e com isso, no capítulo seguinte serão explorados alguns conceitos básicos de caos, assim como algumas maneiras clássicas de avaliálo. 


\section{Dinâmica Não Linear e Caos}

O estudo da dinâmica dos sistemas é de grande importância nas mais variadas áreas do conhecimento, tais como na física, biologia, geologia, química, entre outros [15, 16]. A busca pelo entendimento do comportamento desses sistemas em determinadas condições leva os pesquisadores a buscarem métodos de análises que possam extrair informações desses comportamentos.

Apesar da existência de alguns estudos anteriores relacionados ao assunto, o início da análise da dinâmica dos sistemas ficou marcada com os estudos de Henri-Poincaré (1854-1912) sobre a estabilidade do universo; mais particularmente seus estudos sobre a atração gravitacional de três corpos. A dinâmica de interação de três corpos celestes é muito mais complexa do que entre dois corpos. Naquela época, Poincaré chegou a resultados importantes que seriam, no futuro, identificados por outros pesquisadores nas mais diversas áreas do conhecimento.

Recentemente, estudos tem demonstrados que, em determinadas condições, muitos sistemas podem exibir comportamentos um tanto diferentes do comum. Por exemplo, variações proporcionais de algum parâmetro do sistema pode causar mudanças desproporcionais em sua dinâmica, mudando bruscamente a maneira como o sistema se comporta. Observou-se também que este tipo de comportamento possui algumas características marcantes e que elas aparentam acontecer da mesma maneira em diversos fenômenos, nas mais variadas áreas do conhecimento [16]. Este comportamento que os sistemas apresentam nestas circunstâncias foi denominado de comportamento caótico.

Em termos gerais, podemos destacar duas características que estão fortemente ligadas a este tipo de comportamento:

1. Não preditividade do comportamento futuro do sistema;

2. Sensibilidade às condições iniciais.

A primeira característica se refere a predição de um estado futuro através de estados passados. Em muitos sistemas isso é possível apenas com uma análise visual dos estados anteriores, 
observando, por exemplo, algumas tendências e padrões na sua dinâmica. Porém, em sistemas que exibem comportamento caótico essa tarefa se torna muito difícil, mesmo com a utilização de ferramentas matemáticas. Seu comportamento se assemelha a um comportamento estocástico, apesar de possuir uma dinâmica bem definida (comportamento determinístico).

A segunda característica está relacionada ao conceito do "Efeito Borboleta", no qual se diz que um bater de asas de uma borboleta pode gerar um cilcone do outro lado do mundo. Esta é uma maneira de representar a idéia de que uma pequena perturbação em um sistema, depois de um certo tempo, pode ocasionar efeitos de grande porte. Nestes casos, podemos dizer que o sistema que possui este tipo de comportamento é sensível às condições iniciais, pois variações muito pequenas no início podem acarretar em situações totalmente diferentes no futuro.

A sensibilidade às condições iniciais é uma característica chave para os sistemas caóticos. Esta propriedade foi observada por Lorenz em suas simulações com sistemas de equações meteorológicas. Em dada circunstância, Lorenz desejava repetir simulação, e para economizar tempo, iniciou-a no meio do seu curso, a partir de valores impressos em uma simulação anterior. Feito isto obteve uma surpresa: o clima que a máquina começou a prever era completamente diferente do calculado anteriormente. O computador que fazia os cálculos trabalhava com uma precisão de seis dígitos, mas a impressão dos resultados arredondava esses valores para um número de três dígitos. Lorenz acreditava na época que esta pequena diferença não deveria efetuar praticamente nenhum efeito. No entanto, ele havia descoberto que pequenas mudanças nas condições iniciais produzem grandes mudanças no resultado em longo prazo.

Essas duas características que um sistema pode apresentar são de grande importância para a identificação do caos, mas não são as únicas. Além disso, apesar dos estudo de Poincaré, o interesse por estes fenômenos vem ganhando maior importância entre os pesquisadores mais recentemente [17].

Na seção seguinte será feita uma breve abordagem sobre os sistemas dinâmicos, citando algumas de suas características e representações. Em seguida, será feita uma abordagem do comportamento caótico que pode surgir nestes sistemas e algumas maneiras clássicas de avaliálos.

\subsection{Sistemas Dinâmicos}

Um sistema dinâmico é, basicamente, a representação da evolução de um sistema no qual o seu estado futuro varia de acordo com os estados passados. 
Em termos matemáticos, essa dinâmica pode ser representada de forma contínua ou discreta. Nos sistemas dinâmicos contínuos, a evolução é representada por um conjunto de equações diferenciais que descrevem as variáveis do sistema de maneira contínua. Isso significa que o estado do sistema é definido para qualquer valor das variáveis de referência. Além disso, quando essas equações são explicitamente depentendes do tempo, o sistema é classificado como não autônomo. Caso contrário, o sistema é classificado como autônomo.

Um exemplo clássico de sistema dinâmico contínuo consiste da movimentação de um pêndulo. Para o caso do pêndulo simples, onde não há forçamento nem amortecimento, a equação do movimento pode ser escrita como:

$$
\frac{d^{2} \theta}{d t^{2}}+\frac{g}{L} \sin (\theta)=0
$$

onde $g$ é a aceleração da gravidade e $L$ o comprimento da haste do pêndulo. A Figura 3.1 mostra o pêndulo simples.

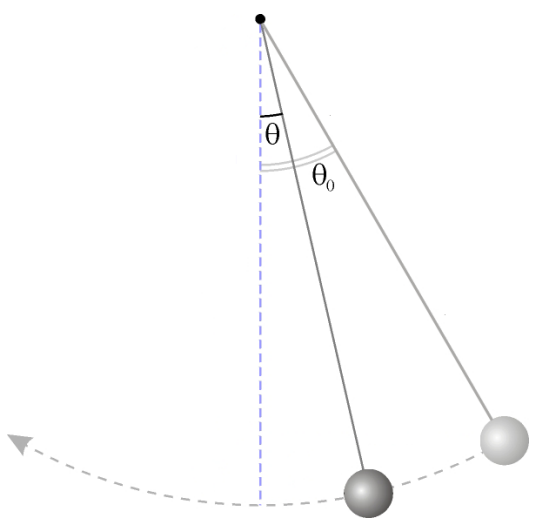

Figura 3.1: Representação do pêndulo simples.

Para resolver esta equação é preciso utilizar métodos numéricos. Mas para explorar melhor a suas características, podemos escrever a mesma dinâmica como um sistema de duas equações, como se segue:

$$
\begin{aligned}
& d \theta / d t=\omega \\
& d \omega / d t=-\sin (\theta) g / L
\end{aligned}
$$

As equações em (3.1) e (3.2) são equivalentes. Porém, usando a representação dada pelas equações em (3.2), podemos representar o estado do sistema em qualquer instante traçando o gráfico de $\omega \times \theta$. Esta representação é conhecida como diagrama de fases, pois representa as várias fases (estados) em que a dinâmica do pêndulo pode estar.

A Figura 3.2 ilustra o diagrama de fases do pêndulo simples. Como pode-se observar, a 
figura é composta por várias linhas que representam as trajetórias da dinâmica do pêndulo. As trajetórias cíclicas representam as situações em que o pêndulo sempre oscila, no qual a altura máxima é atingida no momento em que sua velocidade angular é zero e ocorre a inversão do sentido de movimento. É possível notar que existem infinitas trajetórias com este comportamento, dependendo dos valores iniciais escolhidos para $\theta$ e $\omega$. Neste caso, quanto maior o período da oscilação do movimento, maior é o tamanho de sua representação no espaço de fase. É chegado um ponto, porém, que o movimento do pêndulo muda de característica, passando a realizar revoluções, não atingindo mais o repouso. Essas trajetórias são representadas pelas linhas acima e abaixo das trajetórias cíclicas.

Outro ponto interessante da dinâmica do pêndulo são os pontos de equilíbrio, que podem ser estáveis ou instáveis. Na figura, o ponto $A$ representa um dos pontos de equilíbrio estável e os pontos $B$ os instáveis. Intuitivamente podemos deduzir que esses pontos representam os estados em que o pêndulo tende a ficar em repouso. Porém, no caso de um ponto instável, uma perturbação suave é suficiente para fazer com que o equilibrio seja perdido, ao contrário do ponto estável. Os pontos estáveis ocorrem quando $\omega=0$ e $\theta=k 2 \pi, k$ inteiro, e os instáveis quando $\omega=0$ e $\theta=\pi+k 2 \pi, k$ inteiro. Esses valores podem ser observados na Figura 3.2.

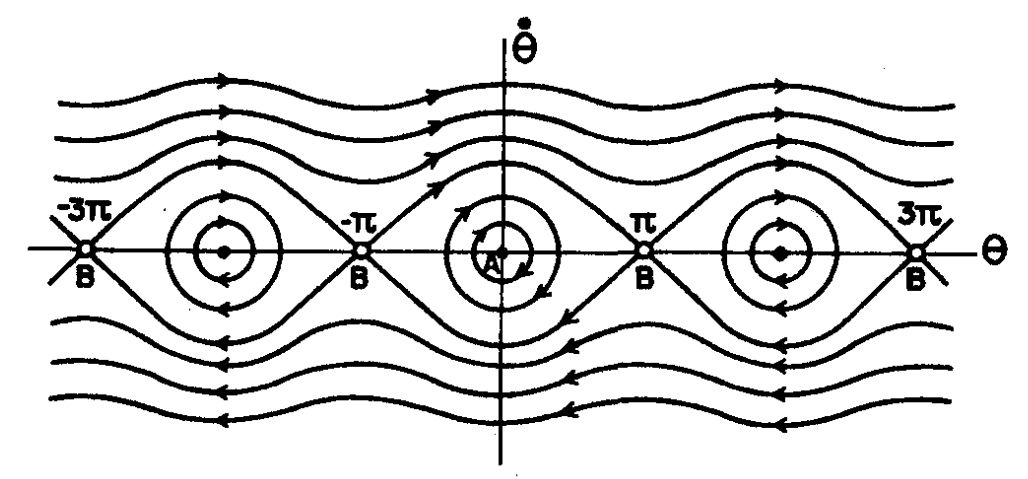

Figura 3.2: Diagrama de fases do pêndulo simples. As linhas mostram as diferentes trajetórias que o pêndulo pode realizar. Neste caso, o valor de $\omega$ está representado por $\dot{\theta}$. Adaptado de [17].

O exemplo do pêndulo simples ilustra de maneira bem simplificada um caso de sistema dinâmico contínuo. Existem diversos outros exemplos de sistemas deste tipo [16].

No caso de sistemas dinâmicos discretos (também chamados de mapas), a representação de sua evolução ao longo do tempo é feita por uma equação de diferença, ao contrário do caso contínuo, no qual são equações diferenciais. Basicamente, mapas descrevem o valor de uma variável $x$ no instante $n+1$ através de seu valor no instante $n$. Assim, podemos definir essa equação de diferença como: 


$$
x_{n+1}=f\left(x_{n}\right)
$$

no qual $f$ é uma função que mapeia o valor de $x_{n}$. No caso dos sistema contínuos, para qualquer valor de tempo existe um valor para a variável de interesse. No caso dos mapas, o tempo é representado por valores discretos $(n)$, podendo este valor ser pensado como amostras igualmente espaçadas do tempo contínuo.

Um dos exemplos de mapa mais conhecidos é o mapa logístico. Sua equação é dada por:

$$
x_{n+1}=r x_{n}\left(1-x_{n}\right)
$$

no qual $r$ é uma constante. O mapa logístico é um modelo que foi originalmente utilizado por Pierre François Verhulst para descrever modelos de crescimento de populações. Neste caso, a equação descrevia o tamanho de uma população na geração $n+1$ a partir de seu tamanho na geração $n$.
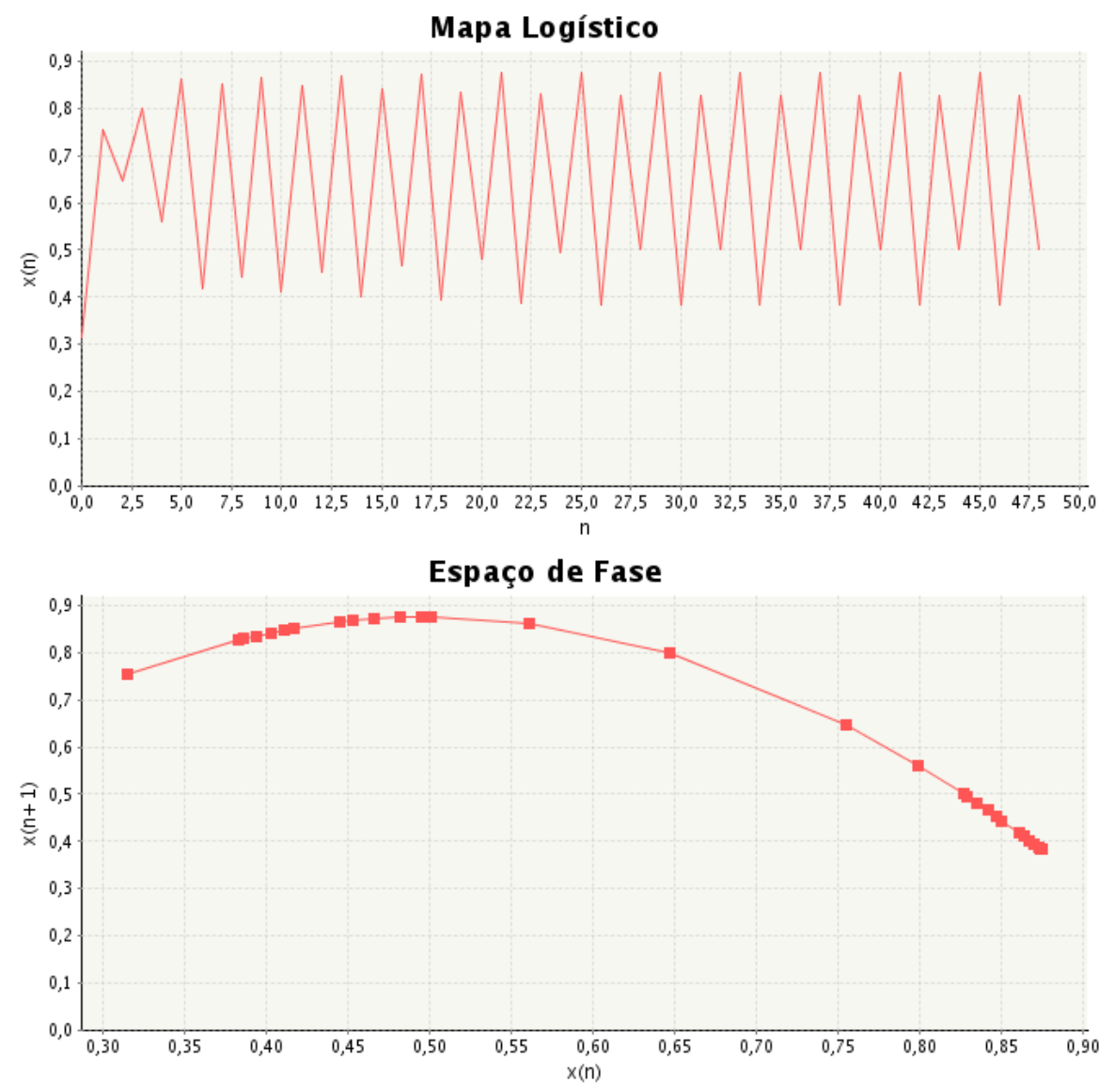

Figura 3.3: Mapa logístico. Acima é ilustrada a evolução do mapa por 48 iterações $(n=48)$. Abaixo a representação do espaço de fases para este mapa. Para a geração do mapa foi utilizado o parâmetro $r=3.5$ e valor inicial de $x$ de 0.9 . Na evolução do mapa é possível notar um período inicial de estabilização seguido pelo comportamento oscilatório com período 4. 
A representação deste mapa sob a forma de uma equação diferencial poderia ser feita como:

$$
\frac{d x}{d t}=r x(1-x)
$$

Observando a equação (3.5), podemos deduzir sua representação no espaço de fases da mesma maneira como feito no caso do pêndulo, sendo composta pelos pontos $(d x / d t, x)$. Utilizando o mesmo raciocínio, agora na equação (3.4), é possível deduzir a representação do mapa no espaço de fases como sendo o conjunto dos pontos $\left(x_{n}, x_{n+1}\right)$.

A Figura 3.3 mostra 50 iterações $(n=50)$ da evolução do mapa logístico para $r=3.5$ e seu respectivo espaço de fase. Pela figura é possível observar que após um período inicial, a série passa a ser periódica com período 4 . O espaço de fases demonstra os pares $\left(x_{n}, x_{n+1}\right)$, que são pontos pertencentes à curva $y=3.5 x(1-x)$. A pequena quantidade de pontos no espaço de fases é um indício da sua característica periódica. Se o mesmo mapa fossem gerado com mais iterações, por exemplo até $n=1000$, o espaço de fases seria o mesmo apresentado devido à periodicidade. Será visto na próxima seção que isso não acontece para alguns outros valores de $r$.

Assim como no caso contínuo, existem vários outros exemplos de mapas além do logístico, como por exemplo o mapa quadrático, mapa de Hénon, entre outros.

\subsection{Não Linearidades e o Caos}

Tanto os sistemas dinâmicos contínuos como os discretos podem ser classificados como lineares ou não lineares. Para que um sistema seja linear, este deve satisfazer as condições de aditividade e homogeneidade, matematicamente definidas pelas seguintes representações [15]:

$$
\begin{gathered}
f(x+y)=f(x)+f(y), \quad x, y \in R^{n} \\
f(\mu x)=\mu f(x), \quad x \in R^{n}, \mu \in R^{p}
\end{gathered}
$$

A Figura 3.4 mostra esquematicamente a representação dessas duas propriedades. Considerase um sistema como não linear quando uma dessas condições não é satisfeita.

Como citado no início deste capítulo, a sensibilidade às condições iniciais e a não preditividade de valores futuros são características presentes em sistemas caóticos. Deve-se esperar que estas características surjam apenas em sistemas não lineares. Por exemplo, sistemas linea- 
(a)

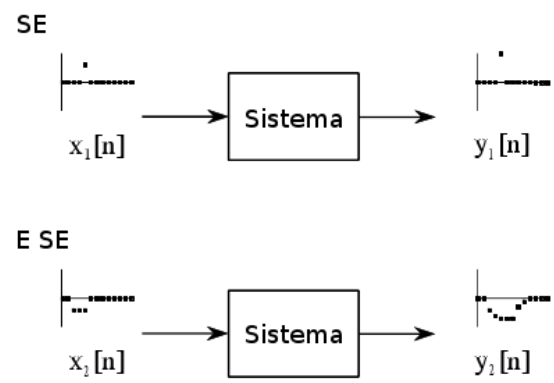

ENTÃO

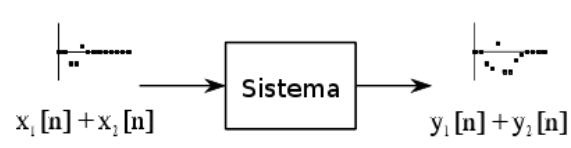

(b)

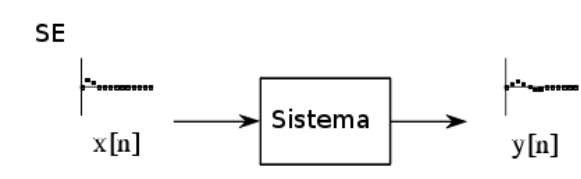

ENTÃO

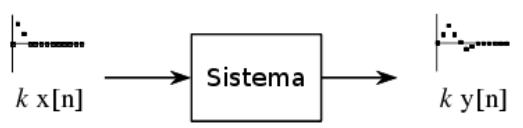

Figura 3.4: Diagrama representando as propriedades que um sistema linear deve satisfazer: (a) aditividade; (b) homogeneidade. Adaptado de [18].

res não podem ser sensíveis às condições iniciais, uma vez que as mudanças iniciais impostas produzem resultados que são possíveis de se prever no futuro. Apesar disso, nem todo sistema não linear exibe comportamento caótico. Podem existir sistemas não lineares que também são, por exemplo, previsíveis no futuro, não sendo então caóticos. Em síntese, pode-se dizer que todo sistema caótico é necessariamente não linear; porém, um sistema não linear pode ou não apresentar comportamento caótico em determinadas condições.

A sensibilidade às condições iniciais nos sistemas caóticos causa uma grande divergência de trajetórias, inicialmente próximas, ao longo do tempo. Essa divergência é considerada, em média, exponencial. Isto quer dizer que duas trajetórias irão divergir, em média, exponencialmente com o tempo. Considerando o caso de um sistema discreto unidimensional, a equação a seguir ilustra essa característica [16]:

$$
\varepsilon(n) \approx \varepsilon e^{\lambda n}
$$

no qual $\varepsilon(n)$ representa a diferença entre duas trajetórias iniciadas em pontos muito próximos após $n$ passos, $\varepsilon$ representa um pequeno valor, tal que $x$ e $x+\varepsilon$ são os estado iniciais das duas trajetórias e $\lambda$ é o expoente de Lyapunov. Este expoente representa a taxa média de afastamento das trajetórias ao longo de suas evoluções e é muito utilizado para caracterizar os sistemas como caóticos ou não. Por exemplo, quando $\lambda<0$ significa que as trajetórias estão convergindo, e neste caso tem-se um comportamento não caótico. Porém, se $\lambda>0$, então as trajetórias divergem, o que significa que, de fato, existe sensibilidade às condições iniciais e pode-se classificar o comportamento como caótico. 
No caso de sistemas $n$-dimensionais, a equação (3.8) passa a ser representada por:

$$
V \approx V_{0} e^{\left(\lambda_{1}+\lambda_{2}+\lambda_{3}+\ldots+\lambda_{n}\right) n}
$$

Neste caso, o que se mede é a diferença de volumes $n$-dimensionais, pois trata-se da evolução de $n$ variáveis com o tempo. Cada valor de $\lambda_{n}$ representa a taxa média de divergência das trajetórias em uma dimensão. Quando o sistema é caótico, ao menos um valor de $\lambda_{n}$ é positivo.

Com isso, nota-se que o cálculo do expoente de Lyapunov pode ser útil para caracterizar um sistema. Para ilustrar o cálculo deste expoente, considere um sistema dinâmico discreto $f$. Podemos escrever a equação (3.8) como [16]:

$$
f^{n}(x+\varepsilon)-f^{n}(x) \approx \varepsilon e^{\lambda n}
$$

dividindo ambos os lados por $\varepsilon$, aplicando o logaritmo e assumindo que $\varepsilon \rightarrow 0$, temos:

$$
\lambda \approx \frac{1}{n} \log _{e}\left|\frac{d f^{n}}{d x}\right|
$$

usando a regra da cadeia e fazendo $n \rightarrow \infty$, chegamos na equação final que define o expoente de Lyapunov:

$$
\lambda=\lim _{n \rightarrow \infty} \frac{1}{n} \sum_{i=0}^{n-1} \log _{e}\left|f^{\prime}\left(x_{i}\right)\right|
$$

O expoente de Lyapunov é um índice bastante utilizado na análise da dinâmica dos sistemas uma vez que sua definição está diretamente ligada ao conceito de sensibilidade às condições iniciais. Ao analisar a dinâmica do pêndulo ou do mapa logístico em condições que surgem o caos, será ilustrado como esse índice identifica essas situações.

Como citado anteriormente, sistemas não lineares podem ou não exibir comportamento caótico. Em geral, quando um sistema apresenta comportamento caótico, isto se dá em algumas condições especiais. Assim, para determinados parâmetros, um sistema pode exibir um comportamento regular. Porém, o mesmo sistema pode exibir caos para outros valores destes parâmetros.

Na seção anterior foram analisados dois exemplos de sistemas dinâmicos: o pêndulo simples para o caso contínuo, e o mapa logístico para o caso discreto. Nos dois casos foram analisados os comportamentos destes sistemas em condições onde não ocorria o caos. Serão analisadas agora algumas situações nestes sistemas que fazem seu comportamento ser caótico. 
No caso do pêndulo, temos na equação (3.1) o pêndulo simples. Porém, podemos incluir nesta equação um termo de amortecimento, que faz com que haja dissipação de energia, e outro de forçamento, responsável por inserir energia no sistema com uma determinada frequência.

Desprezando os termos dimensionais, como massa, comprimento e aceleração, podemos escrever a equação do pêndulo amortecido forçado como:

$$
\frac{d^{2} \theta}{d t^{2}}+\frac{1}{q} \frac{d \theta}{d t}+\sin (\theta)-g \cos \left(\omega_{d} t+\phi_{0}\right)=0
$$

no qual $q$ é o parâmetro de amortecimento, $g$ a amplitude do forçamento (e não a aceleração da gravidade) e $\omega_{d}$ a frequência do forçamento. Da mesma maneira que no caso do pêndulo simples, essa equação pode ser escrita em termos de equações diferenciais de primeira ordem. Neste caso, o sistema de equações é:

$$
\begin{aligned}
d \omega / d t & =-(1 / q)-\sin (\theta)+g \cos (\phi) \\
d \theta / d t & =\omega \\
d \phi / d t & =\omega_{d}
\end{aligned}
$$

Para analisar a dinâmica do pêndulo nestas circunstâncias poderíamos verificar todas as combinações dos parâmetros da equação e avaliar o seu comportamento em cada caso. Porém, essa tarefa torna-se impraticável pela quantidade de pontos do tipo $\left(g, q, \omega_{d}\right)$. Uma boa alternativa para se esquivar disto é fixar $\omega_{d}$ e $q$ e variar $g$, observando a dinâmica para cada situação [16]. Com esta abordagem já é possível demonstrar que o sistema exibe caos em determinadas condições.

Fazendo isso, fixados os valores $q=2$ e $\omega_{d}=2 / 3$, a Figura 3.5 mostra o mapa de fases do pêndulo para quatro valores diferentes de $g$. Analisando a figura é possível identificar as características da dinâmica em cada situação.

Na parte (a) pode-se perceber que o pêndulo oscila regularmente, sendo seu comportamento igual ao do pêndulo simples ilustrado na seção anterior. A trajetória mostrada é similar a uma das trajetórias ilustradas na Figura 3.2. Na parte (b) já é possível notar que ocorre uma duplicação de períodos. Enquanto na parte (a) o pêndulo oscila em frequência fixa, em (b) o forçamento ocasiona uma dinâmica que possui dois períodos de oscilação. Em (c) observa-se que a quantidade de períodos fica praticamente incontável. Sua dinâmica não tem período fixo e os pontos representados neste mapa de fases podem levar a trajetórias bem diferentes, ainda que muito próximos. Estas características evidenciam que a dinâmica do pêndulo é, neste caso, caótica. Em (d), curiosamente, pode-se notar que a dinâmica volta à um estado mais organizado, 

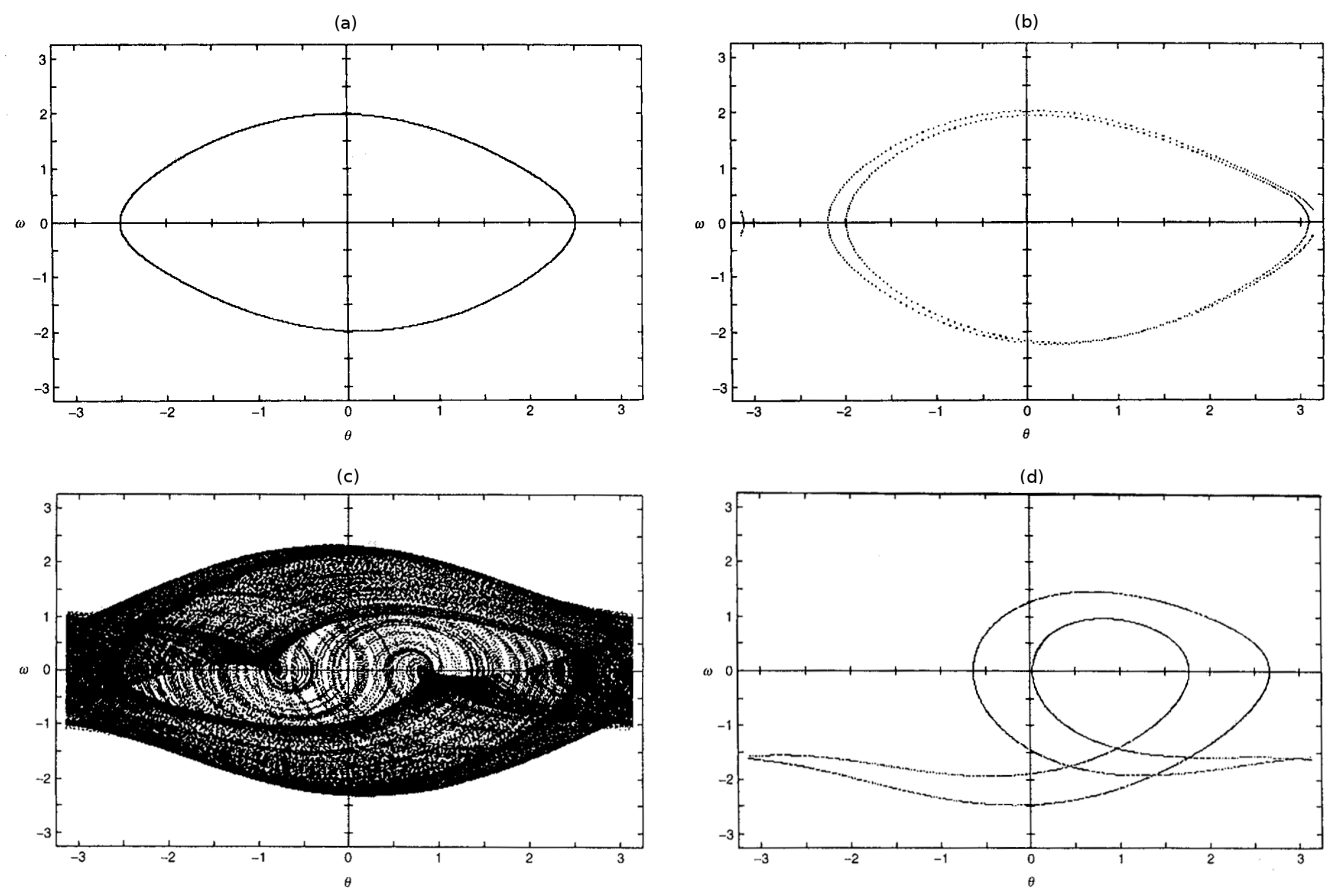

Figura 3.5: Mapas de fase do pêndulo forçado e amortecido. Em (a) $g=0.9$; (b) $g=1.07$; (c) $g=1.15$; (d) $g=1.45$. Em todos os casos, $q=2$ e $\omega_{d}=2 / 3$. Extraído de [16].

novamente com dois períodos de oscilação. Esse comportamento oscilatório também ocorreu na parte (b); contudo, em (d) o forçamento é maior e ocasiona revoluções no pêndulo, o que pode ser observado pelo formato da trajetória.

Esta pequena análise permitiu revelar caracerísitcas da dinâmica do pêndulo quando o valor do parâmetro de forçamento é variado progressivamente. Inicialmente o movimento era o de um oscilador simples, passando para uma oscilação com período duplo; em seguida obteve-se uma dinâmica caótica para, na sequência, retornar a um comportamento oscilatório. Essas mudanças obtidas na dinâmica ao variar-se o forçamento do pêndulo pode ser melhor observada por um outro diagrama, conhecido como diagrama de bifurcação. Este diagrama tem a capacidade de representar a dinâmica de um sistema em relação a um determinado parâmetro (neste caso o forçamento) em uma faixa grande deste parâmetro, identificando as duplicações de período (bifurcações) e as regiões nas quais o comportamento é caótico.

Para construir esse diagrama, primeiramente deixa-se a dinâmica do sistema evoluir livremente com os parâmetros escolhidos. Após um período inicial em que o sistema ainda está se estabilizando, é obtida uma sequência de $n$ amostras consecutivas de sua dinâmica. Esses valores são então colocados em um gráfico que contém no eixo horizontal o parâmetro de referência (no caso do pêndulo, $g$ ) e no eixo vertical a váriável que representará a dinâmica (no caso do pêndulo, $\omega$ ). Este procedimento é repetido várias vezes, variando-se o parâmetro de referência. 
A Figura 3.6 mostra o diagrama de bifurcação do pêndulo analisado, em duas escalas de ampliação diferentes. Neste caso, foram obtidos os valores de $\omega$ a cada instante em que o forçamento acontecia. Foram desconsiderados os 30 primeiros ciclos para a estabilização e obtidos os valores dos 30 ciclos seguintes.

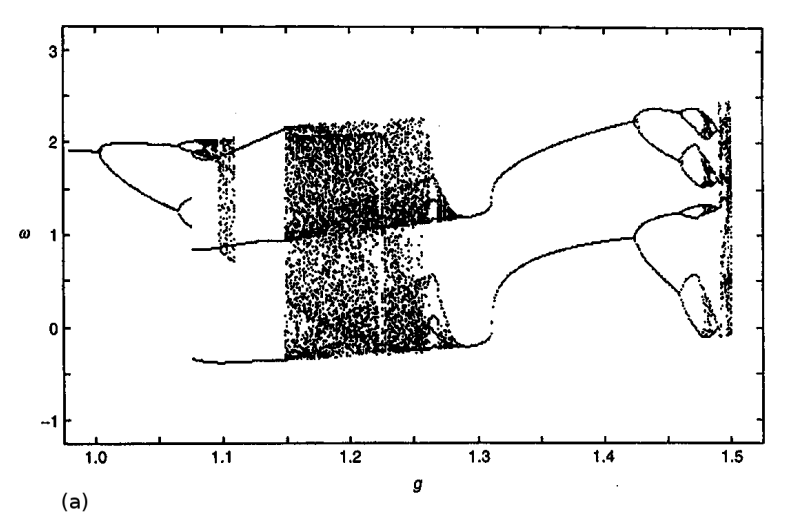

(a)

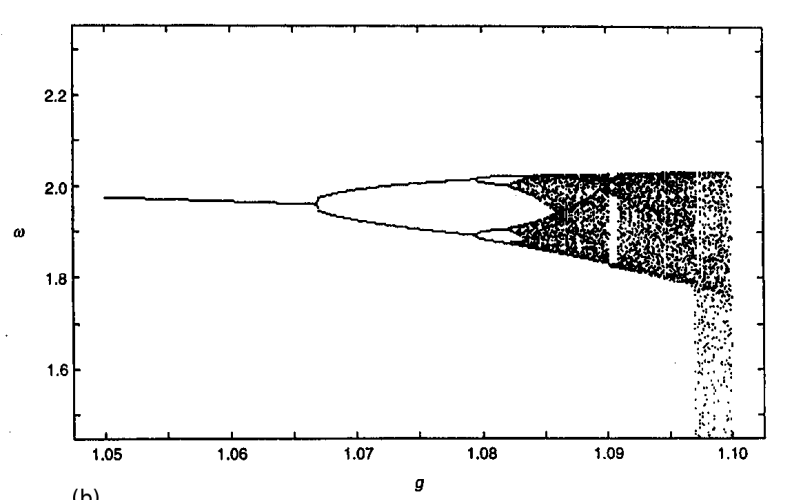

(b)

Figura 3.6: Diagrama de bifurcações do pêndulo. O eixo horizontal representa os valores do forçamento $g$, e o eixo vertical os valores de $\omega$. Em (a) são ilustrado os períodos e bifurcações para um largo intervalo de valores para $g$. Em (b) é mostrada uma ampliação de (a) nas primeiras bifurcações. Neste último caso, como são explorados mais valores de $g$ dentro de um pequeno intervalo, é possível visualizar a cascata de bifurcações com melhor resolução. Extraído de [16].

Analisando este diagrama, observamos os pontos nos quais o período de oscilação duplica. Para $g=0.9$ (Figura 3.5a), observa-se que todos os valores de $\omega$ coincidem. Isto significa que ao final de cada período do forçamento, o pêndulo está sempre na mesma posição. Quando aumentamos o valor de $g$ para 1.07 (Figura 3.5b), pode-se notar que existem dois valores de $\omega$ resultantes. Isso indica o duplo período do movimento. Todavia, quando $g=1.15$ (Figura 3.5c) percebe-se que os pontos estão todos espalhados, não caracterizando períodos de oscilação, sendo por isso um comportamento caótico. A figura não ilustra o comportamento para $g>1.5$; porém, não é difícil ver que existem faixas de periodicidade entre os locais onde ocorrem as duplicações de períodos que levam ao caos, o que explica o comportamento observado na Figura $3.5 \mathrm{~d}$.

A dinâmica do pêndulo representa um sistema no espaço contínuo. Analisaremos agora, da mesma maneira, as condições de surgimento do caos em um sistema discreto, através do mapa logístico.

Como citado anteriormente, para que um sistema exiba caos é necessário que este seja um sistema não linear. Percebe-se que equação (3.4), que representa o mapa logístico, tratase de uma equação não linear, satisfazendo essa condição. Para analisarmos sua dinâmica em diferentes condições utilizaremos, da mesma maneira que no caso do pêndulo, o diagrama de 
bifurcação. Neste caso, novamente analisando a equação (3.4), é possível notar que só há um parâmetro a variar $(r)$, determinando os diferentes comportamentos que o sistema pode exibir. Assim, o eixo vertical do diagrama consistirá dos diferentes valores de $r$ e o eixo horizontal dos valores de $x$. Lembrando que para construir este diagrama, da mesma forma que no caso do pêndulo, os valores de $x$ são obtidos em sequência após um período de estabilização. A Figura 3.7 ilustra o diagrama de bifurcação para o mapa logístico. Quanto mais valores de $x$ são obtidos na sequência e quanto menor o incremento de $r$, maior é a resolução do diagrama.

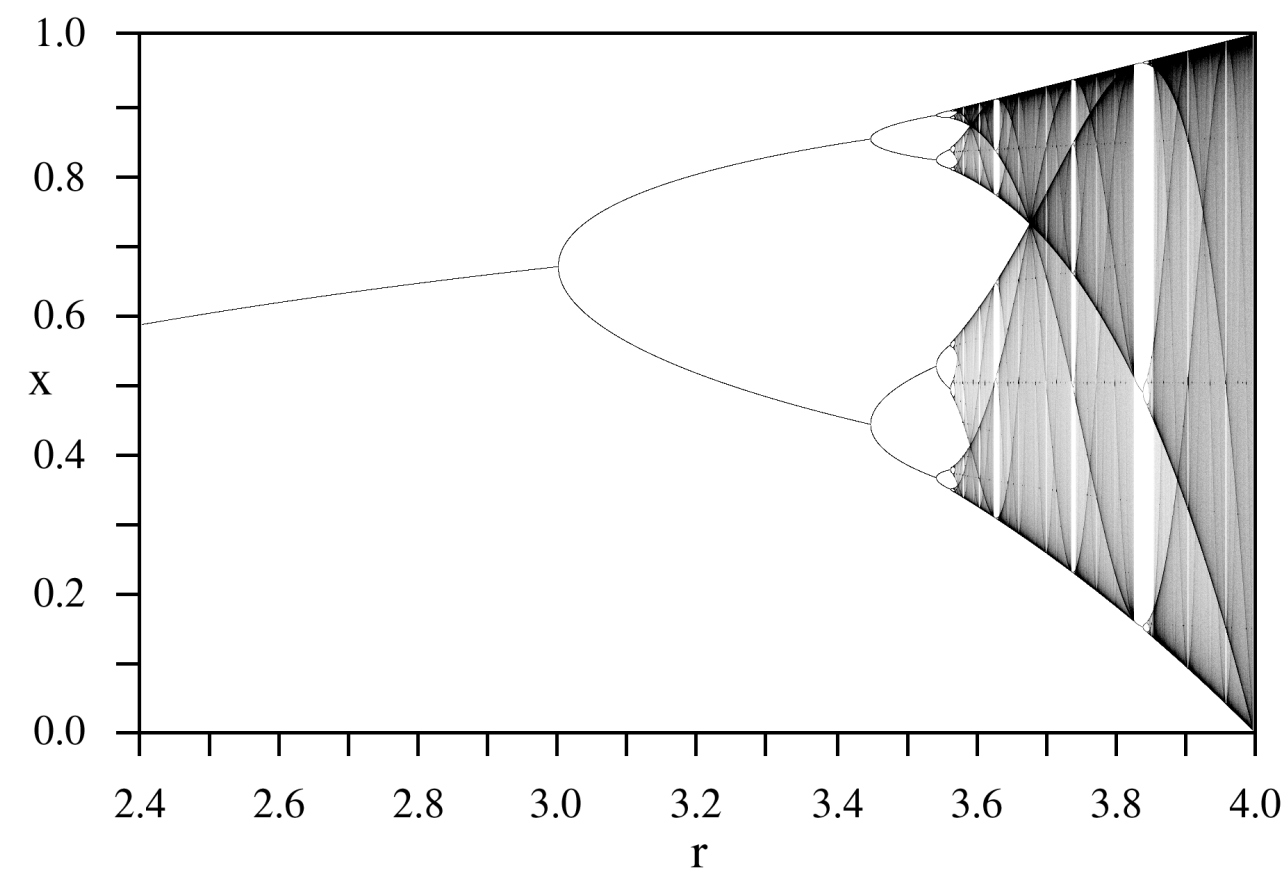

Figura 3.7: Diagrama de bifurcação do mapa logístico. Diagrama gerado utilizando 100.000 pontos sequenciais do mapa logístico, após um período de estabilização de 1000 iterações. O valor de $r$ foi variado com passo 0,001. Além disso, a intensidade de cada pixel em uma coluna (ou seja, em um valor fixo de $r$ ), procura identificar a proporção dos diferentes valores de $x$ existentes na sequência.

Observando a figura, podemos perceber que para $r<3$, o mapa tem sempre o mesmo valor ao longo das iterações. Quando $r=3$ ocorre a primeira bifurcação no diagrama, o que significa que ocorreu uma duplicação de períodos. Esse comportamento de duplo período segue (mas variando os valores dos períodos) até aproximadamente 3.45, quando então ocorre outra duplicação de períodos. A partir de então o mapa passa a oscilar entre 4 valores diferentes até a próxima duplicação de períodos, que ocorre quando $r$ é próximo de 3.54. Este último intervalo corresponder ao caso da Figura 3.3 mostrada anteriormente. Nela, foi gerada uma sequência de valores para o mapa logístico com $r=3.5$. Nela podemos visualizar a oscilação em 4 valores.

Se continuarmos aumentando o valor de $r$, iremos nos deparar com intervalos de oscilação 
com 8 períodos, 16, 32, e assim por diante, intervalos esses cada vez menores até que próximo de $r=3.57$ não é mais possível observar períodos de oscilação e pequenas mudanças iniciais levam a comportamentos totalmente distintos. Isso identifica o caos e este valor de $r$ é considerado a fronteira para o caos. Continuando a aumentar o parâmetro $r$ é possível identificar muitos outros valores que levam a estados caóticos; porém, existem alguns intervalos deste parâmetro que fazem o sistema retornar à sua característica estável. Estes intervalos são conhecidos como ilhas de estabilidade, justamente por estarem cercadas por intervalos de $r$ que fazem a dinâmica ser caótica. Nestas ilhas de estabilidade é possível encontrar dinâmicas com período de oscilação inicialmente ímpar, que voltam a ser par após a primeira bifurcação.

Se observarmos o diagrama de bifurcações do pêndulo, perceberemos que este exibe as mesmas características discutidas no mapa logístico.

Este diagrama é uma ferramenta importante na análise dos sistemas. Como visto, ele identifica as condições nas quais o caos ocorre, mostrando as cascatas de bifurcações que levam ao caos, e ainda que estas estão separadas por regiões de estabilidade. Além dos exemplos do pêndulo e do mapa logístico, muitos outros sistemas que exibem caos apresentam este diagrama com essas propriedades. Por exemplo, uma característica muito interessante e universal observada neste diagrama está relacionada às distâncias entre duas bifurcações consecutivas em uma cascata de bifurcação. Supondo que $\mu_{i}$ seja o valor do parâmetro de análise no qual ocorre a $i$-ésima bifurcação, observou-se que:

$$
\lim _{i \rightarrow \infty} \frac{\mu_{i}-\mu_{i-1}}{\mu_{i+1}-\mu_{i}}=\delta
$$

no qual $\delta=4.669201 \ldots$ é a constante de Feigenbaum.

Isso demonstra que existe uma característica universal no comportamento dos sistemas que exibem caos, reforçando a característica de ubiquidade do caos nas diferentes áreas do conhecimento.

Como visto, as cascatas de bifurcação são indícios de que o sistema está caminhando para um estado caótico. Como também citado anteriormente, um dos métodos utilizados para tentar identificar se uma dinâmica é caótica é o expoente de Lyapunov. Como ambas trazem informações a respeito da identificação do caos, é interessante comparar os resultados de cada uma nas mesmas situações. Para isto, a Figura 3.8 mostra o diagrama de bifurcações do mapa logístico junto com o gráfico do expoente de Lyapunov calculado para cada valor de $r$. Como ambas estão com o eixo horizontal em comum, é possível comparar o resultados para cada valor de $r$. Resultados similares também podem ser obtidos para o caso do pêndulo. 


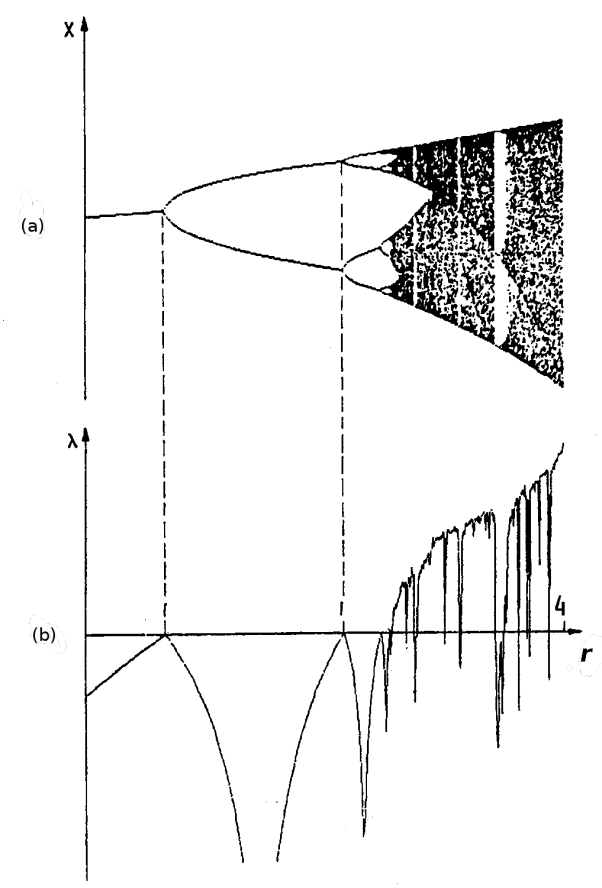

Figura 3.8: Relação entre o diagrama de bifurcação e expoentes de Lyapunov do mapa logístico. Em (a) o diagrama de bifurcações e em (b) os expoentes de Lyapunov ( $\lambda$ ). O valor de $\lambda$ é calculado sob o mapa logístico, gerado para cada valor de $r$ representado no eixo horizontal. Com esta representação é possível visualizar os valores de $\lambda$ nas várias regiões de $r$, identificando o valor deste expoente nas regiões em que as bifurcações se tornam infinitas (caóticas). Adaptado de [17].

Lembrando a definição do expoente de Lyapunov, discutido anteriormente, espera-se que os valores de $\lambda$ apresentados sejam tais que $\lambda<0$ quando o comportamento do mapa for estável, isto é, quando o mapa possuir um período bem estabelecido em sua dinâmica, e $\lambda>0$ quando o mapa apresentar comportamento caótico, o que significa que o número de bifurcações no diagrama tende à infinito.

A Figura 3.8 possui duas linhas tracejadas indicando os pontos nos quais ocorrem as duas primeiras duplicações de período. Analisando apenas esta parte, pode-se ver que, de fato, $\lambda<0$ quando o mapa é estável, e $\lambda=0$ nos pontos de transição de períodos. Se observarmos valores um pouco maiores de $r$, veremos que em dado momento $\lambda$ assume valores maiores que zero, seguido por trechos em que seu valor volta a ser menor que zero. Como discutido anteriormente na análise dos diagramas de bifurcação, existem as ilhas de estabilidade no meio do caos. Pela figura é possível observar algumas dessas ilhas em (a), associadas com valores negativos de $\lambda$, ilustrado em (b). Isso está totalmente de acordo com os resultados obtidos para $\lambda$. Para valores de $r$ nos quais o mapa é caótico, temos que $\lambda>0$.

Esta pequena introdução ao caos permitiu demonstrar algumas de suas caracterísiticas prin- 
cipais, bem como algumas maneiras de visualizar a dinâmica do sistema em diferentes condições, como o mapa de fases e o diagrama de bifurcações. Sistemas caóticos é um tema que vem ganhando cada vez mais interesse por ser um fenômeno que tem se apresentado em diversas áreas do conhecimento.

Neste trabalho, o interesse está na análise da variabilidade cardíaca, que em muitas situações pode apresentar uma dinâmica caótica e diferenciar situações de saúde ou doença. Além do expoente de Lyapunov existem outros métodos que podem ser utilizados na busca pela identificação de estados caóticos. Um deles é a Entropia. Por ser o método utilizado como base nas análises deste trabalho, o capítulo seguinte foi inteiro dedicado para sua abordagem. Nele será feita uma descrição do conceito de entropia e de suas várias interpretações e aplicações para a análise de sistemas dinâmicos. 


\section{Entropia}

O conceito de entropia surgiu pela primeira vez no contexto da Termodinâmica, em meados do século XIX, período de Revolução Industrial e que ficou marcado pelo aparecimento das máquinas térmicas. Neste cenário, o físico e matemático Rudolf Clausius se destacou ao definir o conceito entropia. A idéia geral era representar a reversibilidade ou não dos processos físicos com uma medida da energia acessível nos sistemas $[19,20]$. A segunda lei da termodinâmica é a representação desta idéia, afirmando que a variação da entropia é sempre nula (processos reversíveis ou que possuem toda a sua energia acessível) ou positiva (processos irreversíveis ou que possuem parte de sua energia inacessível).

Posteriormente, com o surgimento da mecânica estatística, o conceito de entropia é retomado, desta vez com outro enfoque. A mecânica estatística procura descrever comportamentos macroscópicos dos sistemas a partir de médias dos diferentes valores microscópicos destes (média dos ensembles). Para representar estas características macroscópicas através dos valores microscópicos, o físico Ludwig Boltzmann (com ajuda de Willard Gibbs) propôs a conhecida fórmula da entropia de Boltzmann-Gibbs $\left(S_{B G}\right)$, dada por

$$
S_{B G}=k \ln (W)
$$

no qual $k$ é a constante de Boltzmann (valor que depende da unidade tomada) e $W$ é a quantidade de microestados possíveis para o sistema. Nesta definição de Boltzmann, a entropia é vista como o grau de desordem de um sistema. A medida em que o número de microestados possíveis do sistema aumenta, a sua entropia também aumenta indicando que existem mais configurações possíveis para aquele sistema e que as moléculas deste sistema estão mais dispersas (mais desorganizadas).

A equação (4.1) é válida para o exemplo clássico do ensemble microcanônico, no qual todos os microestados são equiprováveis $\left(p_{i}=1 / W\right)$. Porém, quando estas probabilidades são diferentes, é preciso utilizar a forma mais geral de sua representação, dada pela equação 


$$
\begin{aligned}
S_{B G} & =k \sum_{i=1}^{W} p_{i} \ln \left(1 / p_{i}\right) \\
& =-k \sum_{i=1}^{W} p_{i} \ln \left(p_{i}\right)
\end{aligned}
$$

no qual $p_{i}$ é a probabilidade de ocorrência do microestado $i$ (configuração das moléculas). No caso dos estados equiprováveis, $p_{i}=1 / W$ e a equação (4.1) é obtida.

Além destas duas abordagens citadas, uma outra interpretação da entropia que ficou bastante conhecida está ligada à teoria da informação, proposta pelo engenheiro e matemático Claude Shannon. Na busca pela quantização do conceito de informação (e, consequentemente, o de incerteza) de um sistema ou evento, primeiramente associou-se a idéia de que a quantidade de informação deveria estar relacionada ao número de resultados possíveis de se obter em um sistema. Por exemplo, ao jogar-se um dado existem seis possibilidades de resultados, ao contrário de quando se joga uma moeda, em que são somente dois os resultados possíveis. Logo, a quantidade de informação obtida ao lançar um dado é teoricamente maior do que a informação obtida ao lançar-se uma moeda. Podemos ainda interpretar isso de outra forma dizendo que a incerteza ao se lançar um dado é maior do que ao se lançar uma moeda, pois o número maior de possibilidades nos deixa com um grau maior de incerteza quanto ao resultado.

Segundo os pesquisadores, uma formulação matemática para o cálculo da informação deveria satisfazer dois requisitos:

- A informação de um sistema composto deve ser a soma das informações dos subsistemas que o compõem;

- O número de estados possíveis de um sistema composto deve ser a multiplicação do número de estados dos subsistemas que o compõem.

Estes requisitos podem ser confirmados analisando o lançamento simultâneo de um dado e de uma moeda. Ao lançá-los simultaneamente, os resultados possíveis são pares $[d, m]$, no qual $d$ é o resultado obtido no dado ( 1 a 6 ) e $m$ o resultado obtido com a moeda (cara ou coroa). O número de pares possíveis de se obter é exatamente a multiplicação dos possíveis estados em cada evento, ou seja, $N=6 * 2=12$. Já a informação contida nestes eventos consiste simplesmente da informação oferecida pelo dado e da informação obtida com a moeda, ou seja, é a simples soma das informações (o resultado [3,cara], por exemplo, contém a mesma informação dos eventos 3 e cara quando obtidos separadamente). 
Para satisfazer estas duas relações em uma expressão matemática, Shannon propôs o uso da função logarítmo, no qual a informação $(I)$ pode ser medida pela equação

$$
I=\log (N)
$$

no qual $N$ indica o número de estados possíveis do sistema. Vejamos a validade de sua representação quanto aos requisitos citados.

Suponhamos a união de dois sistemas $A$ e $B$ com número de estados possíveis $N_{A}$ e $N_{B}$ e informação $I_{A}$ e $I_{B}$, resultando em um sistema com $N$ estados e informação $I$. Com isso, devemos ter

$$
\begin{aligned}
I & =I_{A}+I_{B} \\
N & =N_{A} N_{B}
\end{aligned}
$$

Para relacionar estas duas variáveis e satisfazer essas relações, percebeu-se que era preciso utilizar uma equação exponencial. Assim, a expressão que relaciona o número de estados com a informação é dada por

$$
N=\text { base }^{I}
$$

no qual base indica um valor tomado para a base da função exponencial. Aplicando no caso dos sistemas $A$ e $B$, temos que

$$
\begin{aligned}
N_{A} N_{B} & =\text { base }^{I_{A}} \text { base }^{I_{B}} \\
& =\text { base }^{I_{A}+I_{B}} \\
N & =\text { base }^{I}
\end{aligned}
$$

o que comprova que a expressão satisfaz os requisitos propostos. Aplicando o logarítmo em ambos os lados de (4.7), temos 


$$
\begin{aligned}
\log (N) & =\log \left(\text { base }^{I}\right) \\
& =I \log (\text { base }) \\
I & =\frac{\log (N)}{\log (\text { base })}
\end{aligned}
$$

sendo que $\log$ (base) é uma constante (que terá valor 1 se a base do logaritmo utilizada for igual a base). Assim, a equação (4.8) equivale à equação (4.3). Percebe-se ainda que esta representação da informação obtida é equivalente à expressão de entropia proposta por Bolztmann, daí também utilizar o nome entropia neste contexto (entropia da informação).

Assim como acontece com a entropia de Boltzmann, a equação (4.3) representa o caso em que todos os estados são igualmente prováveis. Sua formulação para o caso geral é equivalente ao caso geral da entropia de Boltzmann, equação (4.2), adotando $k=1$. Neste caso, podemos entender que a informação total de um sistema depende da informação de cada um dos seus estados separadamente, ponderado pela frequência com que é visitado. Isto quer dizer que um estado que é visitado mais vezes (possuir maior probabilidade de ocorrência), além de possuir um valor maior de informação $\left(\ln \left(p_{i}\right)\right)$ também contribui para a informação total do sistema com maior peso, o que é traduzido pela expressão $p_{i} \ln \left(p_{i}\right)$ na equação (4.3).

$\mathrm{Na}$ teoria da informação, geralmente utiliza-se a base 2 para o logarítmo, ao contrário da base $e$ (2.7182) da entropia de Boltzmann. Esta escolha não é crucial, uma vez que a diferença entre logarítmos de bases diferentes é apenas um fator multiplicativo $\left(\log _{a}(x)=\right.$ constante $*$ $\log _{b}(x)$ ). Com o uso da base 2 para a entropia da informação, a unidade da informação é o "bit", analogia ao termo utilizado na representação de uma informação binária ( 0 ou 1, sim ou não, verdadeiro ou falso).

As três definições de entropia analisadas foram obtidas em contextos diferentes. A entropia da informação, por exemplo, foi obtida na tentativa de representar a informação, culminando em uma expressão igual à proposta por Boltzmann. Isso mostra que a entropia é um conceito amplo e ubíquo [21]. Outros exemplos de interpretação da entropia são, por exemplo, o grau de [20]:

- Uniformidade de uma distribuição;

- Liberdade de escolha;

- Diversidade;

- Surpresa; 
- Aleatoriedade ou previsibilidade de uma amostra.

Em todos os casos nota-se que sua interepretação está intimamente ligada às probabilidades, fato este que a torna aplicável aos mais diversos ramos da ciência no qual as probabilidades aparecem expressando os mais variados fenômenos existentes.

Uma das aplicações para a entropia consiste na identificação de caos em sistemas dinâmicos. Esta abordagem foi proposta pelo matemático Andrey Kolmogorov e ficou conhecida como entropia de Kolmogorov-Sinai (o matemático Yakov Sinai refinou sua fórmula e provou-a) [22] e será discutida a seguir.

\subsection{Entropia de Kolmogorov-Sinai}

Como discutido anteriormente, o conceito da entropia pode ser aplicado nas mais variadas áreas. Com a proposta de Shannon, associando as idéias de entropia e informação, surge uma nova expressão que utiliza a definição de entropia da informação para calcular uma taxa média de crescimento de entropia (ou informação) ao longo do tempo. Esta medida ficou conhecida como entropia de Kolmogorov-Sinai $\left(S_{K S}\right)$ e com ela é possível avaliar o comportamento de sistemas dinâmicos quanto à presença ou não de caos.

Para chegarmos à definição da entropia KS, imaginemos um sistema dinâmico discreto $x(n)$ evoluindo no tempo. Representando o valor da sua entropia no tempo por $S_{I}(n)$, podemos inicalmente definir que

$$
S_{K S}=\lim _{n \rightarrow \infty} \frac{S_{I}(n)}{n}
$$

no qual o limite indica que a taxa calculada é uma média ao longo da evolução do sistema.

É preciso agora definir como calcular o valor da entropia $S_{I}(n)$ para o sistema. A equação geral da entropia de Shannon é definida por (ver equação 4.2):

$$
S_{I}=-\sum_{i=1}^{W} p_{i} \log \left(p_{i}\right)
$$

no qual $p_{i}$ representa a probabilidade de ocorrência de cada estado $i$ do sistema. Em sistemas dinâmicos, a melhor maneira de definir $p_{i}$ é através do espaço de fases do sistema. Primeiramente, divide-se o espaço de fases em caixas, cubos ou hipercubos (no caso de sistemas com dimensão maior que 3) de tamanho $\varepsilon$, de maneira que pontos pertencentes à mesma caixa são considerados estados iguais. $\mathrm{O}$ valor de $\varepsilon$ define o grau de similaridade que será considerado. 
Com isso, podemos definir $p_{i}$ como a probabilidade conjunta do sistema estar no estado $k_{1}$ no tempo $t=1$, em $k_{2}$ no tempo $t=2$ e em $k_{n}$ no tempo $t=n$. Assim, podemos melhor representar $p_{i}$ por $p\left(k_{1}, \ldots, k_{n}\right)$ e definir a entropia no tempo $n$ como

$$
S_{I}(n)=-\sum_{k_{1}, \ldots, k_{n}} p\left(k_{1}, \ldots, k_{n}\right) \log p\left(k_{1}, \ldots, k_{n}\right)
$$

$\mathrm{Na}$ equação acima são calculadas as probabilidades de ocorrência de cada trajetória de tamanho $n$ no espaço de fases. Associando esta última equação com a primeira definição da entropia KS, chegamos à equação

$$
S_{K S}=-\lim _{\varepsilon \rightarrow 0} \lim _{n \rightarrow \infty} \frac{1}{n} \sum_{k_{1}, \ldots, k_{n}} p\left(k_{1}, \ldots, k_{n}\right) \log p\left(k_{1}, \ldots, k_{n}\right)
$$

no qual, por definição, seu valor é obtido quando $\varepsilon \rightarrow 0$. No caso de sistemas dinâmicos contínuos, a diferença é que o estado do sistema é obtido em intervalos de tempo $\delta$, de tal maneira que agora o estado $k_{i}$ está associado ao tempo $t=i \delta$. Neste caso, a definição da entropia KS é

$$
S_{K S}=-\lim _{\delta \rightarrow 0} \lim _{\varepsilon \rightarrow 0} \lim _{n \rightarrow \infty} \frac{1}{\delta n} \sum_{k_{1}, \ldots, k_{n}} p\left(k_{1}, \ldots, k_{n}\right) \log p\left(k_{1}, \ldots, k_{n}\right)
$$

A equação (4.13) é a forma mais geral de representação da entropia KS. No caso de sistemas discretos (mapas), $\delta=1$ e a equação (4.12) é obtida.

Uma forma alternativa de representar a entropia KS consiste em calcular a diferença de entropias ao invés de uma taxa propriamente dita, proposta por Shannon [23] e cujo resultado converge para o mesmo que o da equação (4.13) no limite $n \rightarrow \infty$, sendo, portanto, formulações equivalentes. Sua expressão é dada por

$$
S_{K S}=-\lim _{\delta \rightarrow 0} \lim _{\varepsilon \rightarrow 0} \lim _{n \rightarrow \infty} \frac{1}{\delta n}\left[S_{I}(n)-S_{I}(n-1)\right]
$$

Como a característica de medir a taxa de crescimento da informação, a entropia KS é útil na indentificação dos sistemas em que há constantemente informação sendo criada, que é o caso dos sistemas complexos. Quanto mais informação os sistema gera, menos sabemos a seu respeito, o que aumenta nossa incerteza, imprevisibilidade ou surpresa ao longo de sua evolução [22]. Como nos sistemas caóticos existe uma grande sensibilidade às condições iniciais, há sempre uma grande incerteza a respeito de seus estados futuros e a entropia KS é uma ferramenta valiosa na identificação destas condições. Valores de $S_{K S}$ iguais a zero indicam que 
não há informação sendo criada no sistema, e por conseguinte, não há incertezas quanto à sua dinâmica. Geralmente, estes são os casos de sistemas com regimes periódicos, como o mapa logístico da Figura 3.3. Valores positivos e finitos de $S_{K S}$ são indicadores de caos, pois indicam que o sistema, ao longo de sua evolução, produz novas informações constantemente; e quanto maior o seu valor, maior é o grau de complexidade do sistema. Uma terceira situação possível ocorre quando o valor da entropia KS tende à infinito. Isto acontece nos sistemas aleatórios, nos quais a incerteza a seu respeito é sempre máxima. Fenômenos "completamente aleatórios"são difíceis de acontecerem na prática e encaramos esses casos como fenômenos com graus de liberdade muito altos, fazendo com que esta classificação de aleatórios seja uma aproximação aceitável.

Apesar do seu poder na identificação de situações de caos, a entropia KS é uma definição teórica que não é aplicável na prática. Os limites existentes na sua formulação não permitem o cálculo de seu valor para séries temporais finitas. Devido a essa limitação, surgiram algumas propostas de aproximação da entropia KS para serem utilizadas na prática e que são apresentadas na próxima seção.

\subsection{Entropia para Séries Temporais}

A definição da entropia KS considera o cálculo da taxa de crescimento da entropia (ou informação) nos limites $\lim _{\mathcal{E} \rightarrow 0}$ e $\lim _{n \rightarrow \infty}$ para o caso de sistemas discretos, sendo $\varepsilon$ o tamanho das caixas no estado de fases (ou simplesmente o grau de similaridade entre os estados) e $n$ o tempo, que corresponde ao número de pontos da série obtida do sistema. Na prática, estes limites são impossíveis de serem obtidos pois uma série temporal sempre terá tamanho finito (n) e o grau de similaridade terá sempre um valor fixo, por menor que seja.

A primeira idéia que surge neste caso é calcular a entropia KS para vários valores diferentes de $n$ e $\varepsilon$, buscando identificar se há uma convergência. Uma opção seria, por exemplo, a partir de uma série de tamanho $N$, avaliar sua entropia variando o parâmetro $n$ de 1 a $N$ (ao longo do tempo) para vários valores decrescentes de $\varepsilon$ e verificar se ocorre convergência. Porém, como a série é finita ( $N$ pontos), esses resultados variam ao utilizar séries com tamanhos diferentes. A Figura 4.1 mostra a avaliação de uma série utilizando a equação de diferença (4.14). O primeiro gráfico (esquerda) mostra a convergência da entropia para alguns valores de $\varepsilon$ e o segundo (direita) para diferentes tamanhos da série, fixando o valor de $\varepsilon$

Como se vê, a convergência que aparece no primeiro gráfico desaparece no segundo para $N<10000$. Isto mostra que é muito difícil utilizar essa formulação de entropia na prática, 

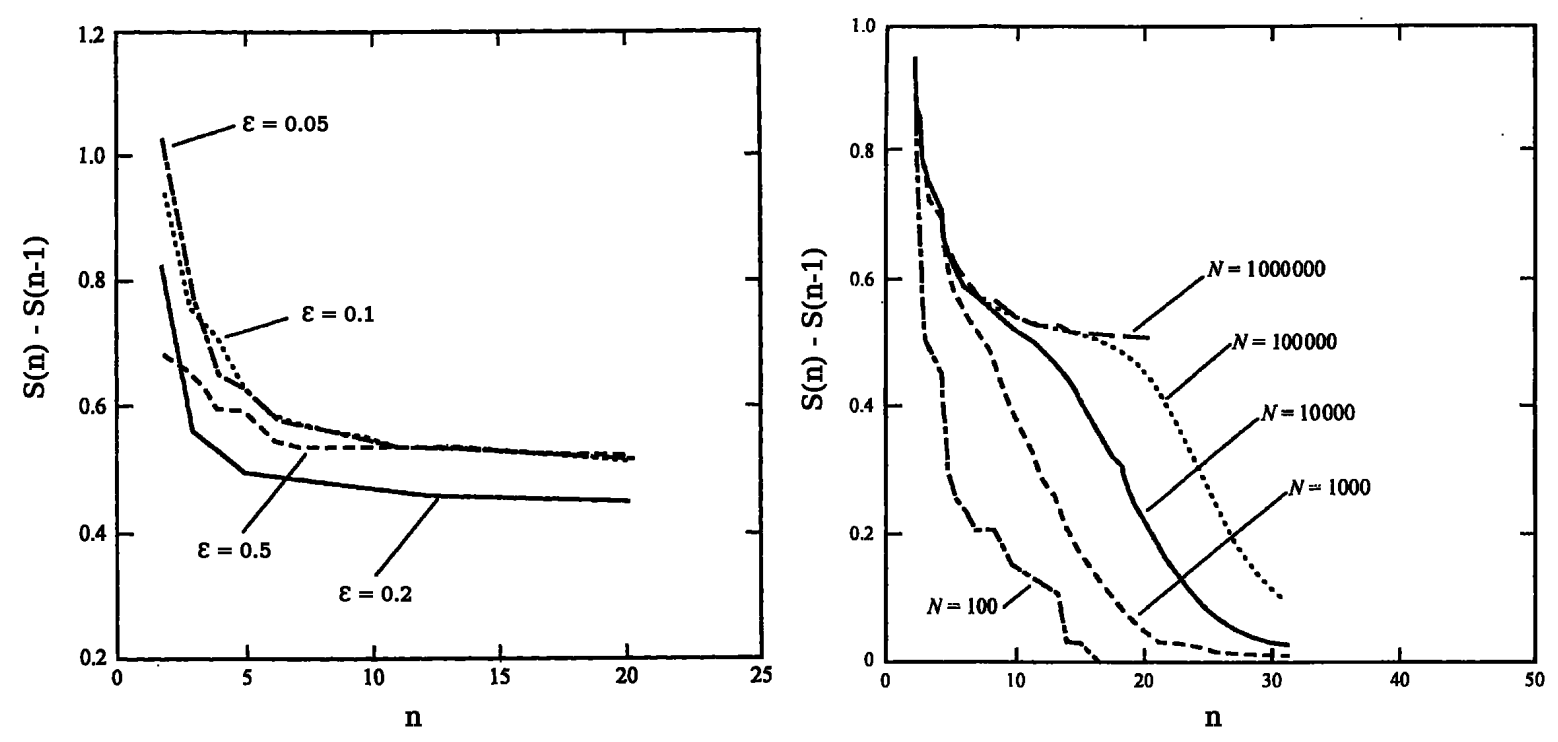

Figura 4.1: Convergência da entropia KS utilizando a equação de diferença (4.14). O gráfico da esquerda mostra a convergência do mapa logístico em regime caótico, no qual $N=1000000$ e $r=3.7$ (equação 3.4). Foram avaliados cinco valores diferentes de $\varepsilon$. No gráfico da direita é mostrada a convergência do mesmo mapa, desta vez variando-se o tamanho da série, fixando o valor de $\varepsilon=0.1$. Adaptado de [20].

pois a série precisa ser grande o suficiente para que se tenha uma convergência confiável e os cálculos exigem muito custo computacional. Em alguns casos, como no mapa logístico caótico, que possui equação bem definida, é possível evoluir sua dinâmica e gerar quantos pontos forem desejados, obtendo séries imensas. Mas na maioria das vezes o que deseja-se avaliar são séries temporais obtidas de fontes reais, nas quais a quantidade de pontos disponíveis é geralmente muito menor.

Na busca de formulações que fossem úteis para analisar a complexidade de séries temporais pequenas, em 1991, Pincus propõem uma família de medidas chamada Entropia Aproximada [24] , baseado em trabalhos anteriores de Grassberger e Proccacia [25] e Eckmann e Ruelle [26] que haviam proposto aproximações para a entropia KS, mas que ainda não se aplicavam a séries pequenas ou com ruídos. Na definição de Pincus, essa família de entropias é dada por:

$$
\operatorname{ApEn}(m, r)=\lim _{N \rightarrow \infty}\left[\Phi^{m}(r)-\Phi^{m+1}(r)\right]
$$

sendo que para uma série de tamanho $N$, ApEn é estimada pela estatística

$$
\operatorname{ApEn}(m, r, N)=\Phi^{m}(r)-\Phi^{m+1}(r)
$$

Para entender a maneira como a estatística ApEn é calculada, suponhamos uma série tem- 
poral dada por $u(1), u(2), \ldots, u(n)$. Definamos o vetor $x_{m}(i)$ como sendo o conjunto de pontos em $u$ de $i$ até $i+m-1$, ou seja, $x_{m}(i)=[u(i), u(i+1), u(i+2), \ldots, u(i+m-1)]$. Assim, temos que

$$
\Phi^{m}(r)=\frac{1}{(N-m+1)} \sum_{i=1}^{N-m+1} \ln C_{i}^{m}(r)
$$

no qual

$$
C_{i}^{m}(r)=\frac{\left(\text { número de vetores } j \text { tais que } d\left[x_{m}(i), x_{m}(j)\right] \leq r\right)}{(N-m+1)}
$$

e

$$
d\left[x_{m}(i), x_{m}(j)\right]=\max _{k=1, \ldots, m}(|u(i+k-1)-u(j+k-1)|)
$$

A equação (4.18) calcula a probabilidade de ocorrência do padrão $i$, de tamanho $m$, dada uma tolerância $r$. A Figura 4.2 mostra um exemplo desta etapa. Isto é feito para todos os padrões de tamanho $m$ presentes na série e a equação (4.17) calcula a média logarítmica desses valores. Em seguida, o mesmo é feito para os padrões de tamanho $m+1$ e a equação (4.16) fornece o resultado final.

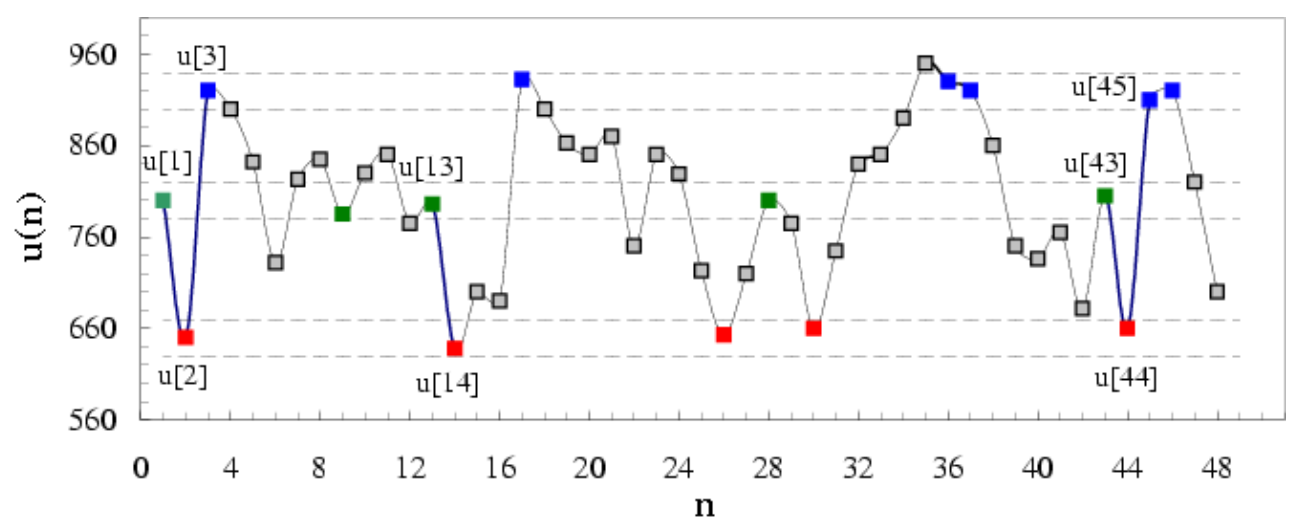

Figura 4.2: Exemplo de contagem de padrões da equação (4.18). Considerando o caso em que $m=3$, temos $x_{3}(i)=[u(1), u(2), u(3)]$. As linhas serrilhadas horizontais indicam a tolerância $(r)$ para cada um dos três pontos do padrão. Como mostra a equação (4.19), a função de distância considera o módulo da diferença entre dois pontos e por isso o intervalo de tolerância em cada ponto é $x_{m}(i) \pm r$. Todos os pontos da série que estão no intervalo de tolerância do ponto $u(1)$ são mostrados em verde. O mesmo foi feito para os pontos $u(2)$ e $u(3)$, sendo representados em vermelho e azul, respectivamente. Como pode ser observado, existe apenas um padrão no qual os três pontos reaparecem em sequência dentro das tolerâncias definidas $([u(43), u(44), u(45)])$. Se avaliarmos para $m=2$, teremos que $x_{2}(i)=[u(1), u(2)]$ e neste caso existem 2 padrões que serão considerados iguais $([u(13), u(14)]$ e $[u(43), u(44)])$. Adaptado de [27].

Se compararmos a definição de Pincus com a definição da entropia KS, é possível notar que os parâmetros $\varepsilon$ e $n$ da equação (4.12) possuem um papel semelhante ao dos parâmetros $r$ e $m$ na Entropia Aproximada. A diferença é que, nesta última, esses parâmetros são fixados e a 
probabilidade é obtida através de uma função de correlação. Para séries pequenas com dinâmica de baixa dimensão (correlação de curto alcance), valores pequenos de $m$ são suficientes para identificar a regularidade da série e o parâmetro $r$ é, na maioria dos casos, definido em termos do desvio padrão da série (uma porcentagem deste) de maneira que sua atribuição seja invariante à escala do sinal [28].

Uma das características da Entropia Aproximada é a contagem da própria ocorrência do padrão $x_{m}(i)$ na equação (4.18). Isto evita que $C_{i}^{r}(r)$ seja zero, fazendo com que o logarítmo da equação (4.17) sempre exista. Contudo, esta característica está em desacordo com o conceito de criação de informação, causando inconsistência nos resultados e tornando-a dependente do tamanho da série. Por exemplo, quando a contagem de padrões semelhantes da equação (4.18) tende a zero, a contagem da própria ocorrência atua como se a série fosse perfeitamente regular.

Para corrigir essas limitações da Entropia Aproximada, Richman e Moorman propuseram uma modificação em sua formulação, resultando em uma medida que ficou conhecida como Entropia Amostral [29]. As principais diferenças para a entropia aproximada são duas. A primeira é que na entropia amostral não há mais a contagem da própria ocorrência de um padrão. A segunda é que sua equação não está mais baseada na soma de logarítmos, mas no logarítmo de uma divisão. Considerando os mesmos vetores definidos na demonstração da entropia aproximada, a estatística da entropia amostral é definida por:

$$
\operatorname{SampEn}(m, r, N)=-\ln \frac{U^{m+1}(r)}{U^{m}(r)}
$$

sendo que

$$
\begin{aligned}
U^{m}(r) & =\frac{1}{N-m} \sum_{i=1}^{N-m} U_{i}^{m} \\
U_{i}^{m} & =\frac{\left[\text { núm. de vetores } j \neq i \text { tais que } d\left[x_{m}(i), x_{m}(j)\right] \leq r\right]}{N-m-1}
\end{aligned}
$$

e

$$
\begin{aligned}
U^{m+1}(r) & =\frac{1}{N-m} \sum_{i=1}^{N-m} U_{i}^{m+1} \\
U_{i}^{m+1} & =\frac{\left[\text { núm. de vetores } j \neq i \text { tais que } d\left[x_{m+1}(i), x_{m+1}(j)\right] \leq r\right]}{N-m-1}
\end{aligned}
$$

A função de distância utilizada é a mesma da equação (4.19). As equações (4.22) e (4.24) mostram que não há mais a contagem da própria ocorrência $(j \neq i)$ e as equações (4.21) e (4.23) 
mostram que os limites dos somatórios são iguais, o que significa que as contagem dos padrões de tamanho $m$ e $m+1$ são feitas no mesmo espaço da série (de 1 a $N-m$ ). Isso permite ainda que a razão $U^{m+1}(r) / U^{m}(r)$ seja simplificada, de maneira que sua equação (4.20) pode ser escrita por:

$$
\operatorname{SampEn}(m, r, N)=-\ln \frac{A}{B}
$$

no qual $A$ e $B$ são as contagens de padrões similares presentes na série com tamanhos $m+1 \mathrm{e}$ $m$, respectivamente, respeitando o espaço de busca da série de 1 a $N-m$ para ambos os valores de $m$.

A entropia amostral tem as mesmas características da entropia aproximada, com a diferença de que seus resultados são mais consistentes e menos dependentes do tamanho da série. Assim como na definição da entropia $\mathrm{KS}$, ambas avaliam a taxa de aumento da entropia, mas neste caso para valores específicos de $m$ e $r$. Com isso, quanto maior o valor da entropia, mais complexa, mais irregular ou mais imprevisível é a série.

Como citado anteriormente, estas formualções de entropia são úteis e boas aproximações para fenômenos de baixa dimensão, no qual um valor pequeno para $m$ é suficiente para detectar a complexidade. Porém, não existe nenhum roteiro confiável para se determinar os valores ótimos de $m$ e $r$. Um dos autores da entropia amostral, Douglas Lake, em um trabalho que avalia séries de variabilidade cardíaca fetal, discute um pouco este problema e propõe uma maneira de detectar os valores ótimos desses parâmetros a partir das próprias séries [28]. Segundo Lake, várias regras existentes definem que para séries com tamanhos de 100 a 5000, geralmente valores de $m$ iguais a 1 ou 2 e $0.1<r<0.25$ são avaliados, lembrando que este último é definido como uma fração do desvio padrão da série.

A Figura 4.3 ilustra o cálculo da entropia amostral de dois sinais para vários valores de $m$ e $r$. Em ambos os casos é possível perceber que quando o valor de $m$ é grande em relação ao tamanho da série, os valores da SampEn divergem da tendência que havia sido atingida para $m$ menores, e isso é mais rápido quanto menor é o valor de $r$ utilizado. Interessante observar que no caso do mapa logístico, a medida em que $r$ diminui, aparece uma forte tendência de convergência para a SampEn com o crescimento de $m$. Essa tendência mostra que a SampEn aproxima a entropia KS, e que isso é atingido logo para valores pequenos de $m$. Isto foi possível de ser observado graças ao tamanho grande da série, o que não ocorre na série RR avaliada.

Algum tempo depois do surgimento da entropia amostral, Madalena e coautores propuseram uma nova abordagem de aplicação da entropia, que ficou conhecida com Entropia Multies- 

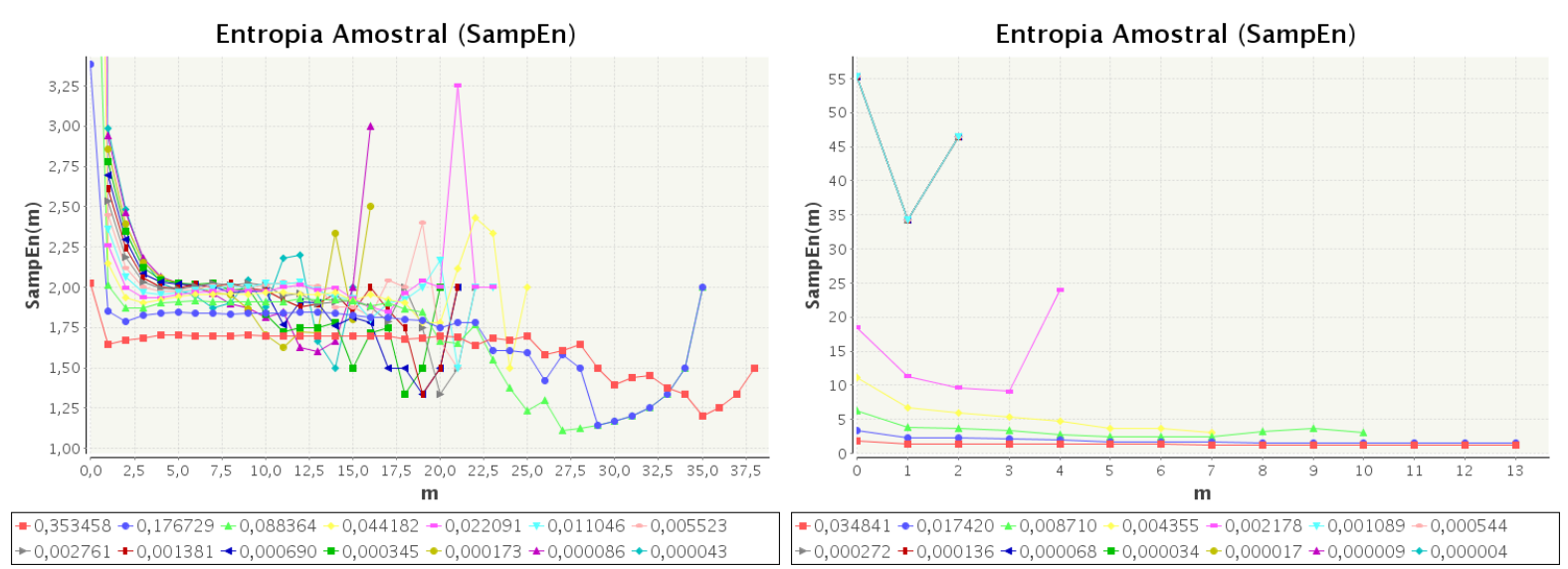

Figura 4.3: Exemplo de cálculo da entropia amostral para diferentes valores dos parâmetros $m$ e $r$. No gráfico a esquerda foi utilizado uma série de 20 mil pontos gerada pela equação do mapa logístico em regime caótico ( $r=4$, equação 3.4) e o gráfico a direita corresponde a uma série RR real de um paciente saudável, com 939 pontos. Em ambos os casos, cada série representa um valor diferente para $r$, iniciando com o valor de um desvio padrão da série $(r=S D)$ dividindo seu valor pela metade em cada passo $(r=S D, S D / 2, S D / 4, S D / 8, \ldots, S D / 8192)$. Os resultados são semelhantes aos da Figura 4.1.

cala (MSE) [27, 30]. Neste trabalho os autores discutem o fato de que nem sempre um aumento no valor da entropia amostral está associado a um aumento na complexidade da série, e que isto pode estar ligado ao fato de que a entropia amostral é calculada para apenas uma escala do sinal. Assim, esta nova abordagem consiste do cálculo da entropia amostral para várias escalas de um sinal.

Considere a série temporal $u(1), u(2), \ldots, u(n)$ utilizada nos exemplos anteriores. Para calcular a MSE, primeiro são construidas as séries em diferentes escalas. Cada elemento de uma série em escala $\tau$ é definido por:

$$
u^{\tau}(j)=\frac{1}{\tau} \sum_{i=(j-1) \tau+1}^{j \tau} u(i), \quad 1 \leq j \leq N / \tau
$$

A Figura 4.4 ilustra bem esta etapa. Uma vez geradas as séries para várias escalas $(1 \leq \tau \leq$ $\tau_{\text {max }}$ ), calcula-se a entropia amostral para cada uma e os resultados são apresentados em um gráfico de entropia versus escala.

A Figura 4.5 ilustra o resultado da MSE para sinais reais de variabilidade cardíaca e para os ruídos branco e 1/f. Fica claro pela figura que, de fato, ao analisar uma série em diferentes escalas, mais informações relevantes a seu respeito são obtidas. Como se sabe, indivíduos saudáveis possuem um mecanismo de regulação cardíaco mais complexo do indivíduos doentes, e avaliando tais séries com a MSE, essa complexidade é detectada nas diferentes escalas, 


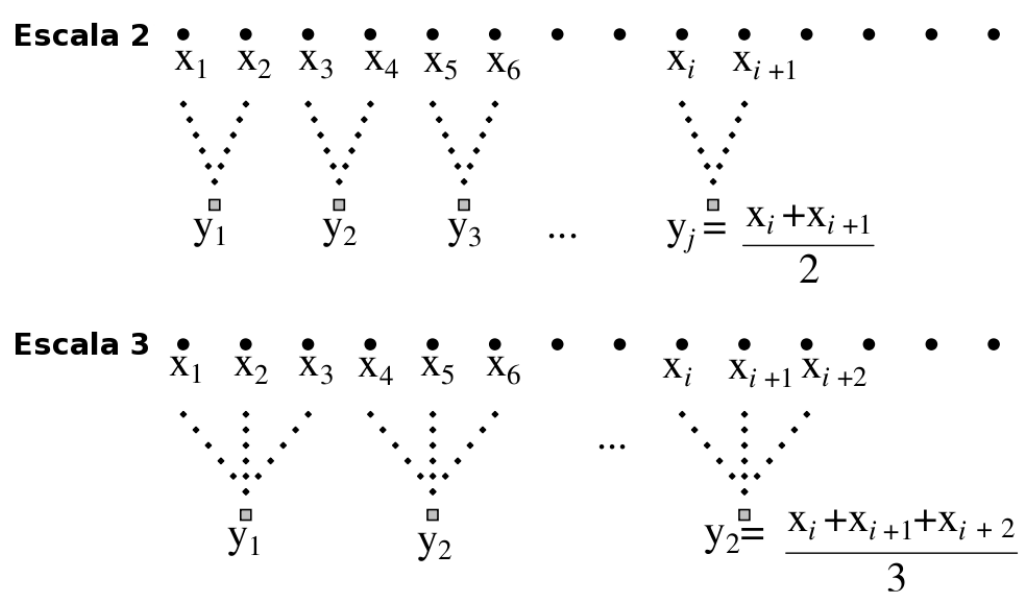

Figura 4.4: Ilustração da construção das séries em diferentes escalas. Esta etapa também é conhecida por coarse-graining. Para cada escala, a série $y$ resultante equivale aos $N / \tau$ pontos obtidos pela média a cada $\tau$ pontos consecutivos, sem sobreposições. A figura ilustra o caso para $\tau=2$ e $\tau=3$. Traduzido de [27].

revelando estruturas com correlações de longo alcance, ao contrário de sinais provenientes de pacientes com alguma patologia. O mesmo acontece com o ruído 1/f, que reconhecidamente possui estruturas de correlação em diferentes escalas, diferentemente do ruído branco.
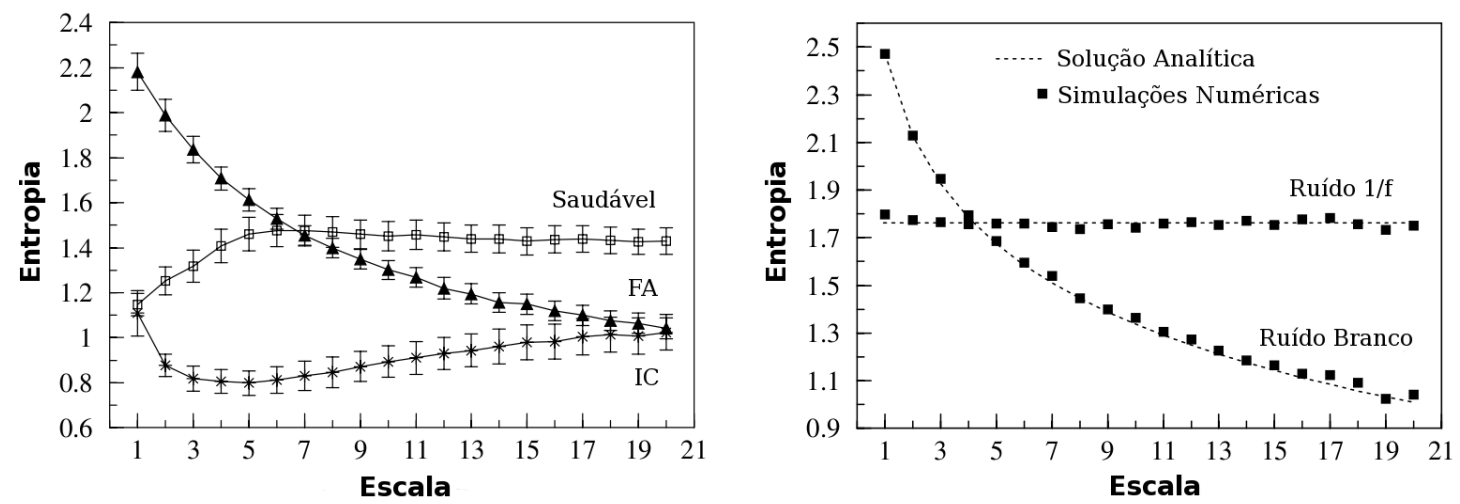

Figura 4.5: Exemplos de resultado da entropia multiescala. À esquerda estão os resultados para sinais de variabilidade cardíaca de grupos normais, com fibrilação atrial (FA) e insuficiência cardíaca (IC). À direita estão os resultados para os ruídos. Traduzido de [30]

Estas três abordagens de entropia discutidas aqui são as mais utilizadas na avaliação de séries de variabilidade cardíaca. Porém, seus resultados ainda não são totalmente reconhecidos no ponto de vista prático, sendo necessário ainda mais estudos para validá-las melhor antes de poderem ser aplicadas em rotinas clínicas.

Na seção a seguir será apresentada uma generalização do conceito clássico da entropia, o qual foi utilizado para generalizar estas três abordagens de entropia para séries temporais. $\mathrm{O}$ 
capítulo 5 descreve a metodologia utilizada para isso.

\subsection{Entropia Não Extensiva}

Como mostrado no exemplo do lançamento simultâneo de um dado e uma moeda, no início do capítulo, a informação contida em um sistema composto é a simples soma da informação dos subsistemas que o compões. Isto significa dizer que a entropia de Shannon é aditiva. O mesmo ocorre com a entropia Boltzmann-Gibbs, sendo neste caso relacionado à desordem das moléculas em sistemas compostos.

Essa relação é verdadeira em sistemas simples, no qual o comportamento de cada subsistema é o mesmo na presença ou não de outros sistemas interagentes. Contudo, nos sistemas complexos, aparecem propriedades emergentes que são características do conjunto e que fazem seu comportamento ser diferente de uma simples soma dos comportamentos de cada subsistema. Surge então a idéia de propensões [31]. Um exemplo disso são as formações de ciclones e tornados decorrentes das interações entre vários fatores presentes nas correntes de ar e que, sozinhos, não aparentam poder produzir tal fenômeno. Outro exemplo disso está na interação entre as pessoas no mundo. Se avaliarmos o total de informação que duas pessoas produzem ao escreverem sozinhas um livro cada uma, por exemplo, poderá ser diferente da informação contida em um único livro produzido em parceria por essas duas pessoas ao se unirem e interagirem entre si, trocando informações e experiências. Neste caso, a interação pode gerar elementos que não apareceriam nos sistemas (pessoas) isolados, situação característica dos sistemas caóticos.

Com isso, as formulações clássicas da entropia de Boltzmann-Gibbs e Shannon tornamse inadequadas para descrever sistemas com interações de longo alcance e memória de longo termo. Buscando solucionar isso, em 1988, o físico Constantino Tsallis propôs uma generalização da entropia de Boltzmann-Gibbs (que também se aplica à de Shannon), na qual aparece um parâmetro de não extensividade $(q)$ que procura descrever esta característica propulsora.

A entropia de Tsallis $\left(S_{q}\right)$ ficou conhecida como entropia não extensiva, justamente pela sua características de não aditividade, e sua definição para o caso do ensemble microcanônico (estados equiprováveis) é dada por

$$
S_{q}=k \frac{W^{1-q}-1}{1-q}
$$

sendo $W$ o número de estados do sistema.

No caso geral, no qual a probabilidade de cada estados $i$ é $p_{i}$, a entropia de Tsallis é dada 
por

$$
S_{q}=k \frac{1-\sum_{i=1}^{W} p_{i}^{q}}{q-1}
$$

Com essa abordagem, a entropia de um sistema composto deixa de ser a simples soma das entropias. Para um sistema composto pelos dois subsistemas $A$ e $B$, a entropia será

$$
S_{q}^{(A \cup B)}=S_{q}^{(A)}+S_{q}^{(B)}+(1-q) S_{q}^{(A)} S_{q}^{(B)}
$$

Percebe-se pela equação acima que, com esta nova formulação, surge um termo não linear na entropia total, dado por $(1-q) S_{q}^{(A)} S_{q}^{(B)}$, de maneira que para $q>1$ a entropia do sistema composto é menor do que a soma das entropias (sub-aditiva), para $q<1$ esta é maior e para $q=1$, ela é exatamente a soma das entropias dos subsistemas.

As equações (4.27) e (4.28) da proposta de Tsallis são generalizações das equações (4.1) e (4.2) das entropias de Boltzmann-Gibbs e Shannon $(k=1)$, sendo que no limite quando $q \rightarrow 1$, a formulação de Tsallis recupera as equaçôes clássicas de entropia. Isso faz desta proposta uma ampliação do conceito clássico, sendo este obtido para um valor específico do parâmetro entrópico $(q=1)$.

Analisando as versões clássicas e generalizadas das equações (4.2) e (4.28), a generalização proposta pode ser entendida como uma generalização da função logarítmo (e consequentemente, também da função exponencial). Pelas equações citadas é possível deduzir a forma generalizada dessas funções $\left(\ln _{q}(x)\right.$ e $\left.e_{q}(x)\right)$, dadas por [32]:

$$
\begin{aligned}
\ln _{q}(x) & =\frac{x^{1-q}-1}{1-q}, \quad x>0 \\
e_{q}(x) & =[1+(1-q) x]_{+}^{1 /(1-q)}, \quad x, q \in \mathbb{R}
\end{aligned}
$$

A Figura 4.6 mostra a superfície da equação (4.30) em função de $x$ e do parâmetro de não extensividade $q$.

É nesta generalização da função logarítmo que reside a principal proposta deste projeto, que é a aplicação do paradigma não extensivo nas entropias para séries temporais discutidas anteriormente. A idéia principal é verificar a contribuição do parâmetro entrópico nesses métodos, avaliando se as características não extensivas (interações não lineares) presentes na dinâmica das séries são melhor representadas com esta abordagem. 


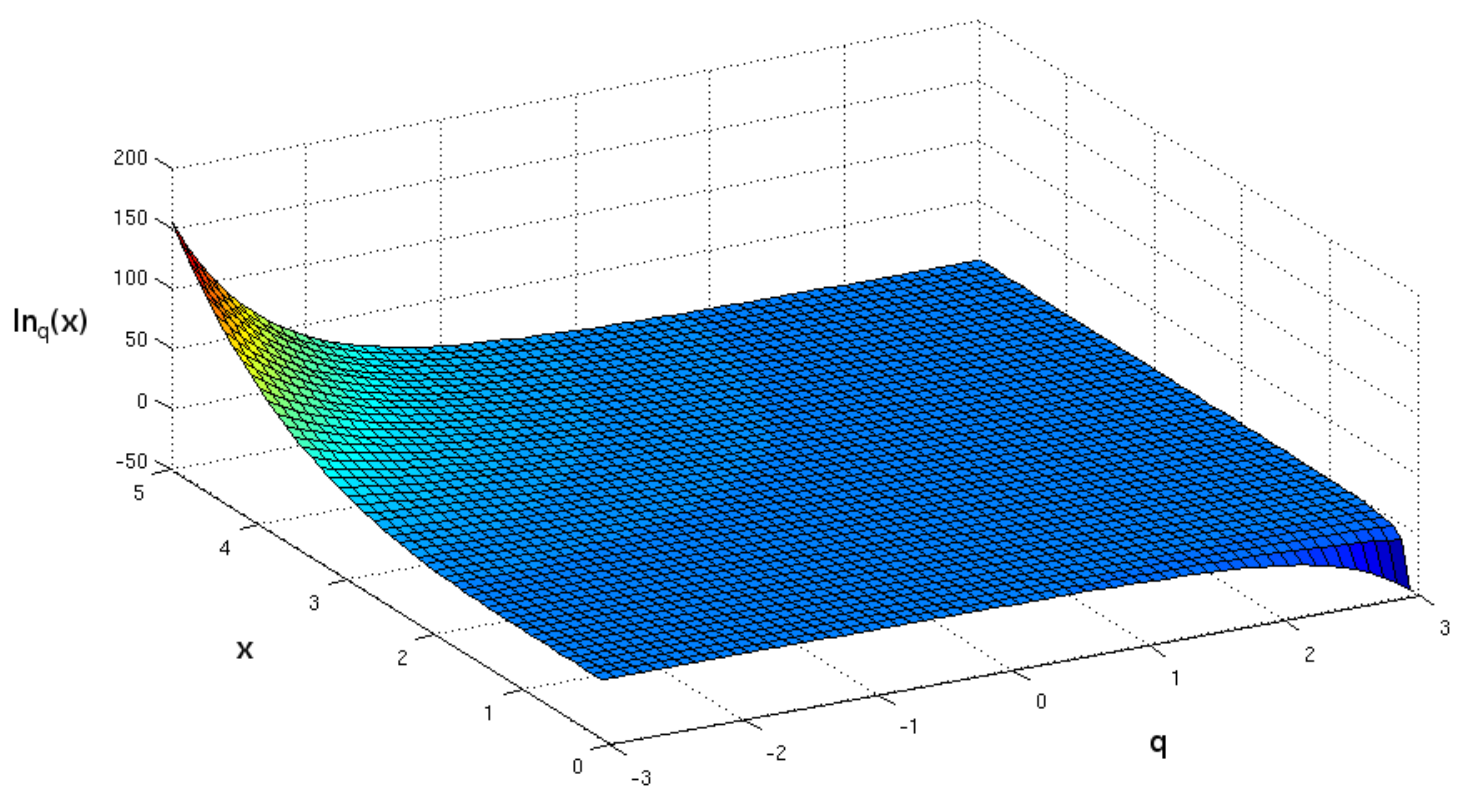

Figura 4.6: Ilustração da função $\ln _{q}(x)$ em função de $x$ e $q$.

Os detalhes de como esse paradigma foi avaliado, assim como outras informações a respeito das análises serão discutidos no próximo capítulo. 


\section{$5 \quad$ Metodologia}

O principal intuito deste projeto é avaliar a variabilidade da frequência cardíaca através de uma nova abordagem, utilizando o conceito da entropia não extensiva de Tsallis. A proposta consiste em aplicar este conceito não extensivo em dois modelos de análise: a entropia e a transformada de Fourier. Foi dada maior ênfase nas análises dos métodos baseados na entropia, e por isso seus resultados serão o foco da discussão.

Para as avaliações foram utilizados dados reais de variabilidade cardíaca e alguns tipos de sinais artificiais. As características dos sinais e os detalhes dos métodos avaliados serão descritos a seguir.

\subsection{Dados Utilizados}

As séries de variabilidade da frequência cardíaca (séries RR) utilizadas neste projeto foram todas obtidas junto Laboratório de Fisiologia do Exercício, Divisão de Cardiologia da Faculdade de Medicina de Ribeirão Preto, através do Prof. Dr. Lourenço Gallo Júnior e do técnico de Laboratório Júlio César Crescêncio. Juntamente com as séries RR, algumas informações antropométricas dos paciente também foram obtidas, como idade e peso. No total, foram obtidos dados de 57 indivíduos, sendo 15 indivíduos saudáveis, 23 indivíduos chagásicos e 19 indivíduos hipertensos. As séries RR de cada um foram obtidas tanto em condições de repouso como em testes de manobra postural passiva (tilt). As tabelas 5.1, 5.2 e 5.3 mostram os dados de cada grupo analisado.

A coleta de dados no Laboratório de Fisiologia do Exercício da FMRP segue um controle de qualidade rigoroso, pois sabe-se que variações nas condições, como por exemplo a temperatura ambiente da sala de coleta e nível de stresse do paciente, podem causar inconsistência ao avaliar dados de vários pacientes. Por isso, todos os dados utilizados neste trabalho foram coletados buscando manter as condições iguais para cada paciente. O protocolo de obtenção utilizado nas coletas é ilustrado na Figura 5.1. 


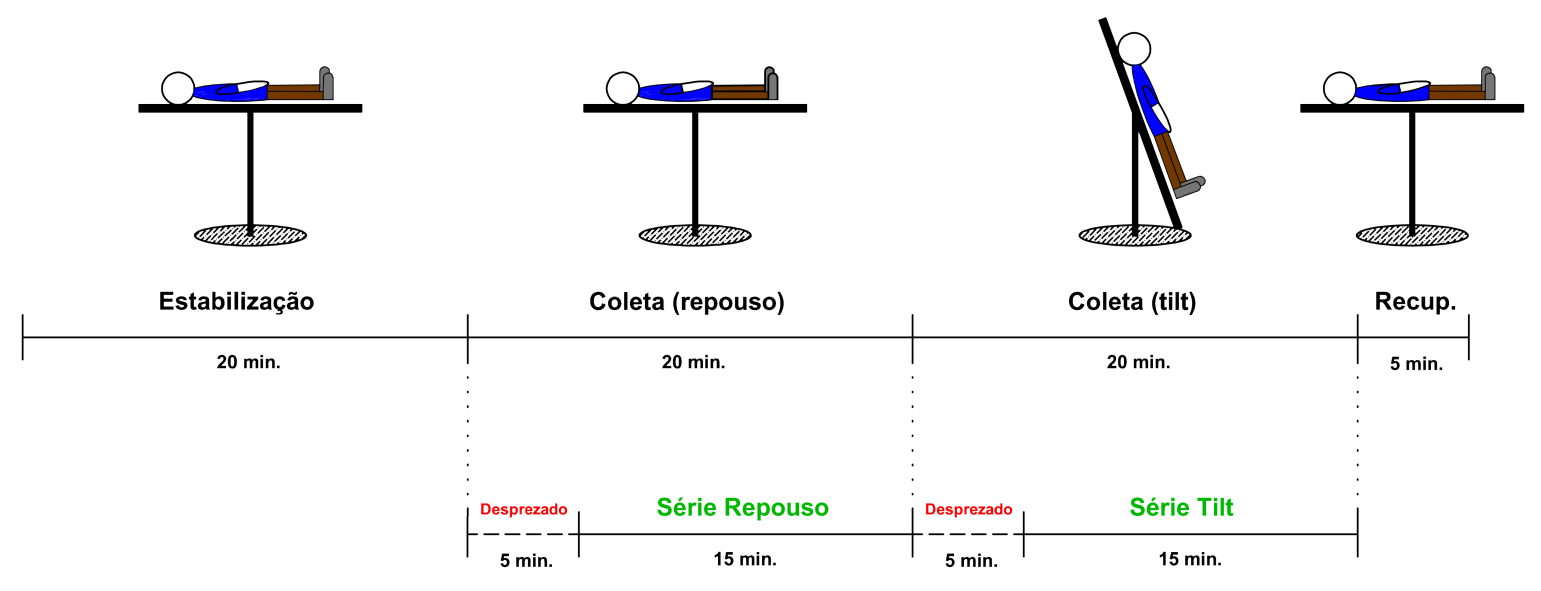

Figura 5.1: Protocolo de obtenção de dados no Laboratório de Fisiologia do Exercício da FMRP. Inicialmente, o paciente permanece deitado por 20 minutos, sem que haja coleta de dados. Em seguidas são coletados 40 minutos, sendo os 20 primeiros em repouso na posição horizontal e os 20 últimos em posição vertical $\left(70^{\circ}\right)$, após uma manobra postural passiva (tilt). Ao final, o paciente é levado novamente para a posição horizontal por mais 5 minutos, quando então o protocolo é finalizado. Nas análises são descartados os 5 primeiros minutos de cada fase de coleta para remoção de transientes e artefatos.

Tabela 5.1: Informações do grupo de pacientes saudáveis.

\begin{tabular}{lccrr}
\hline Voluntário & $\begin{array}{r}\text { Idade } \\
\text { (anos) }\end{array}$ & $\begin{array}{r}\text { Peso } \\
(\mathbf{K g})\end{array}$ & $\begin{array}{r}\text { Num. Pontos da Série RR } \\
\text { Repouso }\end{array}$ & Tilt \\
\hline AER & 55 & 78,9 & 818 & 1.091 \\
CMF & 52 & 74,4 & 1.162 & 1.401 \\
\hline CSS & 26 & 84,0 & 1.040 & 1.412 \\
DF & 30 & 57,0 & 837 & 975 \\
\hline JAA & 26 & 66,3 & 946 & 1.089 \\
\hline JAM & 47 & 88,6 & 1.229 & 1.457 \\
\hline JBAD & 41 & 100,6 & 908 & 1.126 \\
JCC & 32 & 80,4 & 1.075 & 1.481 \\
\hline JJM & 49 & 75,0 & 752 & 821 \\
JLS & 28 & 81,0 & 879 & 730 \\
\hline JoLS & 32 & 90,0 & 1.002 & 1.407 \\
LCSC & 42 & 60,0 & 1.139 & 1.359 \\
MF & 35 & 80,0 & 901 & 1.261 \\
\hline MJS & 56 & 76,0 & 994 & 1.153 \\
\hline SAG & 37 & 91,0 & 884 & 1.237 \\
Média & $\mathbf{3 9}$ & $\mathbf{7 8 , 9}$ & $\mathbf{9 7 1}$ & $\mathbf{1 . 2 0 0}$ \\
\hline
\end{tabular}

Como mostra a Figura 5.1, o paciente fica inicialmente em respouso na posição supina por um período de 20 minutos, necessário para sua adaptação ao ambiente e estabilização de 
Tabela 5.2: Informações do grupo de pacientes chagásicos.

\begin{tabular}{lccrr}
\hline Voluntário & $\begin{array}{r}\text { Idade } \\
\text { (anos) }\end{array}$ & $\begin{array}{r}\text { Peso } \\
(\text { Kg) }\end{array}$ & $\begin{array}{r}\text { Num. Pontos da Série RR } \\
\text { Repouso }\end{array}$ & Tilt \\
\hline AAP & 22 & 67,0 & 899 & 1.022 \\
ACM & 25 & 75,7 & 831 & 1.188 \\
AFB & 35 & 63,3 & 905 & 1.155 \\
AVMR & 34 & 63,2 & 816 & 1.026 \\
CRPS & 33 & 62,8 & 851 & 1.146 \\
DJRS & 40 & 62,0 & 1.208 & 1.315 \\
EGP & 49 & 60,0 & 817 & 901 \\
FGS & 51 & 65,0 & 1.032 & 1.162 \\
GGF & 26 & 63,4 & 967 & 1.245 \\
GLC & 27 & 62,6 & 767 & 1.027 \\
JAAP & 23 & 64,0 & 1.601 & 2.158 \\
JBP & 30 & 77,0 & 757 & 965 \\
JCG & 38 & 80,9 & 880 & 971 \\
JMSS & 33 & 70,5 & 718 & 944 \\
JRS & 37 & 61,8 & 931 & 1.062 \\
LUC & 50 & 72,0 & 898 & 1.219 \\
MBS & 51 & 75,7 & 1.051 & 1.297 \\
MPT & 48 & 79,9 & 1.032 & 1.236 \\
NBJ & 36 & 79,0 & 961 & 1.178 \\
NCS & 31 & 54,2 & 1.223 & 1.305 \\
OLS & 24 & 68,0 & 961 & 1.340 \\
PFC & 31 & 73,0 & 828 & 1.043 \\
VMD & 34 & $\mathbf{6 7 , 8}$ & 664 & 780 \\
Média & & & $\mathbf{9 3 9}$ & $\mathbf{1 . 1 6 0}$ \\
\hline & & & \\
\hline
\end{tabular}

sua atividade fisiológica; em seguida, inicia-se a coleta dos dados. Nos primeiros 20 minutos o paciente permanece na posição horizontal, sendo que os 5 minutos iniciais dessa fase são desprezados para garantir a eliminação de qualquer tipo de artefato. Após isso, a mesa em que o paciente se encontra deitado é girada passivamente em 70 graus, deixando o paciente na posição vertical por mais 20 minutos. Também neste caso são eliminados os primeiros 5 minutos após a mesa ser girada para remoção do transiente que surge com a manobra postural. Após os 20 minutos na posição vertical, o paciente é levado novamente para posição horizontal, e a coleta é finalizada. O paciente ainda permanece na posição horizontal por mais 5 minutos para recuperação. Com isso, todas as séries RR obtidas (tanto de repouso como de tilt) são de aproximadamente 15 minutos. 
Tabela 5.3: Informações do grupo de pacientes hipertensos.

\begin{tabular}{lccrr}
\hline Voluntário & $\begin{array}{c}\text { Idade } \\
\text { (anos) }\end{array}$ & $\begin{array}{r}\text { Peso } \\
(\mathbf{K g})\end{array}$ & $\begin{array}{r}\text { Num. Pontos da Série RR } \\
\text { Repouso }\end{array}$ & Tilt \\
\hline AAF & 38 & 103,0 & 1.361 & 1.423 \\
\hline AB & 47 & 85,0 & 1.274 & 1.533 \\
\hline ADS & 42 & 91,5 & 922 & 1.171 \\
\hline AFMC & 34 & 109,9 & 1.037 & 926 \\
\hline AFP & 43 & 103,8 & 1.030 & 1.379 \\
\hline AJB & 30 & 121,8 & 837 & 1.488 \\
AJS & 37 & 86,0 & 1.247 & 1.545 \\
ASC & 46 & 80,8 & 875 & 1.053 \\
CDS & 49 & 82,8 & 958 & 1.149 \\
CLG & 43 & 84,7 & 985 & 869 \\
FCD & 51 & 70,5 & 920 & 1.275 \\
\hline JLV & 55 & 78,0 & 747 & 827 \\
JRCA & 52 & 88,2 & 997 & 1.292 \\
\hline JRN & 50 & 80,0 & 1.276 & 1.429 \\
\hline LCB & 44 & 80,0 & 1.249 & 1.400 \\
\hline MMO & 36 & 81,7 & 1.214 & 1.610 \\
\hline RFL & 47 & 82,7 & 878 & 1.093 \\
\hline SIP & 35 & 131,0 & 1.196 & 1.544 \\
\hline VT & 30 & 85,6 & 1.059 & 1.261 \\
Média & $\mathbf{4 3}$ & $\mathbf{9 0 , 9}$ & $\mathbf{1 . 0 5 6}$ & $\mathbf{1 . 2 7 7}$ \\
\hline & & & & \\
\hline
\end{tabular}

Além das séries RR, foram utilizados também alguns sinais simulados com propriedades estatísticas bem conhecidas, como uma alternativa para melhor compreender os resultados das novas técnicas de análise propostas. Foram escolhidos 4 tipos de sinais simulados:

- Ruído Branco: Uma série de valores aleatórios entre 0 e 1, com distribuição uniforme.

- Ruído 1/f: Este é um ruído que está presente em várias áreas da natureza. Consiste de uma série cujo espectro de potências é a função $1 / f$.

- Mapa Logístico [33]: Este é uma mapa bastante conhecido, citado no capítulo 3, cuja equação de evolução é dada por:

$$
x_{n+1}=r x_{n}\left(1-x_{n}\right)
$$

(Cópia de 3.4)

Dependendo dos valores do parâmetro $r$, este mapa pode apresentar comportamento caótico ou regular, e ter esse conhecimento prévio facilita a validação dos métodos propostos. 
- Mapa de Hénon [34]: Outro mapa bastante conhecido, que evolui com as duas equações abaixo:

$$
\begin{aligned}
& x_{n+1}=y_{n}+1-a x_{n}^{2} \\
& y_{n+1}=b x_{n}
\end{aligned}
$$

Assim como o mapa logístico, este mapa também apresenta comportamento caótico em algumas combinações dos parâmetros $a$ e $b$.

Para este projeto foi implementado computacionalmente um gerador de sinais, capaz de gerar os quatro tipos de sinais simulados citados.

\subsection{Ferramentas Computacionais Utilizadas}

As ferramentas computacionais propostas consistem da generalização dos três métodos de entropia para séries temporais citados no capítulo anterior (Entropia Aproximada, Entropia Amostral e Entropia Multiescala) e da transformada de Fourier. Nos métodos baseados na entropia, o que se fez foi substituir a função logarítmo clássica pela sua forma generalizada, apresentada na equação (4.30). Apesar de ser a formulação da entropia amostral, esta equação também pode ser utilizada para o cálculo da entropia aproximada, que é obtida considerando-se a própria ocorrência de um padrão na contagem de $U^{m}$ e $U^{m+1}$.

A equação (4.20) define a entropia como o negativo do logarítmo da taxa de correlação da série para padrões de tamanho $m+1$ e $m$, respectivamente. Porém, pelas propriedades da função logarítmica, a mesma equação pode ser escrita de duas outras maneiras: o positivo do inverso desta taxa ou a diferença de logarítmos, conforme mostra a equação a seguir:

$$
\begin{aligned}
E n^{\prime}(m, r, N) & =\ln \frac{U^{m}(r)}{U^{m+1}(r)} \\
E n^{\prime \prime}(m, r, N) & =\ln U^{m}(r)-\ln U^{m+1}(r)
\end{aligned}
$$

A generalização da entropia foi implementada utilizando as duas formulações acima e a formulação original da equação (4.20), substituindo as formas clássicas do logarítmo pela generalizada, como mostrado nas equações abaixo. 


$$
\begin{aligned}
& E n_{q}(m, r, N)=-\ln _{q} \frac{U^{m+1}(r)}{U^{m}(r)} \\
& E n_{q}^{\prime}(m, r, N)=\ln _{q} \frac{U^{m}(r)}{U^{m+1}(r)} \\
& E n_{q}^{\prime \prime}(m, r, N)=\ln _{q} U^{m}(r)-\ln _{q} U^{m+1}(r)
\end{aligned}
$$

Contudo, a única diferença observada entre as formulações (5.5) e (5.6) é que os resultados de uma são refletidos pela reta $q=1$ na outra, ou seja, $E n_{q}(m, r, N)=E n_{2-q}^{\prime}(m, r, N)$. Devido a isso, os resultados mostram as análises apenas das formas (5.5) e (5.7) destas generalizações. A formulação que considera a diferença de logarítmos tem as mesmas características de crescimento da formulação (5.5), o que influenciou na opção pela formulação (5.5) ao invés da (5.6), além também de ser a formulação mais próxima das equações originais da entropia.

No caso da transformada de Fourier, a equação generalizada segundo o paradigma de Tsallis já foi sugerida $[35,36]$ e a proposta aqui é implementá-la e aplicá-la na análise da variabilidade cardíaca. Segundo os autores, para $1 \leq q<3$ e $f[k]>0, k \in \mathbf{Z}=\{0, \pm 1, \pm 2, \ldots\}$, sendo $f[k]$ uma função discreta, a equação da $q$-Transformada de Fourier pode ser representada por:

$$
\begin{aligned}
F_{q}[f](\xi) & =\sum_{k=-\infty}^{\infty} e_{q}^{i k \xi} \otimes_{q} f[k] \\
& =\sum_{k=-\infty}^{\infty} f[k] e_{q}^{i k \xi f[x]^{q-1}}
\end{aligned}
$$

A transformada de Fourier clássica pode ser representada pela equação:

$$
F[f](\xi)=\sum_{k=-\infty}^{\infty} e^{i k \xi} f(k)
$$

Observando a equação (5.8) é possível notar que as diferenças entre as formulações clássica e generalizada são, basicamente, a substituição da funções exponencial e produto, pelas suas formas generalizadas. A forma generalizada da função exponencial foi dada na equação (4.31), e sua forma complexa pode ser representada pela generalização das funções seno e cosseno. A forma generalizada do produto é mostrada logo abaixo, na equação (5.11). Todas essas generalizações citadas (funções logarítmo, exponencial, seno, cosseno e da álgebra comum) foram propostas por Ernesto Borges [32, 37]. 


$$
x \otimes_{q} y=\left[x^{1-q}+y^{1-q}-1\right]_{+}^{1 /(1-q)} \quad(x, y>0)
$$

Contudo, a equação (5.8) é difícil de se utilizar na prática devido à limitação da função produto generalizada $(x, y>0)$, e por isso, a implementação computacional da transformada de Fourier generalizada é feita utilizando a equação (5.9), uma forma alternativa que equivale à equação (5.8).

A representação da transformada inversa para a $q$-Fourier ainda não está definida. Contudo, esforços já estão sendo feitos em busca de se encontrar essa definição [38].

Com a generalização das entropias e da transformada de Fourier, esses métodos passam a ter, além dos parâmetros usuais, o parâmetro $q$ de não extensividade. Com isso, cada método necessita ser avaliado em relação a este parâmetro e comparado com os resultados de suas formulações clássicas, que equivale ao caso $q=1$. No caso da Entropia Aproximada e da Entropia Amostral, seus resultados clássicos consistem de um único valor numérico, representando uma estimativa da complexidade da série RR. Na formulação generalizada, esses modelos passam a ter como resultado uma série de valores de complexidade em função do parâmetro $q$. No caso da Entropia Multiescala e da Transformada de Fourier, seus resultados clássicos já consistem de uma série de valores, indicando a entropia nas várias escalas do sinal e as potências de cada componente de frequência, respectivamente. Com a generalização, esses métodos passam a ter como resultado um conjunto de séries para cada valor de $q$ (formando uma superfície).

Além dos resultados para cada método, um outro procedimento proposto para avaliar a influência do parâmetro $q$ na entropia consiste da utilização de séries substitutas (surrogate data) $[39,40]$. Nesta abordagem, séries substitutas são originadas a partir das séries originais, de maneira que estas séries substitutas conservam algumas propriedades da série original, tais como a distribuição (surrogate tipo 1), espectro de potências (surrogate tipo 2), ou as duas características anteriores (surrogate tipo 3), mas perdem características de não linearidade que possam estar presentes na série original. Utilizando uma das formulações de entropia, que funcionará como discriminante estatístico, a idéia é verificar a diferença entre a entropia da série original e a entropia média das séries substitutas, fazendo isso para vários valores diferentes de $q$. O resultado desta metodologia é uma série contendo os valores dessa diferença em função do parâmetro $q$.

Para a geração de séries substitutas do tipo 1, basta embaralhar os valores da série original. Isso mantém sua distribuição mas destrói as correlações temporais que poderiam existir na série original. Chamaremos estas séries de Time-Surrogates, pois consistem de alterações 
dos parâmetros no domínio do tempo das séries originais. No caso das séries substitutas tipo 2, o que se faz é aplicar a transformada de Fourier clássica no sinal original, embaralhar as componentes de fase do espectro, e em seguida aplicar a transformada inversa de Fourier. Isso causa uma mudança nos valores da série no tempo, e consequentemente na sua distribuição, mas mantém a potência de cada componente de frequência do sinal. Chamaremos estas séries de Phase-Surrogates, pois consistem de uma mudança nos parâmetros de fase no espectro do sinal original. O terceiro tipo de série substituta consite em manter tanto a distribuição como a potência da série original. Para gerar este tipo de surrogate, os passos a seguir são citados abaixo [40]. Consideremos uma série temporal $s_{n}$, que será utilizada como base para gerar uma surrogate do tipo 3.

1. Armazenar o espetro potências $\left(P_{s}\right)$ de $s_{n}$.

2. Gerar uma cópia de $s_{n}$, com seus valores embaralhados aleatoriamente $\left(s_{a}\right)$.

3. Aplicar a transformada de Fourier em $s_{a}$, substituir seu espectro de potências por $P_{s}$ e aplicar a transformada inversa $\left(\bar{s}_{a}\right)$.

4. Ordenar os valores em $\bar{s}_{a}$ de maneira que o maior valor dessa série esteja na mesma posição que o maior valor em $s_{n}$, e assim por diante.

5. Repetir os passos 3 e 4 até ocorrer convergência. Essa convergência é atingida quando o passo 4 não altera a série de uma iteração para outra.

Esta abordagem de geração de surrogates do tipo 3 não proporciona uma série com espectro totalmente igual ao da série original, mas tenta aproximá-lo ao máximo, mantendo a distribuição idêntica à da série original. Chamaremos estas séries de Mixed-Surrogates, pois trata-se de uma combinação mista das surrogates do tipo 1 e 2.

$\mathrm{Na}$ análises utilizando esta abordagem com séries substitutas, o discriminante estatístico a ser utilizado precisa ser uma métrica que produza como resultado um único valor númerico que caracterize as séries de acordo com o que se deseja identificar. Por isso, a Entropia Amostral foi escolhida, visto que é uma melhoria da Entropia Aproximada e uma métrica que busca identificar a complexidade de uma série temporal. Desse modo, esta abordagem permite avaliar como o parâmetro $q$ modifica a Entropia Amostral na detecção dessa complexidade, diferenciando séries que realmente apresentam complexidade de suas surrogates.

Além destas abordagens propostas, todos os modelos citados no capítulo 2 (com excessão do SDA que é recomendado apenas para séries longas) foram também implementados com- 
putacionalmente para comparação de resultados. O modelo autorregressivo foi implementado utilizando o método de Burg [41].

Todos os métodos implementados neste projeto foram feitos na linguagem Java e foram agrupados em um sistema computacional, também criado neste projeto, que fornece uma interface de fácil utilização das ferramentas e seleção dos sinais a serem avaliados. No capítulo seguinte este sistema será brevemente descrito, juntamente com os resultados das análises. 


\section{$6 \quad$ Resultados}

\subsection{Transformada de Fourier Generalizada ( $q$-Fourier)}

A transformada de Fourier clássica consiste da representação de um sinal no domínio da frequência. Isso pode ser feito pelos espectros de magnitude e fase ou através das componentes reais e imaginárias de cada frequência. Neste projeto foram avaliados apenas os espectros de magnitude da transformada $q$-Fourier, para o intervalo $1 \leq q<3$, e comparados com os resultados da formulação clássica. A Figura 6.1 mostra os espectros de magnitude da transformada $q$-Fourier de alguns sinais reais e simulados. Todos os sinais simulados foram gerados com 1.000 pontos, tamanho este que mostrou, por alguns testes, não influenciar muito nos resultados.

Observando a Figura 6.1, a primeira característica a ser notada é que a $q$-Fourier não possui espectro simétrico, sendo isso uma propriedade bastante conhecida da transformada de Fourier clássica. Comparando os resultados com o resultado clássico $(q=1)$, nota-se que os espectros de magnitude apresentam valores absolutos próximos ao do espectro clássico, mas com comportamentos diferentes deste. De uma maneira geral, todos apresentam amortecimento com o aumento da frequência. Percebe-se também que ao aumentar o valor de $q$, o espectro aumenta sua variabilidade, apresentando curvas mais suaves para valores mais próximos de 1 .

Uma característica interessante aparece no espectro do mapa logístico regular (período 2), cujo espectro clássico ilustra um pico na frequência 0.5 , que representa a metade da frequência de amostragem. Os $q$-espectros $\operatorname{com} q=2.2$ e $q=2.6$ apresentaram picos semelhantes, sendo que no primeiro caso, um dos picos coincide com o presente no espectro clássico.

A Figura 6.2 ilustra o comportamento desta transformada para valores de $q$ bem próximos de 1, utilizando alguns dos sinais anteriormente avaliados.

A figura mostra que para valores muito próximos de 1 , as séries voltam a apresentar uma alta variabilidade, fato anteriormente observado com o aumento de $q$. Apesar de os valores de $q$ se aproximarem de 1 , o espectro só se aproxima do espectro clássico no limite $q=1$. 

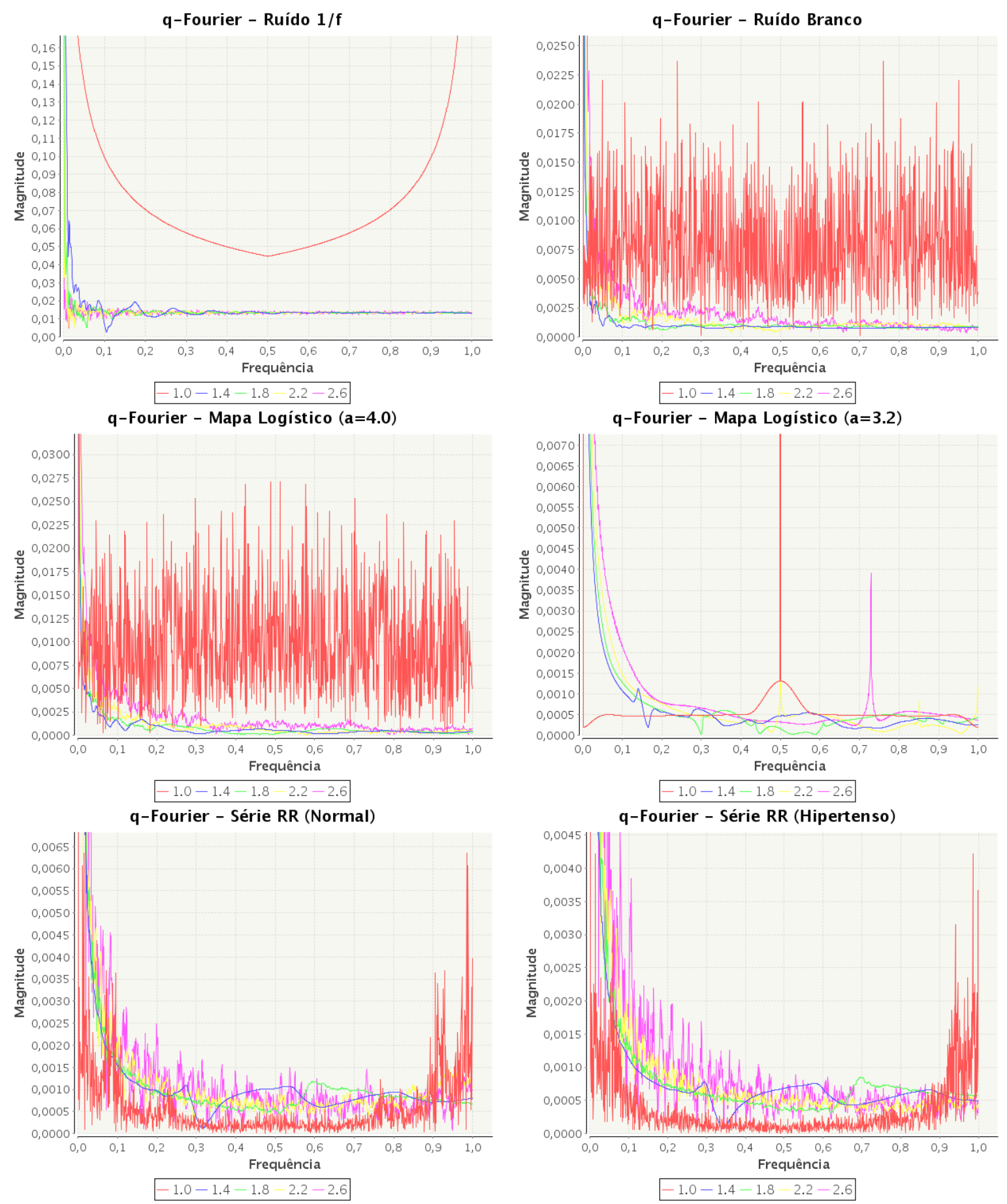

Figura 6.1: Transformada q-Fourier para alguns valores de $q$ entre 1 e 3. Acima os resultados para o ruído 1/f (esq) e ruído branco (dir); no meio para o mapa logístico caótico (esq) e periódico (dir); abaixo para uma série RR de indivíduo normal (esq) e hipertenso (dir). O parâmetro $a$ do mapa logístico é o parâmetro $r$ da equação (3.4).

Esses resultados ainda não permitem compreender o significado desta transformada generalizada, sendo preciso um estudo mais aprofundado, explorando mais detalhes. 

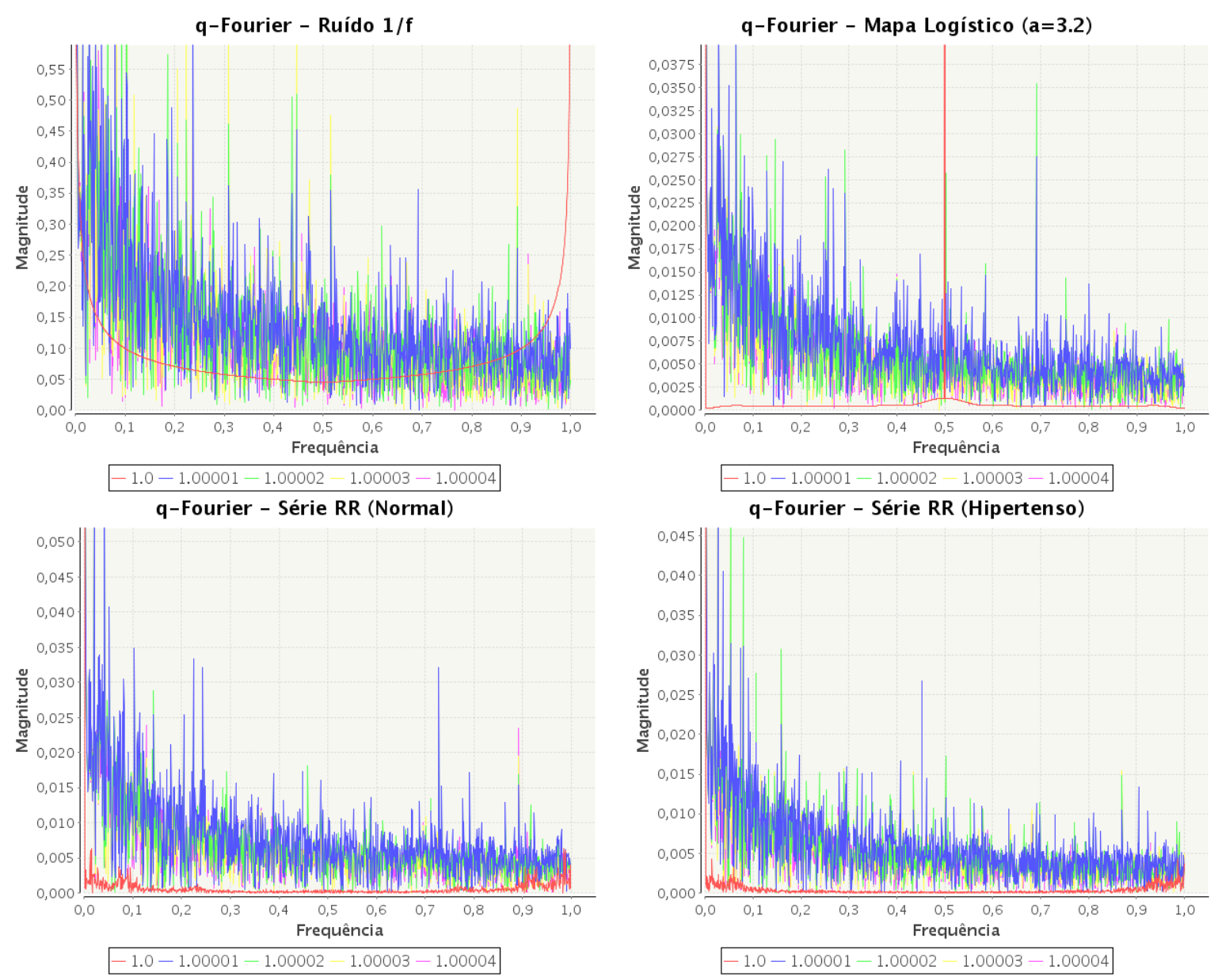

Figura 6.2: Transformada q-Fourier para alguns valores de $q$ próximos de 1. Acima os resultados para o ruído 1/f e mapa logístico periódico; abaixo para as mesmas séries RR utilizadas anteriormente. O parâmetro $a$ do mapa logístico é o parâmetro $r$ da equação (3.4).

\subsection{Entropias}

Em todos os resultados utilizando a entropia que serão apresentados a seguir, foram fixados os parâmetros $m=2$ e $r=15 \%$ do desvio padrão da série. Estes valores estão entre os mais usados e recomendados para o cálculo das entropias utilizadas visto que para valores pequenos de $m$ (ver Figura 4.3) já é possível obter boas aproximações da entropia KS, em séries temporais cujo número de graus de liberdade é pequeno.

\subsubsection{Entropia Aproximada e Amostral}

Primeiramente, foi utilizada a forma de generalização da equação (5.5), que considera a entropia como o negativo do logarítmo da taxa de correlação da série para padrões de tamanho $m+1$ e $m$, respectivamente. A Figura 6.3 mostra os resultados da entropia aproximada (AppEn) e entropia amostral (SampEn) em função do parâmetro $q$ para todos os sinais de variabilidade 
cardíaca, nas condições de repouso e manobra postural (tilt), no intervalo de $q$ entre -2 e 2 .
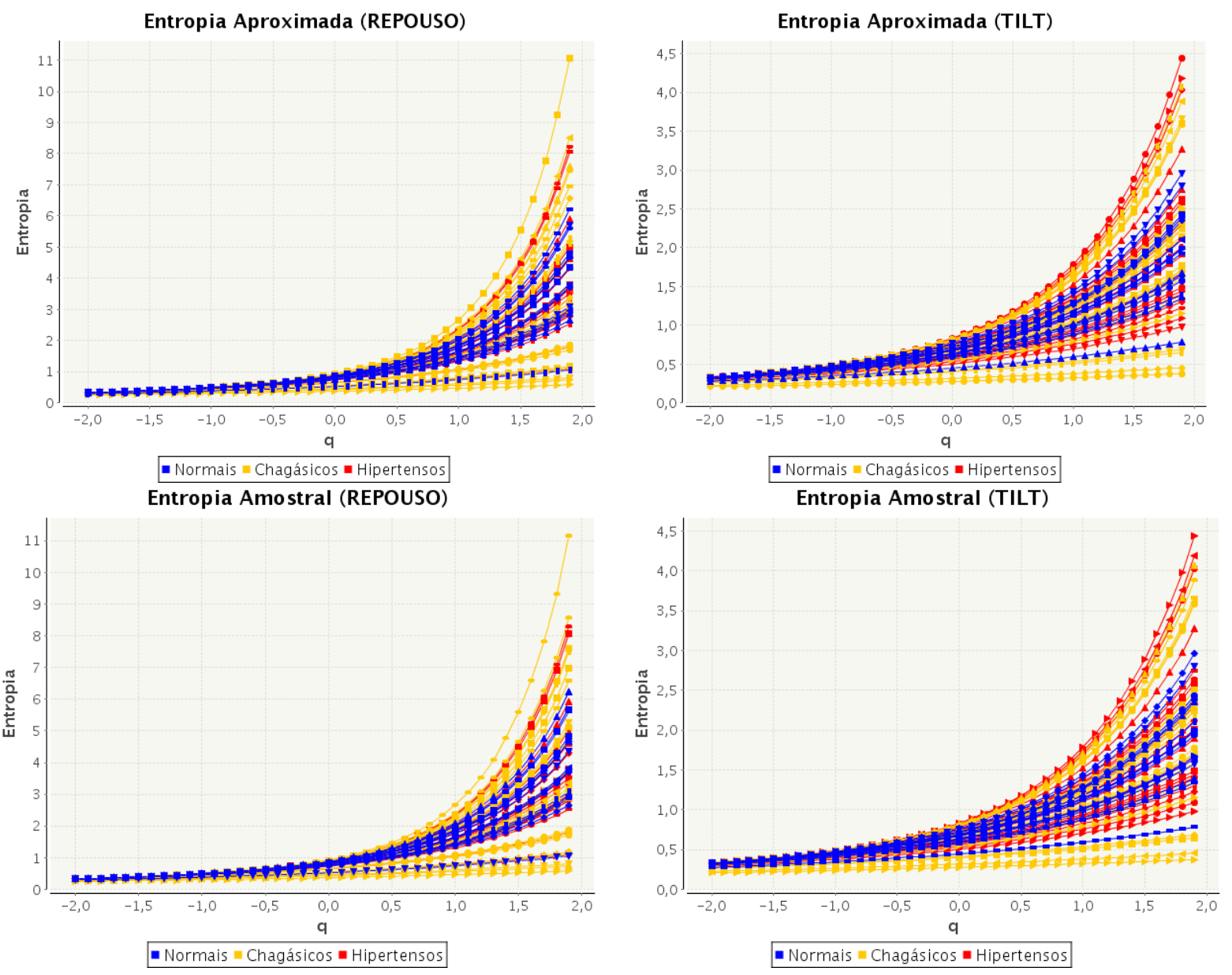

Figura 6.3: Entropia aproximada e amostral das séries de variabilidade cardíaca dos grupos normais, chagásicos e hipertensos. À esquerda os valores para as séries obtidas em repouso e à direita para as séries obtidas durante manobra postural passiva (tilt).

Pela figura é possível perceber que os resultados obtidos com a entropia aproximada e amostral são muito parecidos. Também percebe-se que os valores absolutos de entropia são bem distintos nas condições de repouso e tilt. Enquanto nos resultados com dados de repouso o maior valor de entropia obtido foi em torno de $11(q=2)$, nos resultados com dados de tilt o maior valor obtido foi em torno de $4.5(q=2)$. Sabe-se que a entropia aproximada apresenta um bias e pode não ser consistente ao analisar séries de tamanhos diferentes. A média do número de pontos de todas as séries de variabilidade é 989 para repouso e 1212 para tilt. Esta diferença no tamanho das séries de repouso e tilt poderia ser a explicação para a diferença de resultados, o que não é caso, já que os resultados para a entropia amostral são praticamente os mesmos. Isso leva a crer que estas diferenças estejam relacionadas às características intrínsecas das séries de variabilidade, cuja dinâmica de regimento é diferente nas condições de repouso e tilt.

Uma outra característica avaliada neste contexto é a ordem (classificação) de cada série, em 

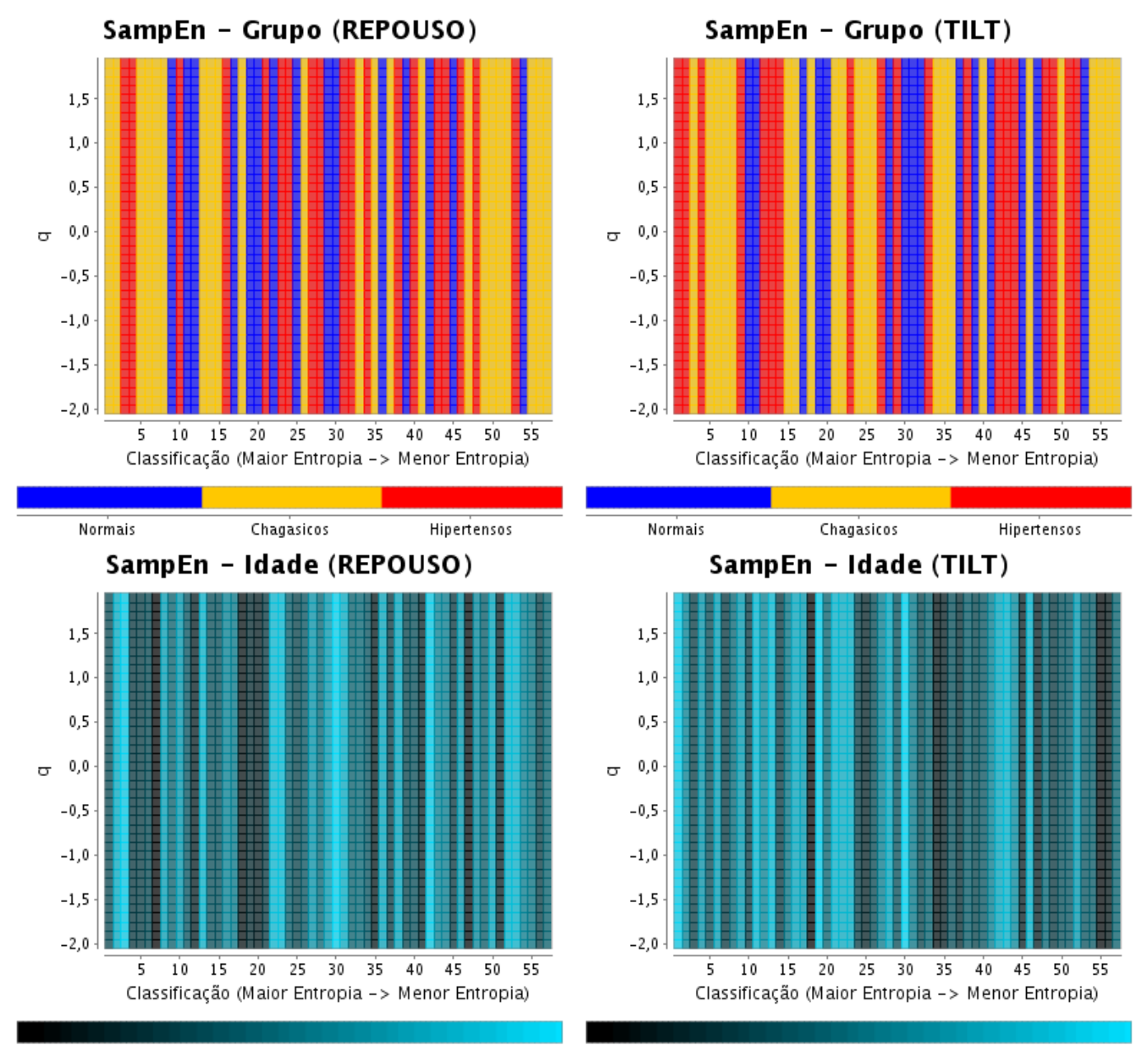

$\begin{array}{lllllllllllllllllllll}22 & 24 & 26 & 28 & 30 & 32 & 34 & 36 & 38 & 40 & 42 & 44 & 46 & 48 & 50 & 52 & 54 & 56\end{array}$

SampEn - Peso (REPOUSO)
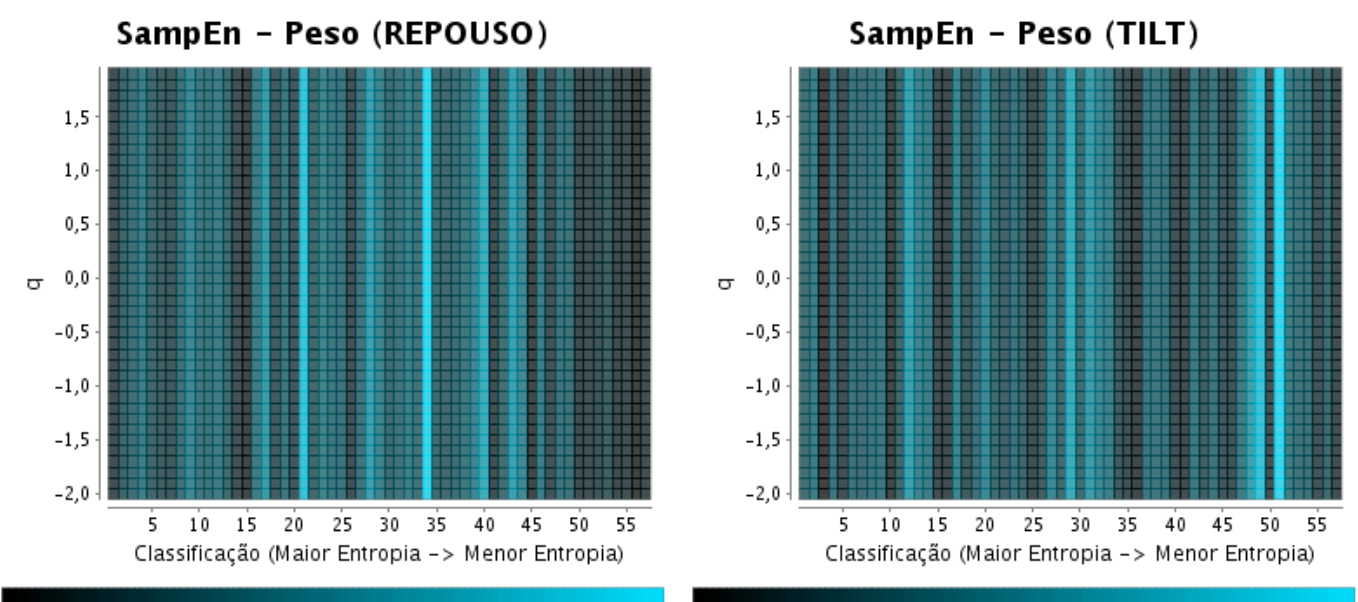

545760636669727578818487909396991031071111151191231271315457606366697275788184879093969910310711111511912312713

Figura 6.4: Diagrama de blocos indicando a ordem (classificação) de cada série RR de acordo com o valor da entropia amostral, para as siutações de repouso e tilt. Em cor são destacadas a idade, peso e grupo de cada paciente. Resultados para a entropia aproximadas são os mesmos, alternando apenas a classificação das séries 26 e 27 na condição de repouso.

função de $q$, considerando seu valor de entropia. Esta classificação de cada série, em termos do maior para o menor valor da entropia, é sempre a mesma ao longo do eixo $q$. Isto é ilustrado na 
Figura 6.4, que mostra esta classificação destacando o peso, a idade e o grupo de cada voluntário. A figura apresenta esta classificação utilizando a entropia amostral. Contudo, os resultados para a entropia aproximada são praticamente os mesmos, apenas alternando a classificação das séries 26 e 27 na condição de repouso. Estes diagramas mostram que, além dessa classificação não variar com o parâmetro $q$, não há uma boa separação entre os indíviduos por nenhum dos parâmetros avaliados (grupo, peso e idade).
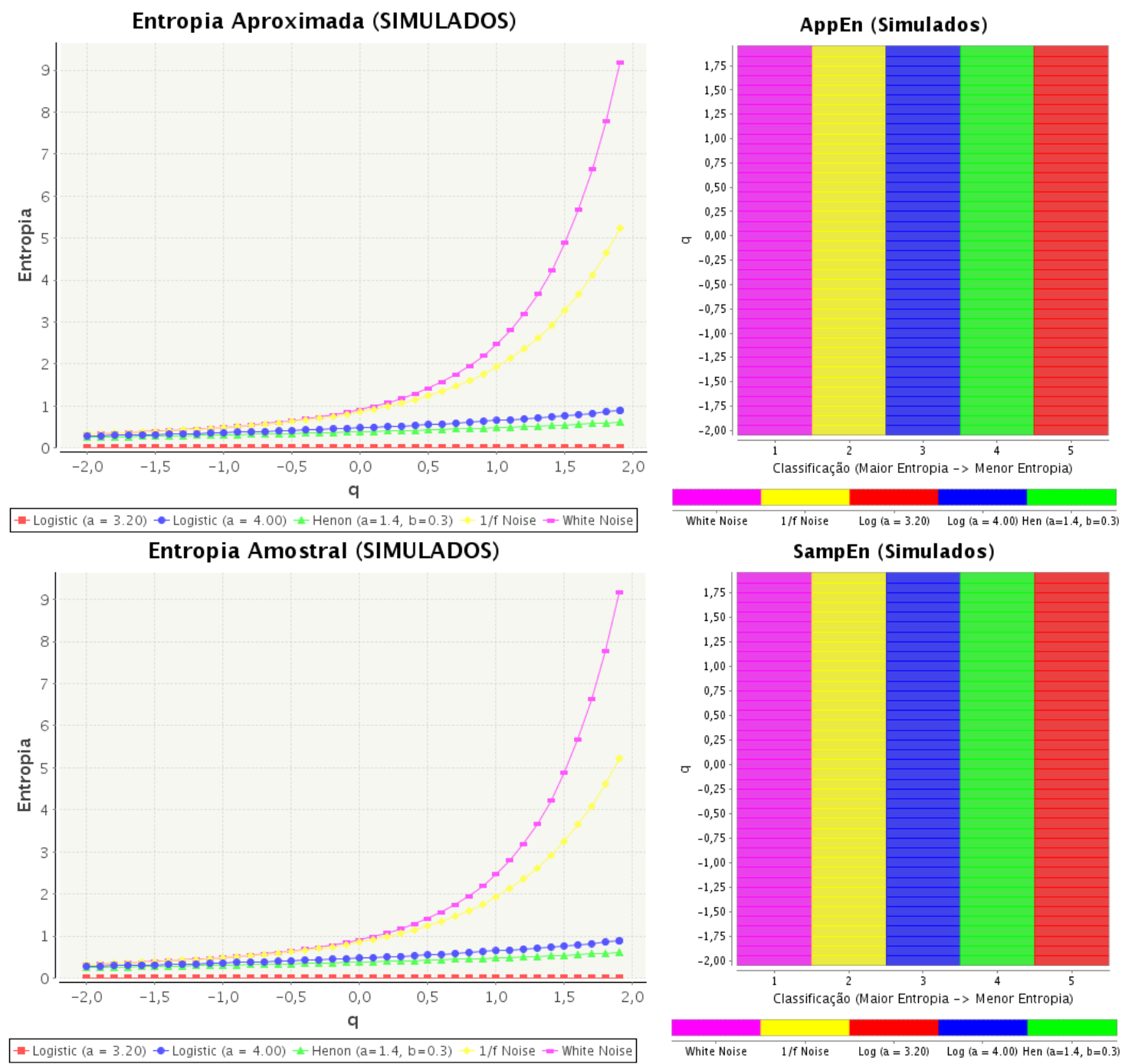

Figura 6.5: Resultado das entropias aproximada e amostral para os sinais simulados. À esquerda as séries de entropia em função de $q$, e à direita o diagrama de blocos com a classificação de cada série de acordo com o maior valor de entropia. O parâmetro $a$ do mapa logístico é o parâmetro $r$ da equação (3.4).

A Figura 6.5 mostra os mesmos resultados das duas entropias para 5 sinais simulados diferentes: ruído branco (White Noise), ruído 1/f (1/f Noise), mapa logístico em situação periódica $(\log (a=3.20))$, mapa logístico em situação caótica $(\log (a=4.00))$ e mapa de Hénon em situação caótica $(\operatorname{Hen}(a=1.4, b=0.3))$, todos gerados com tamanho de 16.384 pontos. O parâmetro $a$ do mapa logístico é o parâmetro $r$ da equação (3.4) deste mapa. Os resultados com 
estes sinais simulados mostram, assim como nos resultados utilizando séries de variabilidade cardíaca, que praticamente não há diferença entre os resultados com a entropia aproximada e amostral. Além disso, o diagrama de blocos com a classificação dos sinais, segundo o valor absoluto de entropia, também é constante em relação a $q$.

Todos os resultados utilizando esta forma de generalização da entropia estão totalmente relacionados à equação que rege a função q-logarítmo. Na equação (5.5), a taxa de correlação de uma série é sempre a mesma, independentemente do parâmetro $q$. Assim, o crescimento de cada série está ligado à sua taxa de correlação, que é o que de fato varia em cada uma.

A seguir são apresentados os resultados utilizando a forma generalizada da equação (5.7), que considera a entropia como a diferença dos logarítmos da correlação da série para padrões de tamanho $m$ e $m+1$, respectivamente. A Figura 6.6 mostra as séries de entropia aproximada e amostral para os sinais de variabilidade cardíaca.
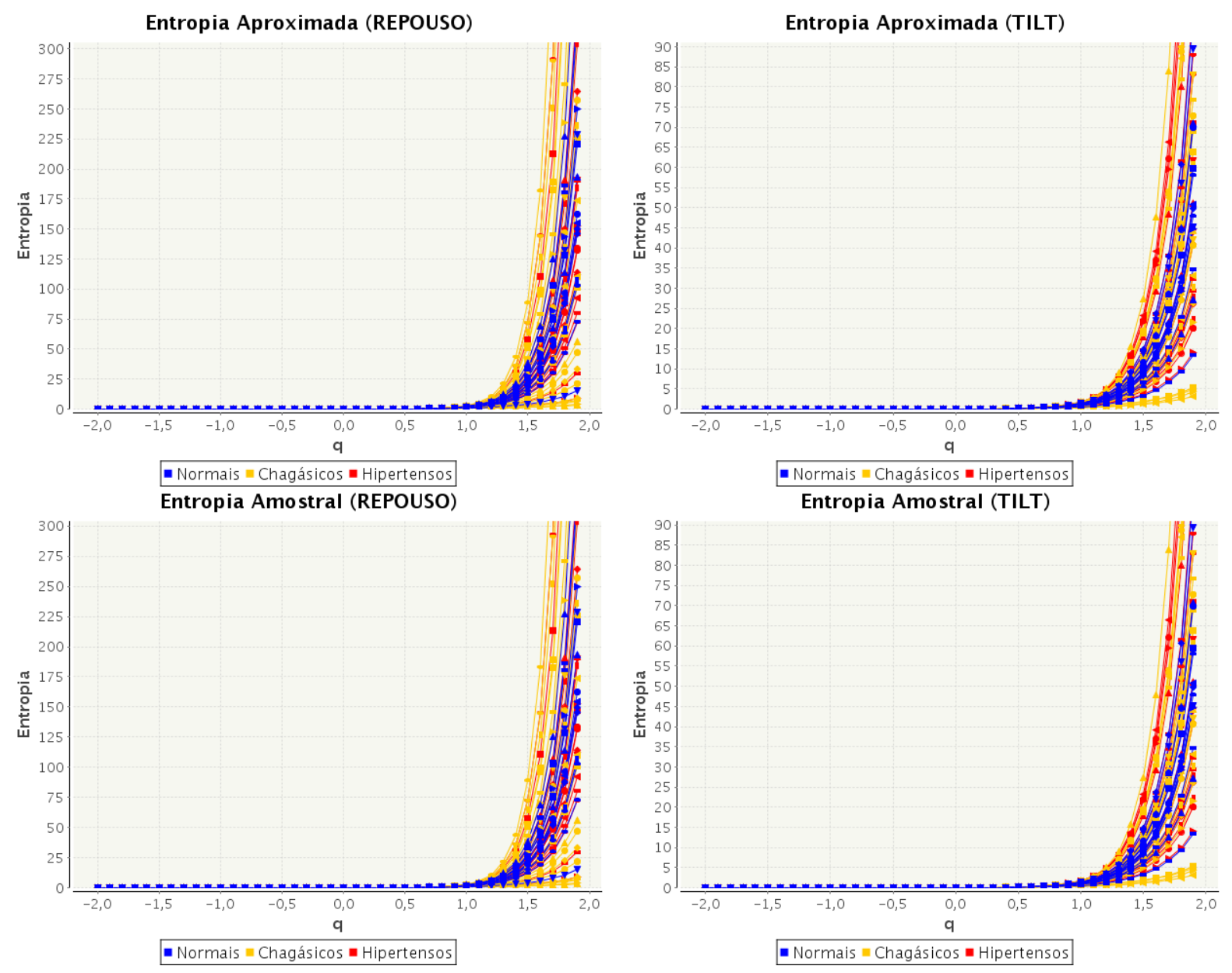

Figura 6.6: Entropia aproximada e amostral das séries de variabilidade cardíaca. À esquerda os valores para as séries obtidas em repouso e à direita para as séries obtidas durante tilt. $\mathrm{O}$ eixo vertical foi ampliado para melhor visualização do formato das séries resultantes. O valor máximo de entropia obtido foi em torno de 1620 para repouso e 260 para tilt $(q=2)$. 

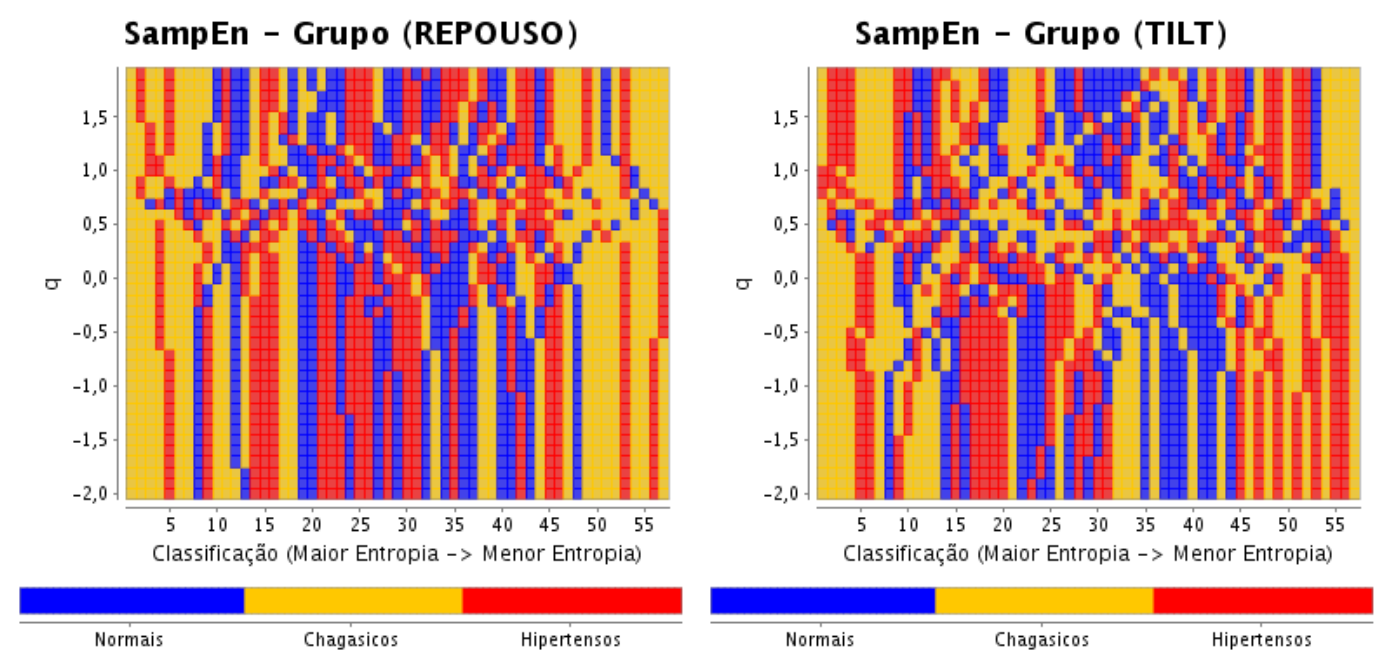

SampEn - Idade (REPOUSO)
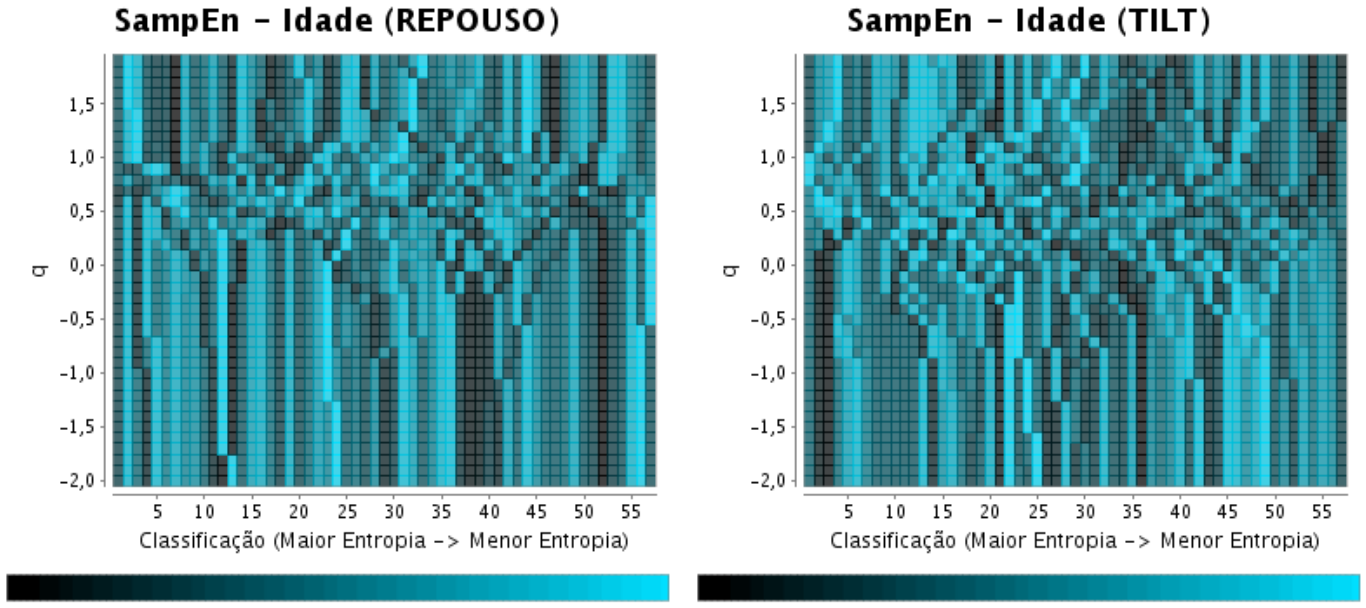

$\begin{array}{lllllllllllllllllllll}22 & 24 & 26 & 28 & 30 & 32 & 34 & 36 & 38 & 40 & 42 & 44 & 46 & 48 & 50 & 52 & 54 & 56\end{array}$

SampEn - Peso (REPOUSO)
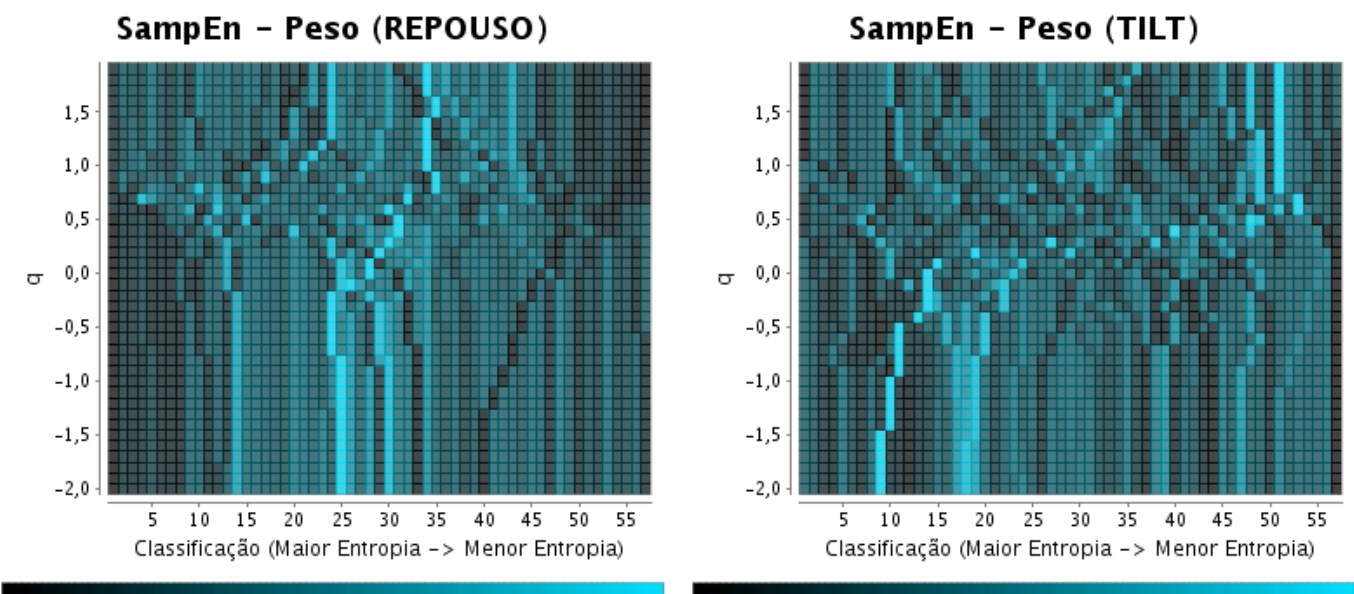

545760636669727578818487909396991031071111151191231271315457606366697275788184879093969910310711111511912312713

Figura 6.7: Diagrama de blocos indicando a ordem (classificação) de cada série RR de acordo com o valor da entropia amostral, para as siutações de repouso e tilt. Em cor são destacadas a idade, peso e grupo de cada paciente. Os resultados para a entropia aproximada são bem próximos destes apresentados, variando algumas poucas posições para alguns valores de $q$.

Novamente os resultados obtidos para a entropia aproximada e amostral são muito próximos. Também se observa que as séries de repouso possuem maior valor de entropia do que 
as séries de tilt. Contudo, esta abordagem de generalização produz resultados diferentes dos obtidos com a abordagem anterior. Neste caso, além dos valores absolutos serem diferentes, o crescimento de cada série de entropia é distinto, sendo que elas se cruzam ao longo do eixo $q$, o que pode ser observado pelo diagrama de blocos com a ordem (classificação) das séries na Figura 6.7. Este diagrama mostra que a classificação das séries varia com o valor de $q$ e que essas variações são mais intensas no intervalo de 0 a 1 (extendendo um pouco mais no caso das séries de tilt). Apesar de não se ter uma boa separação das séries por nenuhm dos parâmetros visualizados (peso, idade e grupo), os resultados indicam que esta região de valores de $q$ parece ser de alta sensibilidade para entropia.
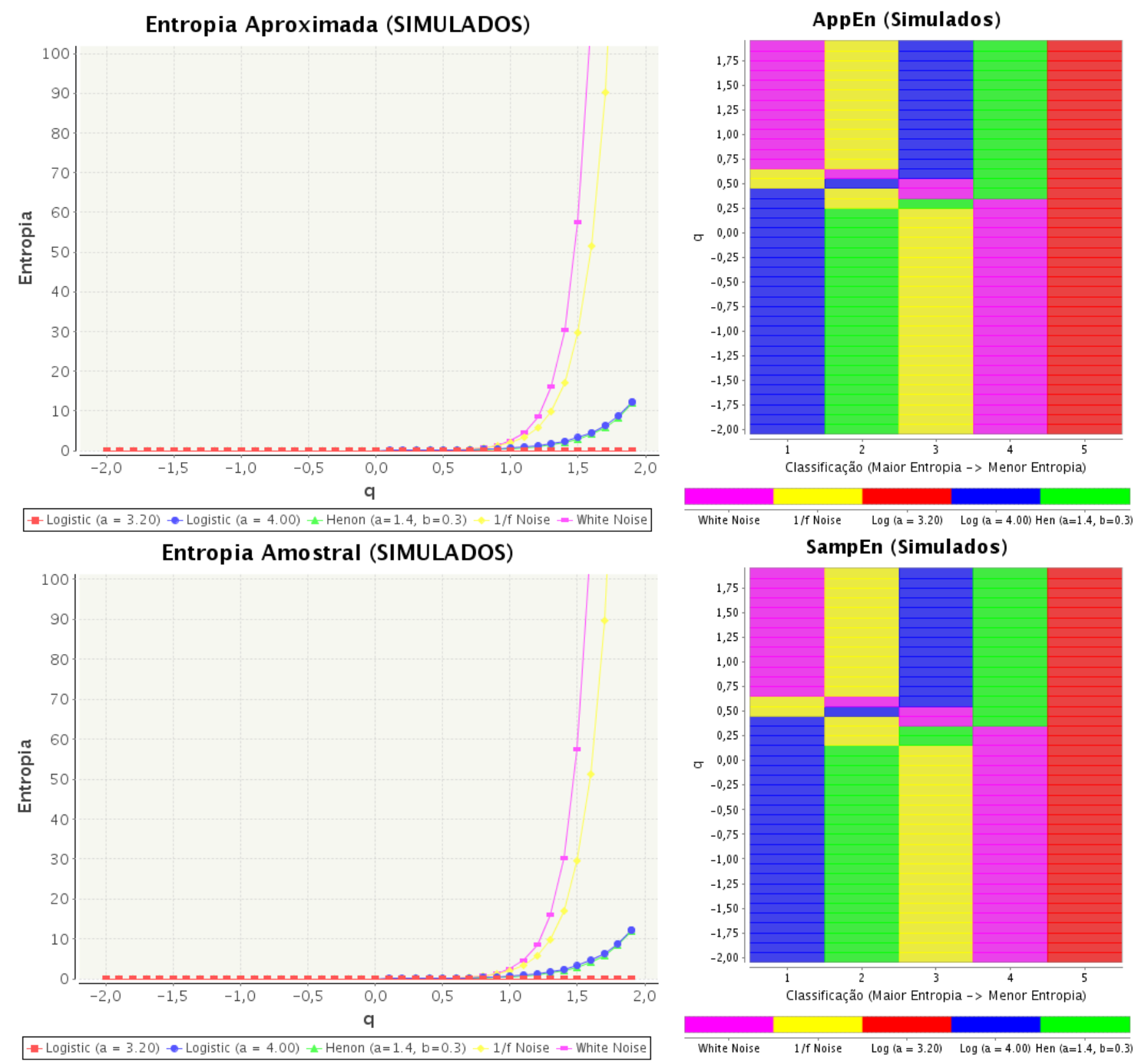

Figura 6.8: Resultado das entropias aproximada e amostral para os sinais simulados. À esquerda as séries de entropia em função de $q$, e à direita o diagrama de blocos com a classificação de cada série de acordo com o maior valor de entropia.

A Figura 6.8 mostra os resultados desta abordagem para os mesmos sinais simulados utilizados anteriormente. Como nos casos anteriores, os resultados para entropia aproximada e 
amostral também foram muito próximos, e novamente o intervalo de 0 a 1 em $q$ foi onde ocorreram as principais variações na ordem das séries (lado direito da Figura 6.8).

Com todos estes resultados, o que se percebe é que a generalização dada pela equação (5.5) não traz novas informações, comparada com a formualção clássica da entropia. Em contrapartida, com a equação (5.7) percebe-se que o parâmetro $q$ modifica a percepção da entropia, parecendo ser esta abordagem mais interessante.

\subsubsection{Entropia Multiescala}

A entropia multiescala (MSE), como já descrita no capítulo anterior, consiste no cálculo da entropia amostral para um mesmo sinal em várias escalas diferentes, obtendo-se séries de entropia versus escala. Com a generalização da entropia amostral, para cada valor de $q$ irá existir uma série MSE diferente. A Figura 6.9 mostra os resultados da MSE para o ruído 1/f e para uma série RR de indivíduo normal, utilizando a generalização da equação (5.5) e variando o parâmetro $q$ de -2 a 2, enquanto que a Figura 6.10 mostra os mesmos resultados, desta vez utilizando a generalização da equação (5.7).
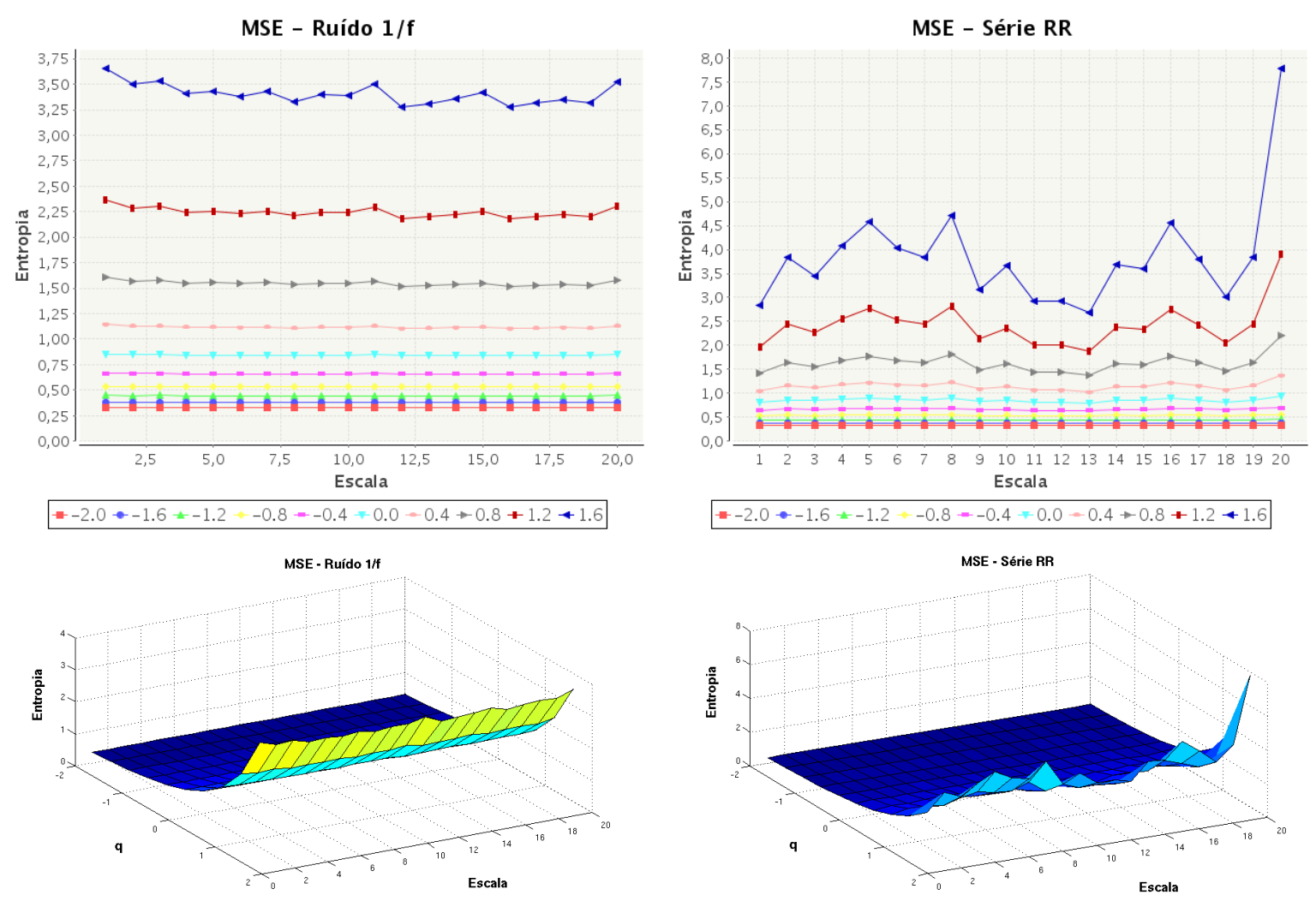

Figura 6.9: Resultado da entropia multiescala (MSE) do ruído 1/f (gerado com 16.384 pontos) e uma série RR, utilizando a generalização da equação (5.5). Na parte de cima é mostrado o resultado em duas dimensões; abaixo o mesmo resultado, visualizado em perspectiva. 

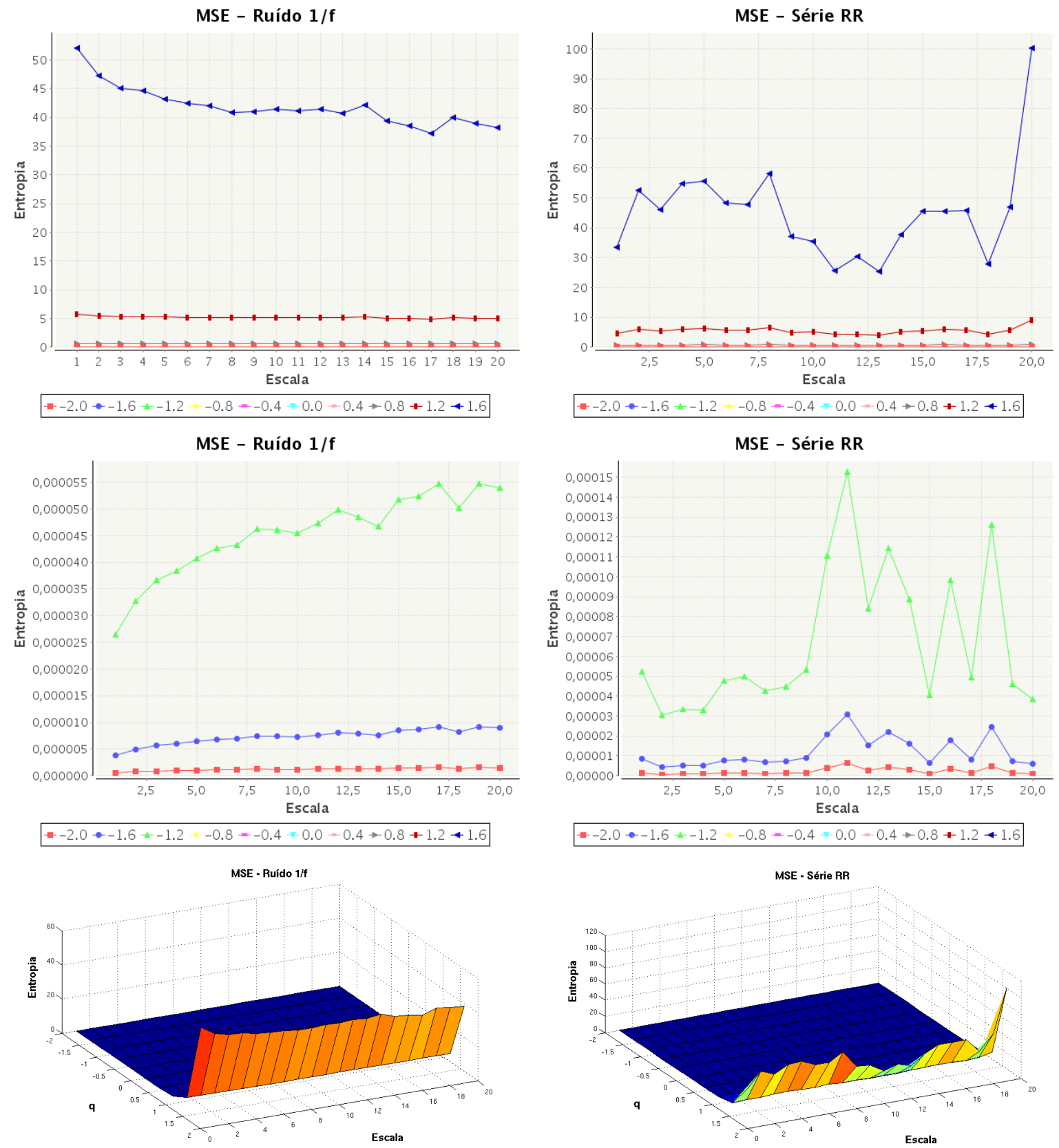

Figura 6.10: Resultado da entropia multiescala (MSE) do ruído 1/f (gerado com 16.384 pontos) e da mesma série RR utilizada anteriormente, utilizando a generalização da equação (5.7). Na parte estão os resultado em duas dimensões; no meio, os mesmos resultados com apliação do eixo da entropia; abaixo, os resultados visualizados em perspectiva.

Nas análises realizadas, o valor máximo da escala escolhido foi 20. É importante ressaltar que o tamanho do sinal diminui com o aumento da escala e o cálculo da entropia em sinais muito pequenos não é representativo.

Como visto nos resultados da seção anterior, as variações do valor da entropia em função de $q$, utilizando a mesma equação de generalização, eram devidas apenas à função $q$-logarítmo. Essa característica também é observada ao analisar a entropia de uma série em qualquer outra 
escala. Isto significa que, ao variar o parâmetro $q$, a entropia de uma série temporal, em qualquer escala, seguirá o crescimento da função $q$-logarítmo, e assim, as instâncias de uma série MSE serão cópias "esticadas" ou "achatadas" desta. Na Figura 6.9 fica claro que a escala varia a percepção da entropia na série (característica na qual está baseada a proposta da entropia multiescala) mas que essa percepção aparentemente não muda com o valor de $q$.

Por outro lado, nos resultados apresentados na Figura 6.10, é possível observar que esta abordagem de generalização da entropia muda o formato das séries de MSE. No caso do ruído 1/f, observando os gráficos com ampliação, percebe-se que as séries de MSE, com comportamento decrescente para os maiores valores de $q$, mudam seu comportamento e passam a crescer com a escala ao diminuir os valores de $q$. No caso da série RR avaliada, nota-se que ocorre uma inversão no comportamento das séries. Em geral, para valores altos de $q$ observava-se os maiores valores de entropia nas menores escala, ocorrendo o oposto nas séries para baixos valores de $q$.

Os resultados obtidos com a generalização da entropia multiescala ainda não são suficientes para tirar-se conclusões quanto ao seu significado prático. Contudo, são resultados intrigantes e merecem ser melhores estudados.

\subsubsection{Análise Surrogate}

A metodologia de análise utilizando séries substitutas (surrogates) proposta neste projeto visa explorar sobre a contribuição do parâmetro $q$ na entropia. A idéia aqui é verificar a diferença entre os valores de entropia amostral de sinais e suas séries surrogates. Essas séries surrogates foram geradas com os três tipos de abordagens citadas no capítulo 5. Da mesma maneira como feito nas análises anteriores, a entropia foi avaliada nas duas formulações diferentes, dadas pelas equações (5.5) e (5.7).

\section{Surrogate tipo 1 (Time-Surrogate)}

A Figura 6.11 mostra os resultados da análise surrogate das séries RR utilizando surrogates do tipo 1. Na parte superior são mostrados os resultados utilizando a generalização da equação (5.5), e abaixo, da equação (5.7).

Pela figura é possível novamente notar que as abordagens de generalização produzem resultados diferentes. Na abordagem que utiliza a equação (5.7) surge um comportamento bastante distinto dos resultados vistos até então. Todas as séries resultantes, em maior ou menor grau e em determinada região do parâmetro $q$, são atraídas para baixos valores de diferença de entro- 

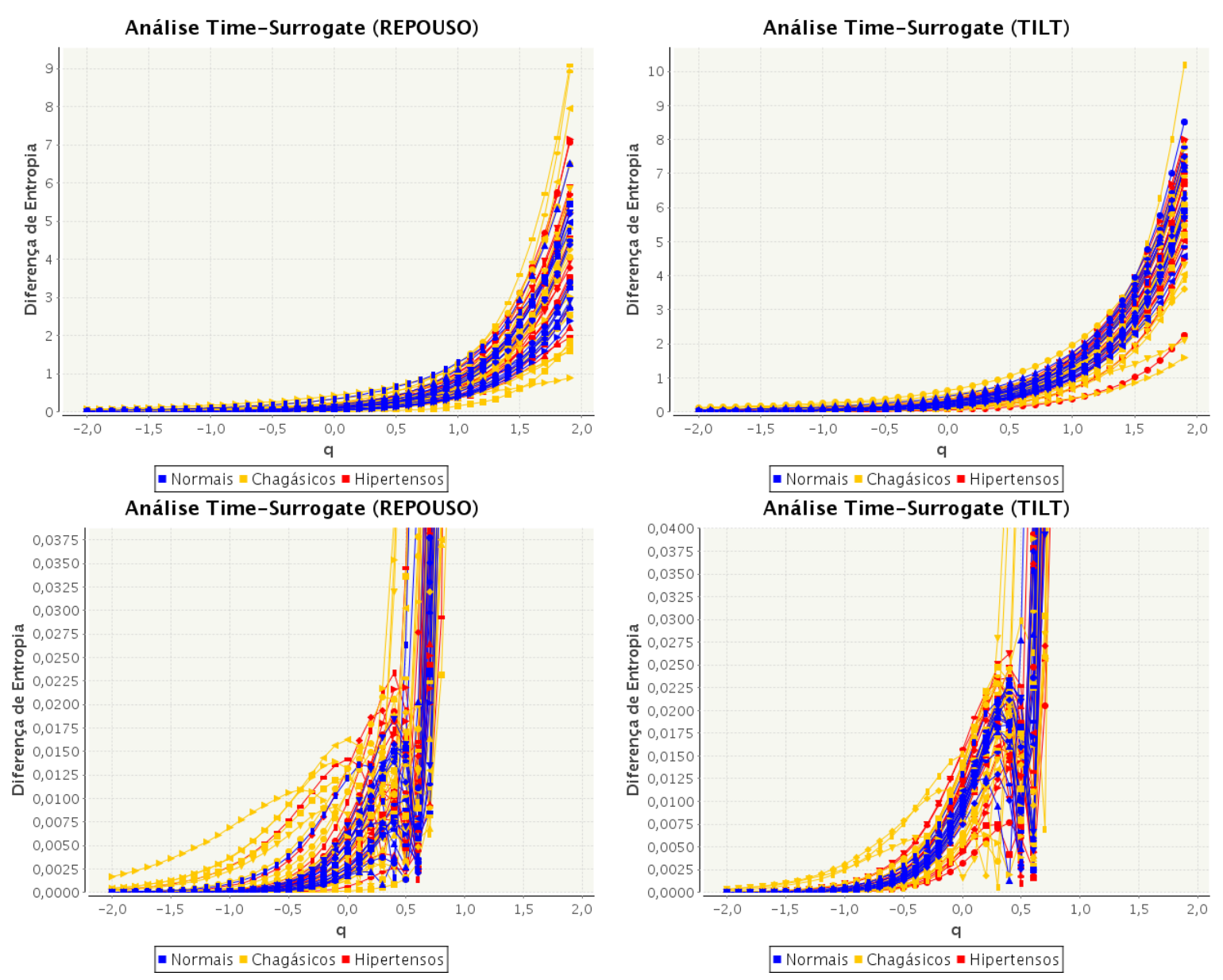

Figura 6.11: Análise surrogate das séries RR, utilizando surrogates tipo 1. Os gráficos acima mostram os resultados utilizando a generalização da entropia dada pela equação (5.5), e abaixo utilizando a equação (5.7). Nestas últimas, o eixo vertical foi ampliado para destacar o comportamento das séries.

pia, chegando a um valor mínimo e subindo, logo em seguida, abruptamente. Nos resultados com a formulação (5.5) observa-se crescimentos regulares das séries, cada qual com uma característica, mas sem a presença deste tipo de comportamento. Mais interessante ainda notar estes comportamentos nos resultados com os sinais simulados, apresentados na Figura 6.12.

Os resultados com sinais simulados são semelhantes aos das séries RR. Porém, o comportamento de decrescimento suave e crescimento abrupto que surge com a formulação (5.7) não ocorre para os cinco sinais simulados, mas apenas para três deles: ruído 1/f, mapa logístico e mapa de Hénon, estes dois últimos em regime caótico. O ruído branco e o mapa logístico em regime periódico não apresentaram este comportamento. Este fato é bastante interessante, pois os sinais que apresentaram o comportamento citado são sinais que apresentam algum nível de complexidade finito, distinguindo-os de sinais aleatórios (ruído branco) e dos que não apresentam nenhuma complexidade (mapa logístico regular). Além disso, é possível observar que, tanto a curvatura do decrescimento como o valor de $q$ do ponto mínimo na região do fenômeno 

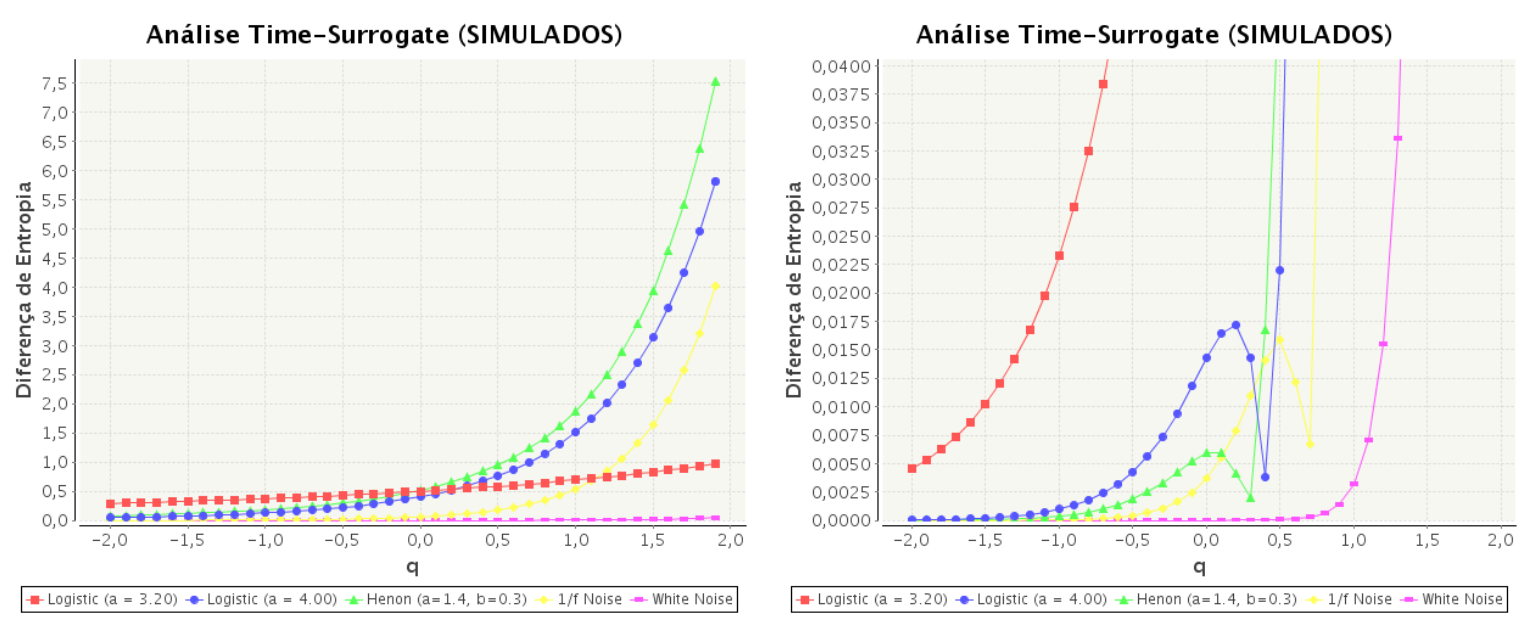

Figura 6.12: Análise surrogate dos sinais simulados, utilizando surrogates tipo 1 . O gráfico à esquerda mostra os resultados utilizando a generalização da entropia dada pela equação (5.5), e à direita utilizando a equação (5.7). O eixo vertical foi ampliado no gráfico à direita para destacar o comportamento das séries.

são diferentes entre as séries, podendo isso ainda representar alguma informação relevante para análise, mas que ainda necessita ser explorada.

Nos resultados obtidos com a generalização da equação (5.5), apesar de não ser observado o fenômeno descrito anteriormente, também se observa uma boa distinção entre as séries que apresentam algum grau de complexidade e as demais.

Outro ponto interessante a destacar é que, no caso do ruído branco, suas séries surrogates são, em essência, iguais a série original e por isso os valores de diferença de entropia devem ser praticamente zero. Isso é observado nos dois casos, sendo que a partir de um determinado valor de $q(q>1)$, a série passa a apresentar um crescimento acentuado, levando a crer que estes valores de $q$ podem não ser significativos neste caso. Esse crescimento só é observado com ampliação do eixo vertical, e por isso só é visualizado no gráfico à direita da Figura 6.12.

Analisando esses resultados obtidos com sinais simulados e comparando-os com os resultados obtidos com as séries RR, poderíamos deduzir que todas as séries RR avaliadas apresentam em sua dinâmica algum grau de complexidade, através das correlações temporais que são perdidas nas séries surrogates. Além disso, assim como observado nos resultados com sinais simulados, cada série RR também apresenta uma curvatura e um valor de $q$ mínimo distinto, o que pode ser relevante na identificação das condições fisiológicas de cada paciente.

As Figuras 6.13, 6.14 e 6.15 mostram os diagramas de blocos com a classificação (ordem) das séries nesta análise surrogate tipo 1, para os dois casos de generalização da entropia. 

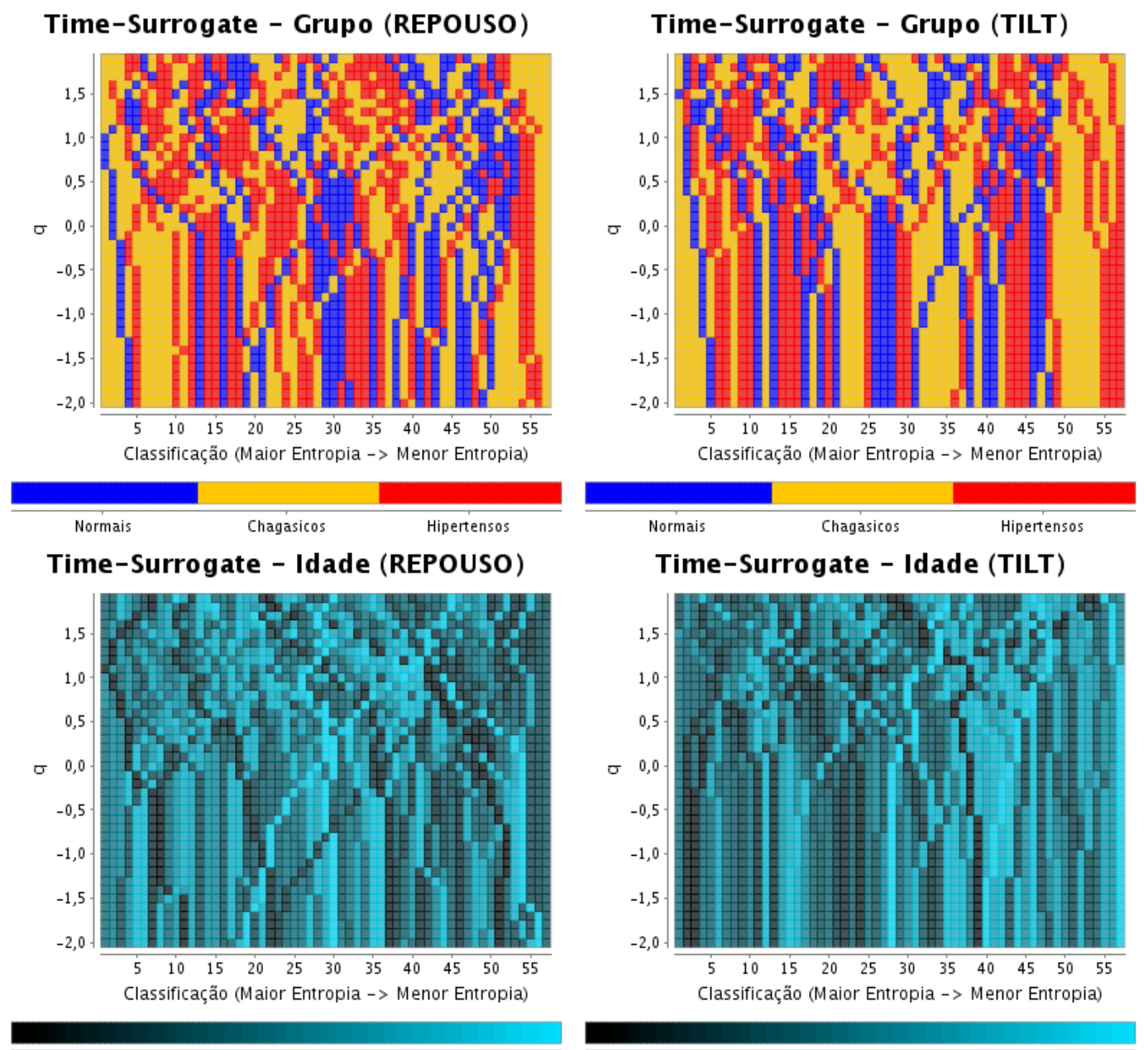

Time-Surrogate - Idade (TILT)
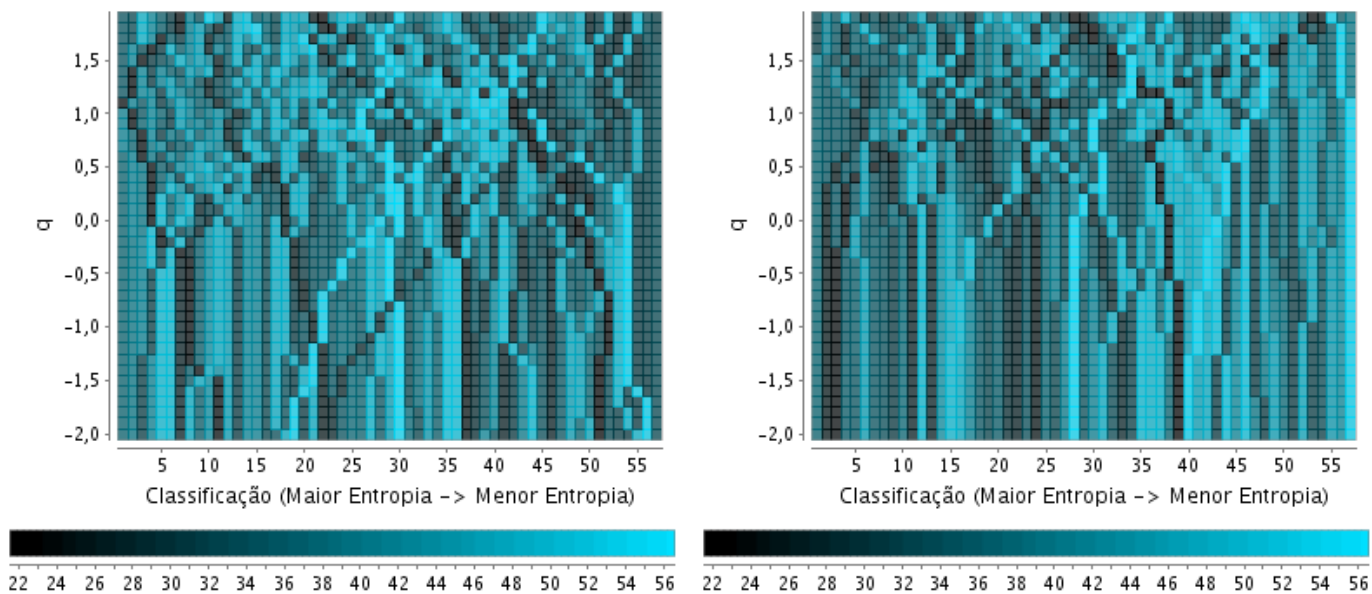

Time-Surrogate - Peso (REPOUSO)

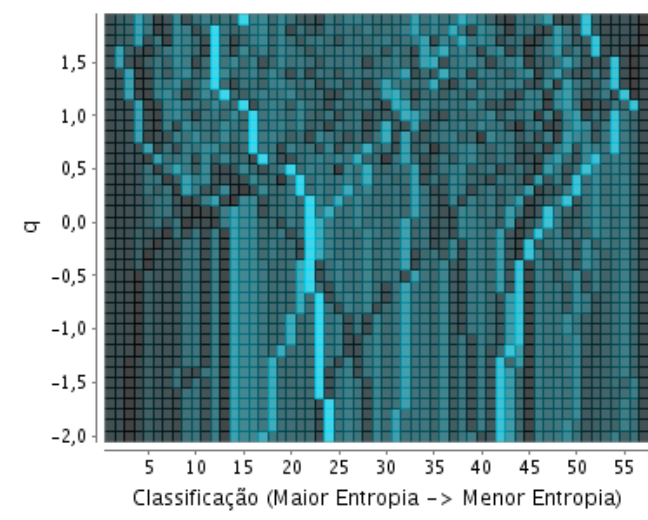

Time-Surrogate - Peso (TILT)

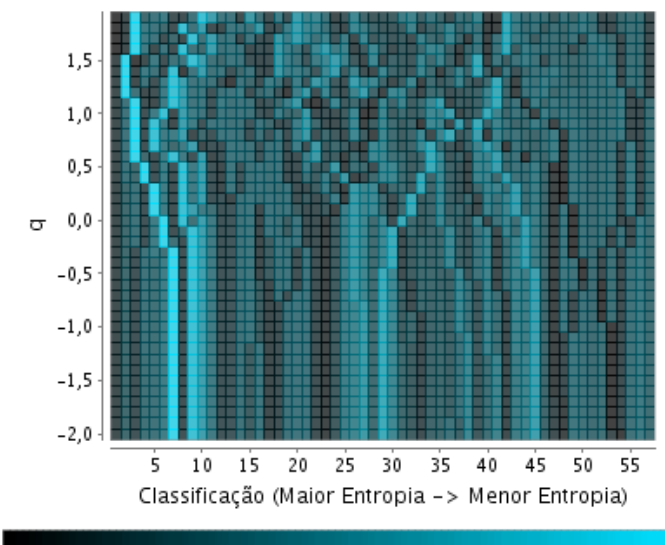

5457606366697275788184879093969910310711111511912312713154576063666972757881848790939699103107111115119123127131

Figura 6.13: Diagrama de blocos com a classificação de cada série RR em relação à diferença de entropia entre a série original e a entropia média das séries surrogates tipo 1, utilizando a generalização da entropia dada pela equação (5.5). Em cor são destacadas a idade, peso e grupo de cada paciente. 

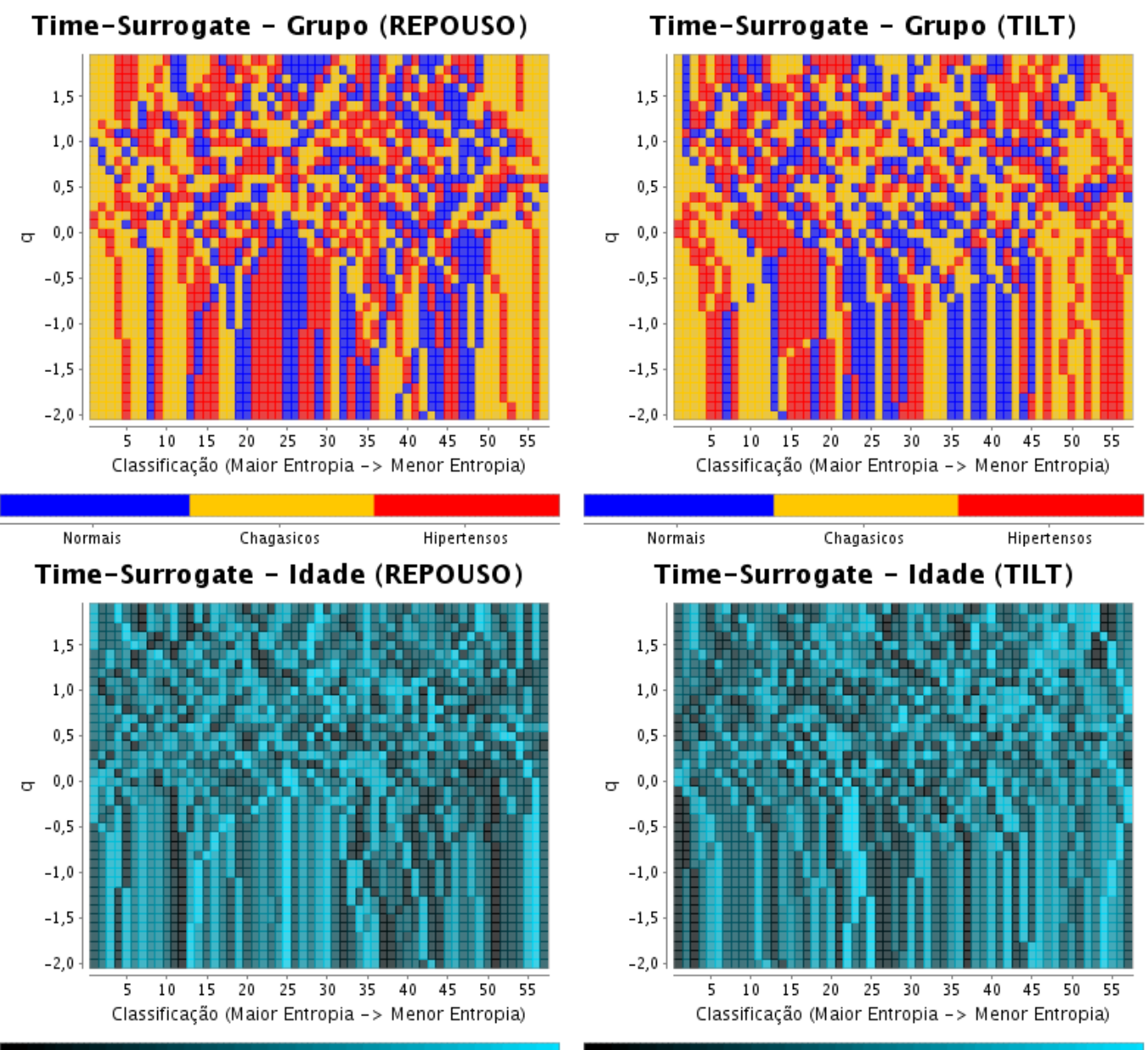

Time-Surrogate - Idade (TILT)
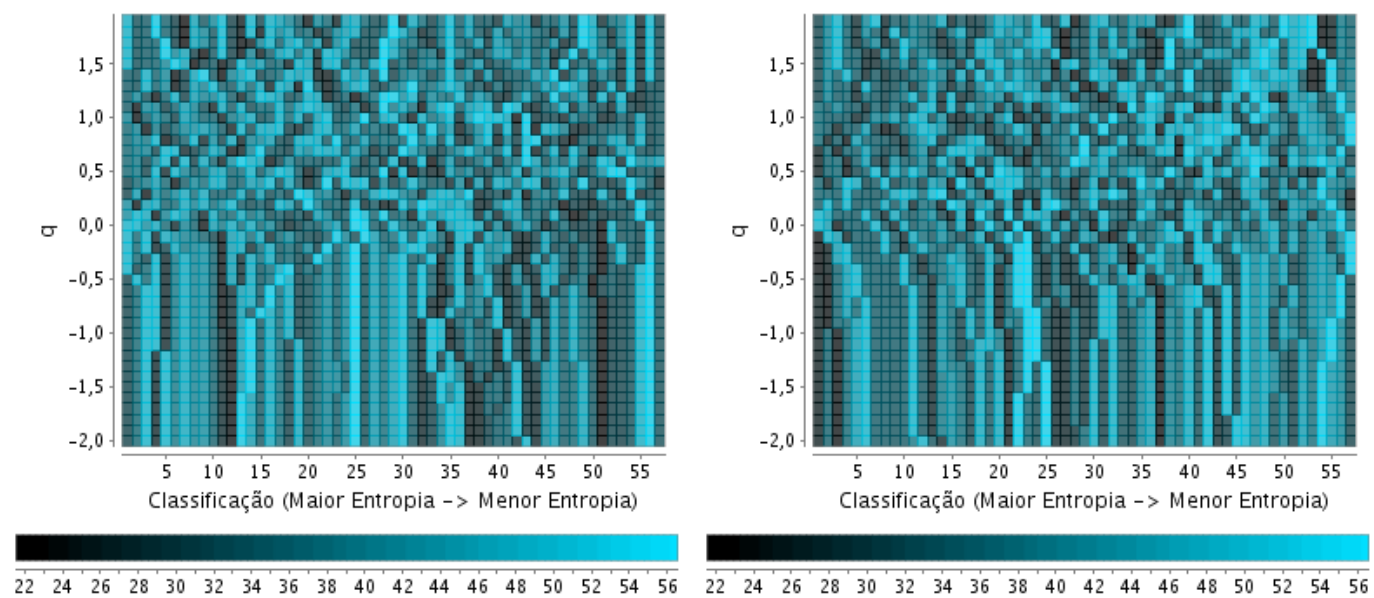

Time-Surrogate - Peso (REPOUSO)

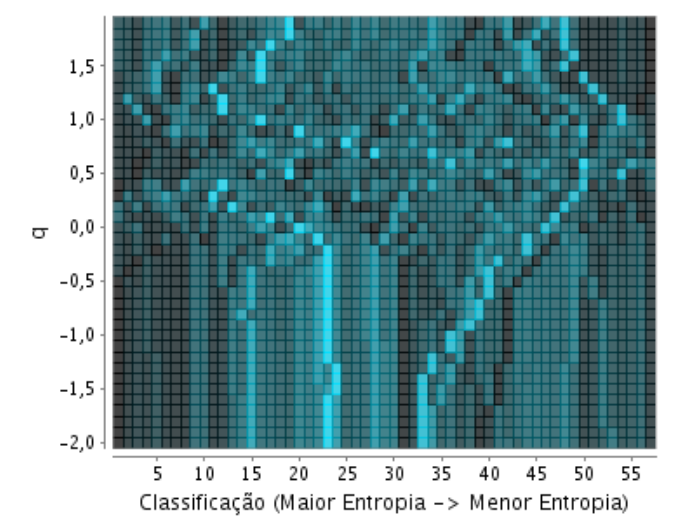

$\begin{array}{llllllllllllllllll}22 & 24 & 26 & 28 & 30 & 32 & 34 & 36 & 38 & 40 & 42 & 44 & 46 & 48 & 50 & 52 & 54 & 56\end{array}$

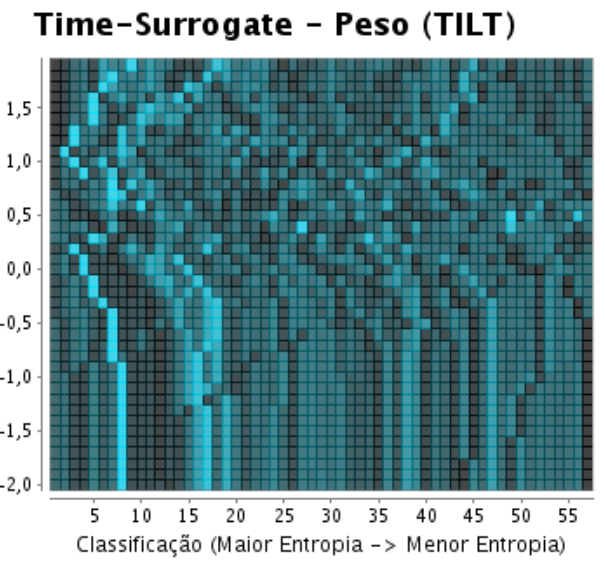

545760636669727578818487909396991031071111151191231271315457606366697275788184879093969910310711111511912312713

Figura 6.14: Diagrama de blocos com a classificação de cada série RR em relação à diferença de entropia entre a série original e a entropia média das séries surrogates tipo 1, utilizando a generalização da entropia dada pela equação (5.7). Em cor são destacadas a idade, peso e grupo de cada paciente. 

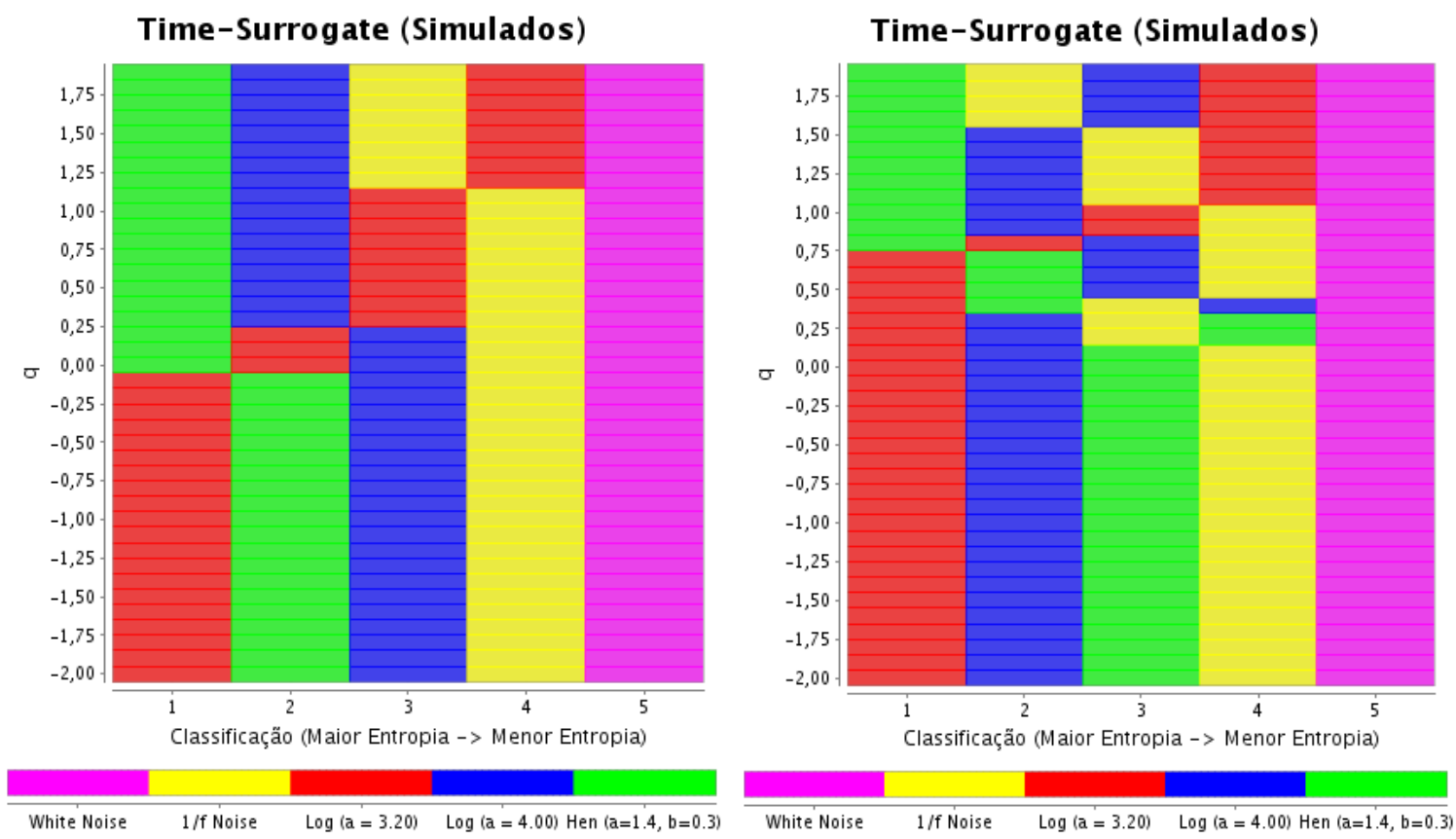

Figura 6.15: Diagrama de blocos com a classificação dos sinais simulados em relação à diferença de entropia entre a série original e a entropia média das séries surrogates tipo 1 . O gráfico à esquerda mostra os resultados utilizando a generalização da entropia dada pela equação (5.5), e à direita utilizando a equação (5.7).

Pelos diagramas percebe-se que, apesar das características interessantes observadas na Figura 6.11, também neste caso não há uma discriminação das séries RR por nenhum dos fatores destacados (peso, idade e grupo), considerando como critério de classificação os valores de diferença de entropia.

No caso dos sinais simulados, como comentado, espera-se que as diferenças de entropia sejam nulas para o ruído branco e o mapa logístico regular, e por consequência que estes dois sinais apresentem os menores valores no diagrama de blocos. Isso ocorre para $q>1$ nos dois casos de generalização. Contudo, nos resultados utilizando a equação (5.7), o comportamento de decaimento e crescimento abrupto não ocorre para estas duas séries, característica que pode tornar não representativa as comparações entre valores absolutos, uma vez que ainda não se obteve o entendimento à respeito deste comportamento distinto observado.

\section{Surrogate tipo 2 (Phase-Surrogate)}

As mesmas análises mostradas anteriormente foram realizadas utilizando-se séries surrogates do tipo 2. A Figura 6.16 mostra os resultados para as séries RR.

Pela figura é possível perceber que na abordagem que utiliza a equação (5.7) surge o mesmo comportamento distinto observado nas análises anteriores. Porém, neste caso, nem todas as 

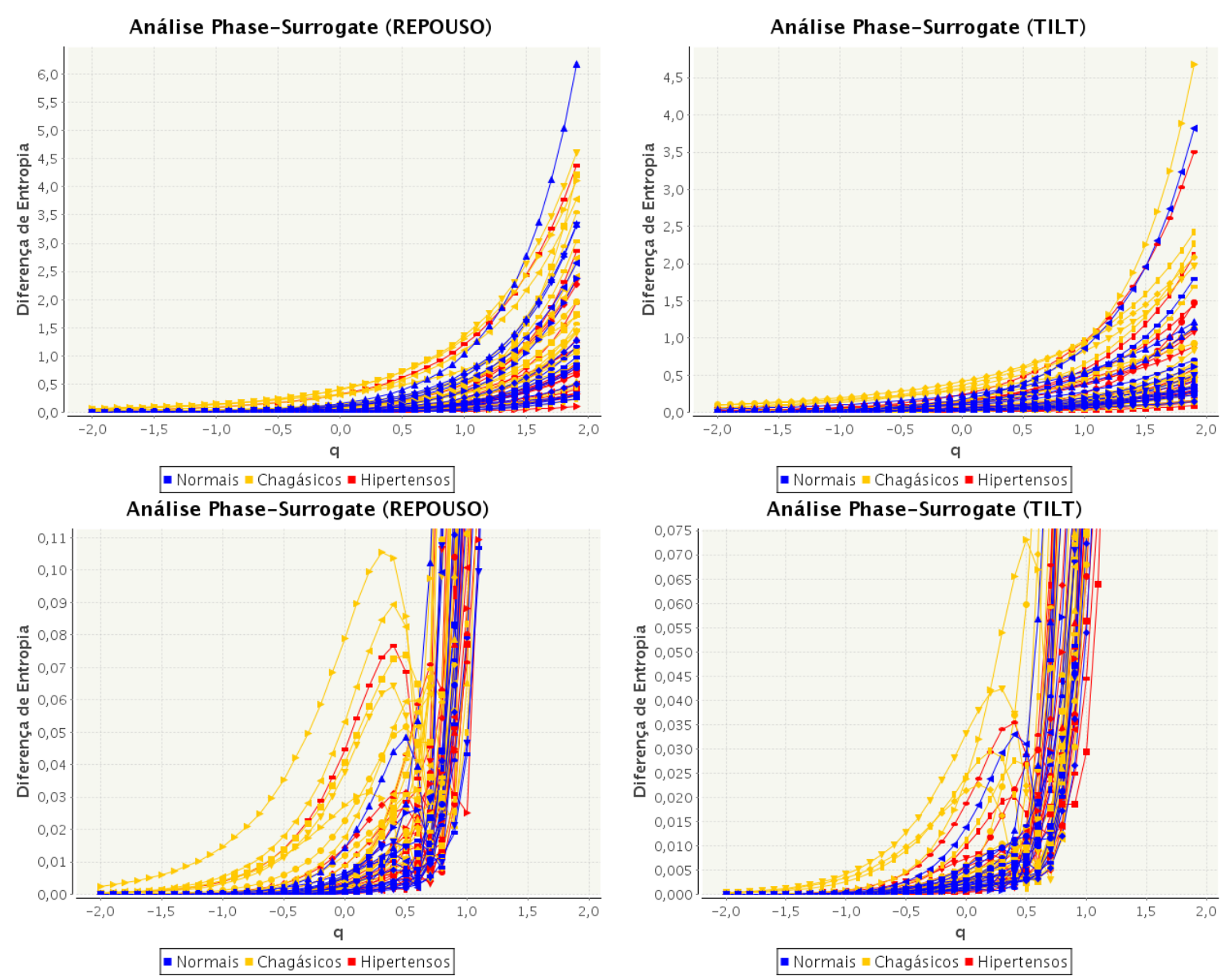

Figura 6.16: Análise surrogate das séries RR, utilizando surrogates tipo 2. Os gráficos acima mostram os resultados utilizando a generalização da entropia dada pela equação (5.5), e abaixo utilizando a equação (5.7). Nestas últimas, o eixo vertical foi ampliado para destacar o comportamento das séries.

séries resultantes apresentam este comportamento, mostrando um crescimento regular ao longo dos valores de $q$. Já nos resultados com a formulação (5.5) observa-se o mesmo comportamento obtido com as surrogates tipo 1: crescimentos regulares para todas as séries, cada qual com uma característica, mas sem a presença de comportamentos estranhos.

A Figura 6.17 mostra os resultados destas mesmas análises com os sinais simulados.

Os resultados com sinais simulados são semelhantes aos obtidos com as surrogates do tipo 1. Da mesma forma o comportamento de decrescimento suave e crescimento abrupto que surge com a formulação (5.7) não ocorre para os cinco sinais simulados; neste caso apenas para três deles: mapa logístico e mapa de Hénon, ambos em regime caótico, e ruído branco, este último quase imperceptível para a ampliação dada na Figura 6.17 por apresentar um decaimento muito pequeno. A principal diferença observada neste tipo de surrogate, comparada com o tipo 1, é que o ruído 1/f não apresenta o comportamento de decaimento seguido de crescimento abrupto, 

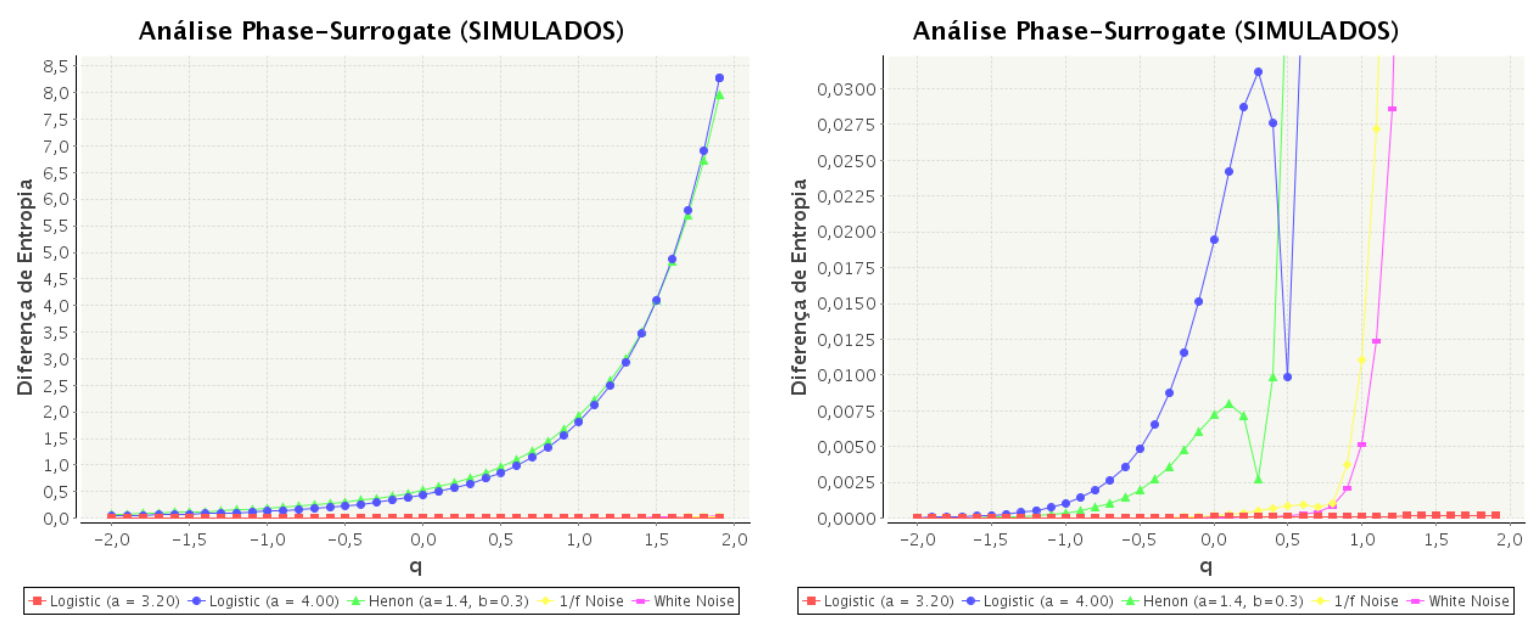

Figura 6.17: Análise dos sinais simulados, utilizando surrogates tipo 2. O gráfico à esquerda mostra os resultados utilizando a generalização da entropia dada pela equação (5.5), e à direita utilizando a equação (5.7). O eixo vertical foi ampliado no gráfico à direita para destacar o comportamento das séries.

fato que ocorria com o ruído branco anteriormente. Isto é explicado pelo mesmo motivo anterior: em essência, o ruído 1/f possui as mesmas características de suas séries surrogates do tipo 2, e é esperado que a diferença de entropia entre elas seja nula. Isto é observado nos resultados para os dois tipos de generalização. Observa-se também que a partir de um determinado valor de $q$, a série resultante do ruído 1/f passa a crescer rapidamente, indicando que a partir de então, talvez os valores de $q$ sejam não representativos. Este crescimento pode ser observado no gráfico à direita da Figura 6.17, que está com o eixo vertical ampliado, mas também ocorre no gráfico à esquerda.

Considerando os resultados observados com os sinais simulados e com este tipo de surrogate, uma conclusão que poderia ser tirada é que as séries RR que não apresentaram o comportamento diferenciado para a equação (5.7) são, de alguma forma, séries que não apresentam uma componente de não extensividade grande.

As Figuras 6.18, 6.19 e 6.20 mostram os diagramas de blocos com a classificação (ordem) das séries RR e sinais simulados nesta análise surrogate tipo 2. 

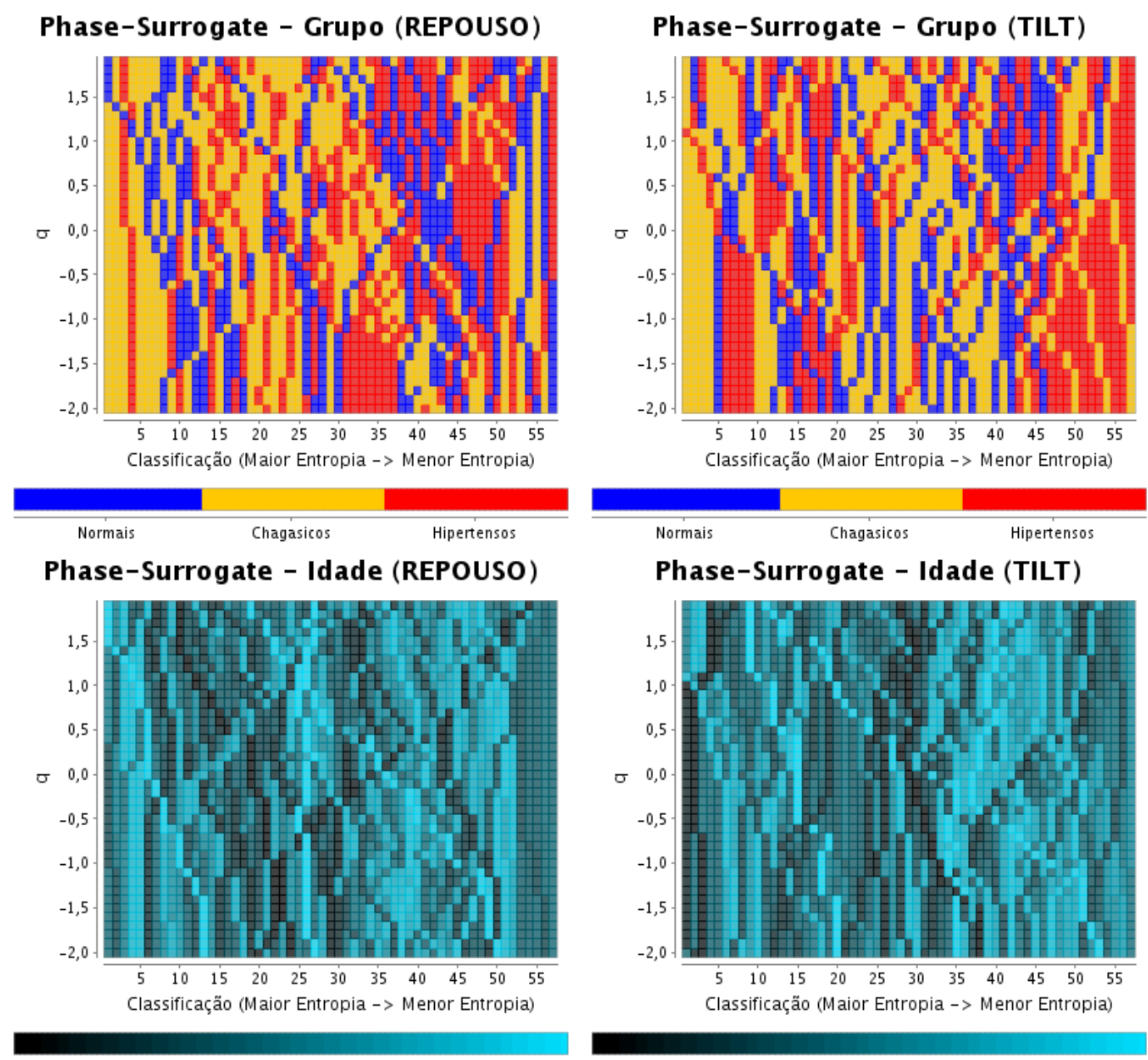

Phase-Surrogate - Idade (TILT)
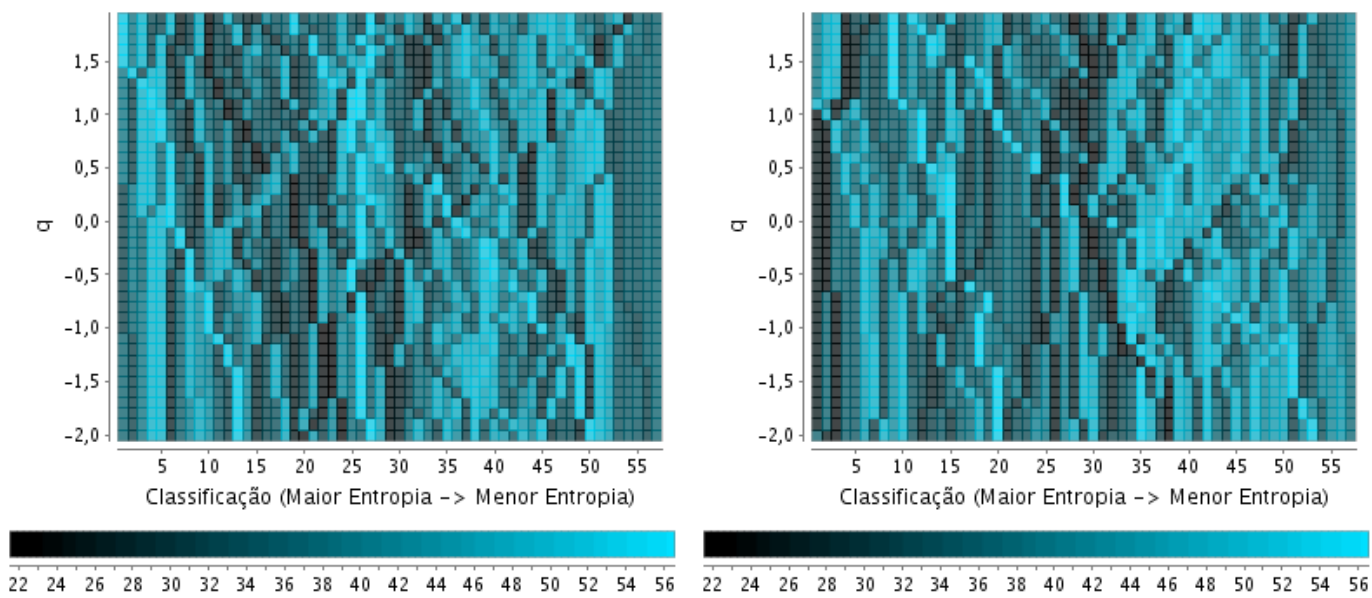

Phase-Surrogate - Peso (REPOUSO)

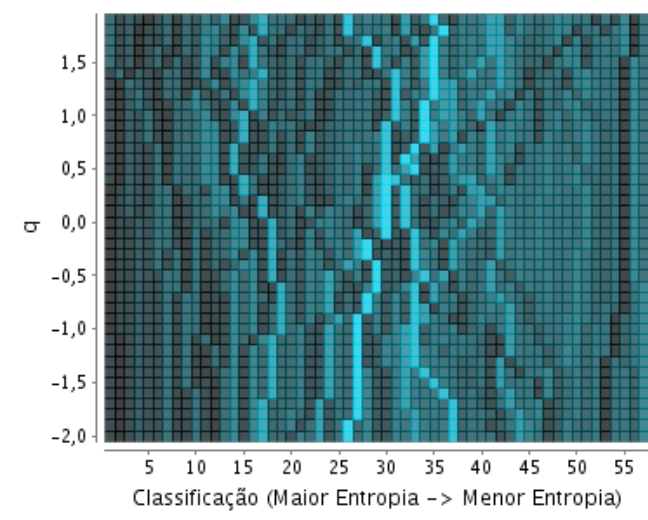

\section{Phase-Surrogate - Peso (TILT)}

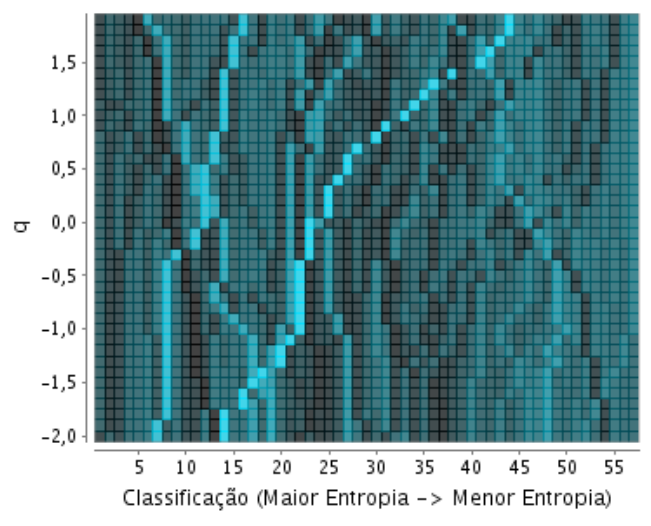

5457606366697275788184879093969910310711111511912312713154576063666972757881848790939699103107111115119123127131

Figura 6.18: Diagrama de blocos com a classificação de cada série RR em relação à diferença de entropia entre a série original e a entropia média das séries surrogates tipo 2, utilizando a generalização da entropia dada pela equação (5.5). Em cor são destacadas a idade, peso e grupo de cada paciente. 

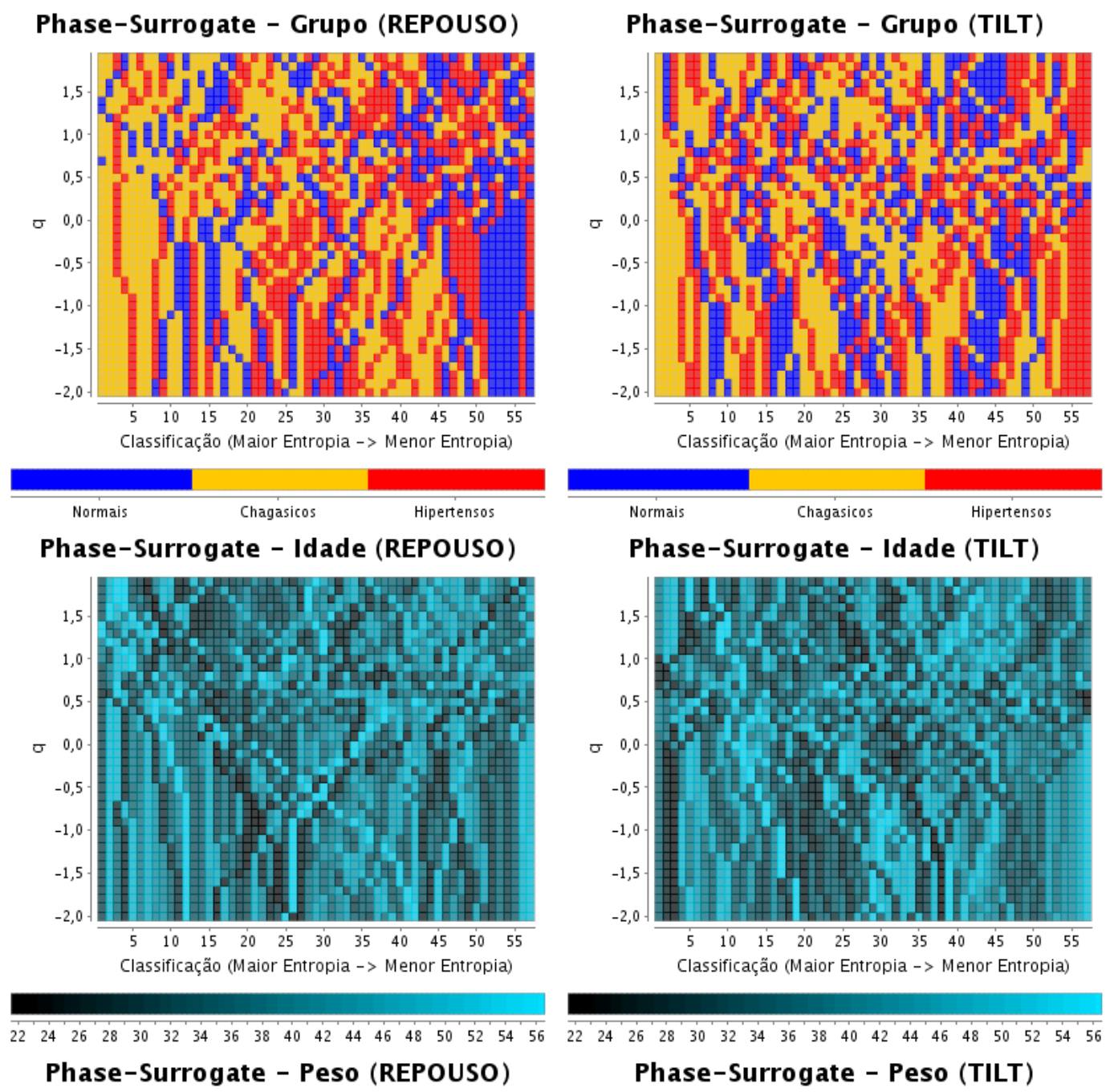

$\begin{array}{lllllllllllllllllllll}22 & 24 & 26 & 28 & 30 & 32 & 34 & 36 & 38 & 40 & 42 & 44 & 46 & 48 & 50 & 52 & 54 & 56\end{array}$
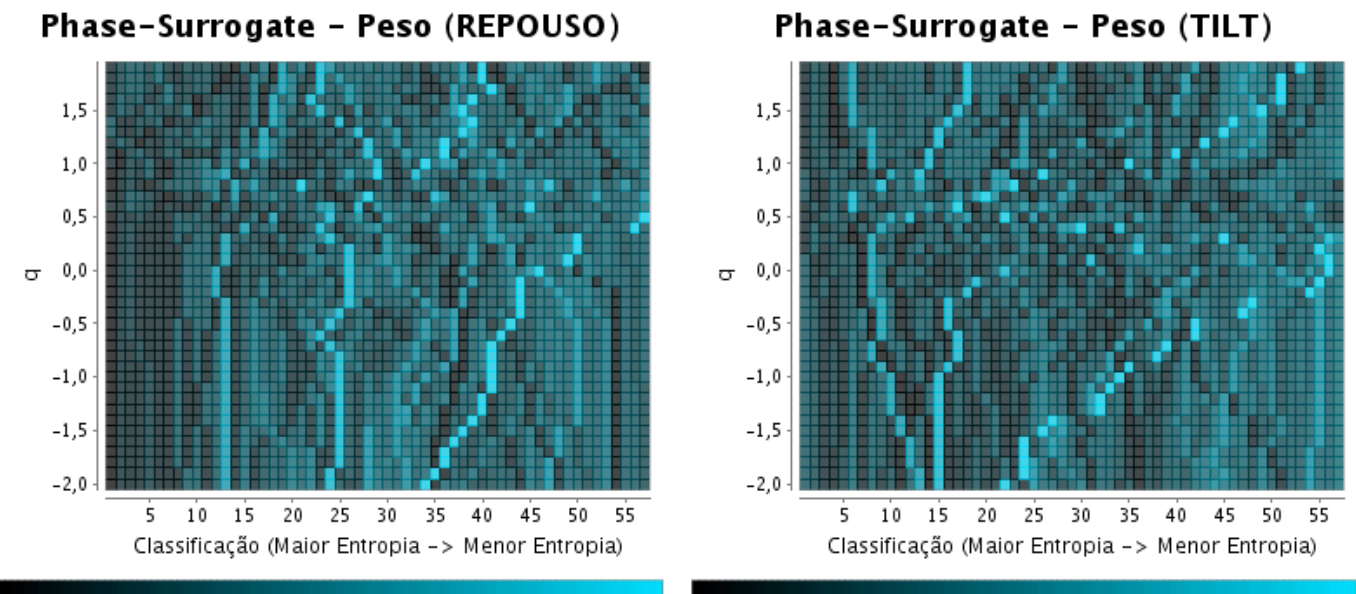

545760636669727578818487909396991031071111151191231271315457606366697275788184879093969910310711115119123127131

Figura 6.19: Diagrama de blocos com a classificação de cada série RR em relação à diferença de entropia entre a série original e a entropia média das séries surrogates tipo 2, utilizando a generalização da entropia dada pela equação (5.7). Em cor são destacadas a idade, peso e grupo de cada paciente. 

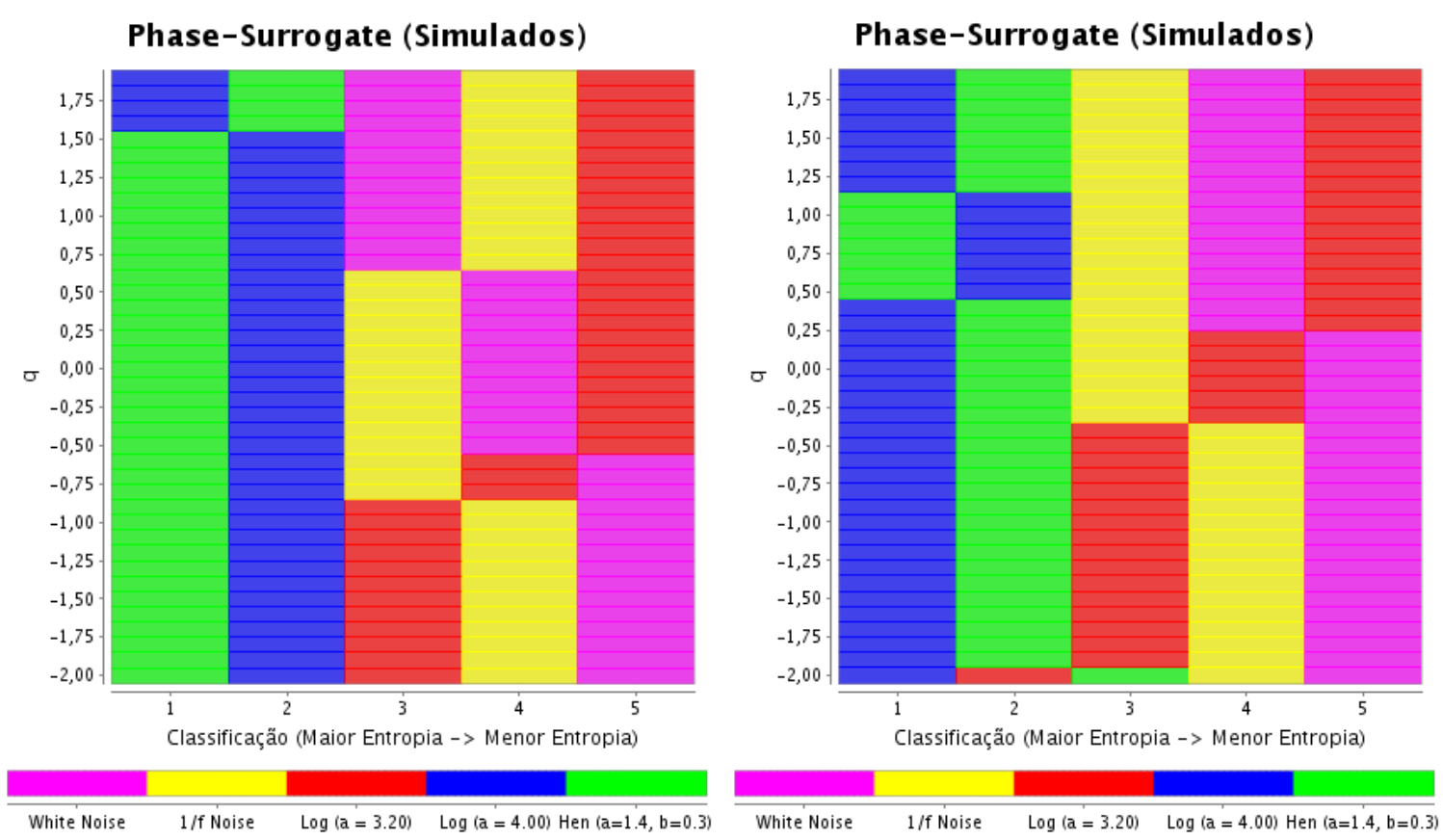

Figura 6.20: Diagrama de blocos com a classificação dos sinais simulados em relação à diferença de entropia entre a série original e a entropia média das séries surrogates tipo 2. O gráfico à esquerda mostra os resultados utilizando a generalização da entropia dada pela equação (5.5), e à direita utilizando a equação (5.7).

Pelos diagramas percebe-se novamente que ainda não há uma perfeita discriminação das séries RR por nenhum dos parâmetros destacados (peso, idade e grupo), considerando como critério de classificação os valores de diferença da entropia. Contudo, utilizando este tipo de surrogate, observa-se um pequeno grau de separação por grupos. Na Figura 6.18, o diagrama que destaca o grupo de cada série de tilt apresenta um ligeiro agrupamento de pacientes hipertensos nos baixos valores de diferença de entropia. Isso é mais evidente para valores de $q<0$. Por outro lado, na Figura 6.19, o diagrama que destaca o grupo das séries de repouso apresenta um ligeiro agrupamento de indivíduos normais em valores baixos de entropia, e de indivíduos chagásicos em valores altos de entropia, também mais observado nos valores de $q<0$.

No caso dos sinais simulados, de maneira semelhante às análises utilizando surrogates tipo 1, espera-se que os menores valores de diferença de entropia sejam para o mapa logístico regular e para o ruído 1/f. Isso é observado para $q>1$ no gráfico que mostra os resultados para a generalização da equação (5.5), mas não no gráfico que utiliza a equação (5.7), característica que novamente mostra que talvez a comparação em termos de valores absolutos dessa diferença de entropia possa ser não representativa nos casos em que ocorrem comportamentos distintos entre as séries. 


\section{Surrogate tipo 3 (Mixed-Surrogate)}

A seguir são mostrados os resultados das mesmas análises utilizando-se séries surrogates do tipo 3. A Figura 6.21 mostra estes resultados com as séries RR. Na parte superior estão os resultados utilizando a generalização da equação (5.5), e abaixo, da equação (5.7).
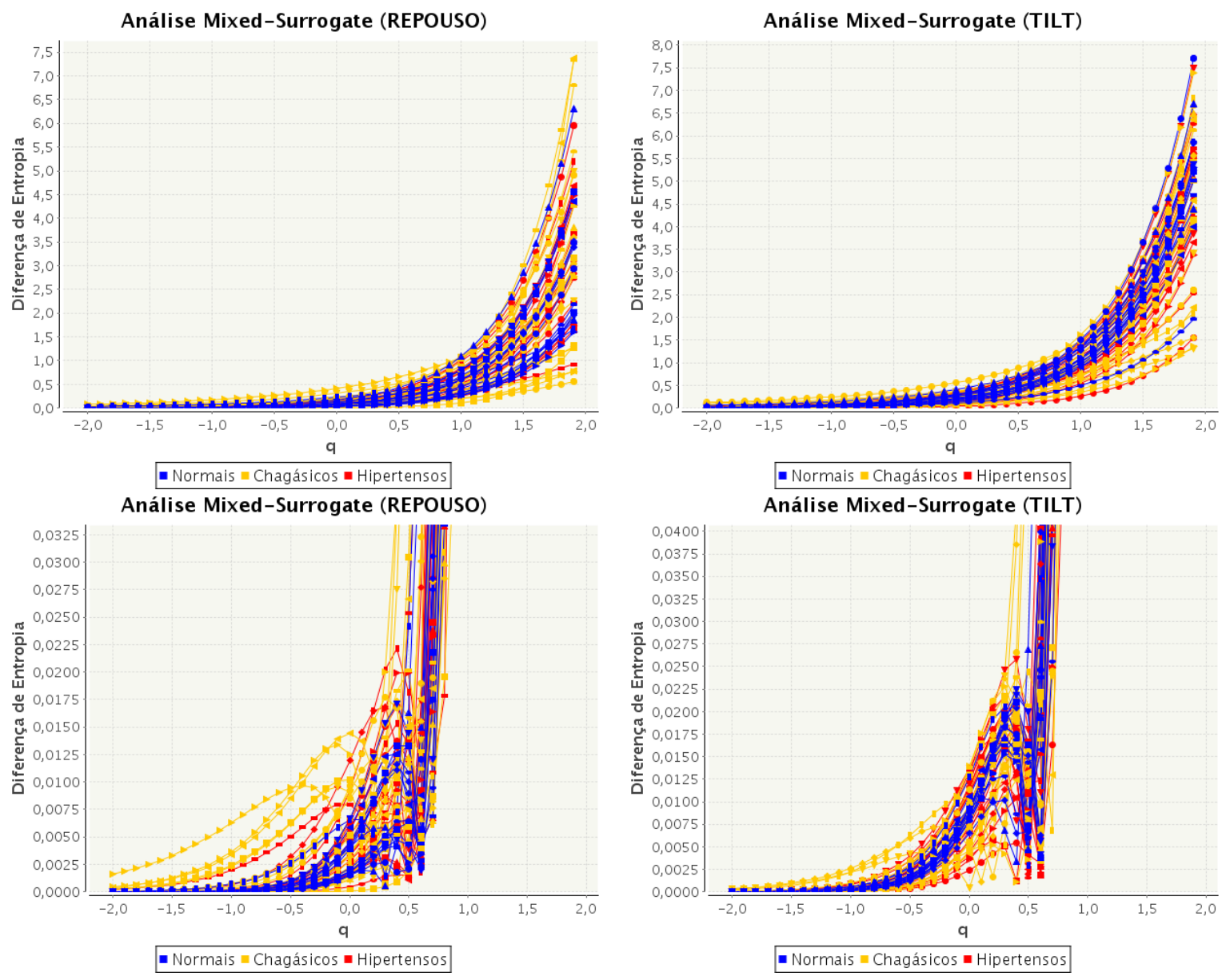

Figura 6.21: Análise das séries RR utilizando surrogates tipo 3. Os gráficos acima mostram os resultados utilizando a generalização da entropia dada pela equação (5.5), e abaixo utilizando a equação (5.7). Nestas últimas, o eixo vertical foi ampliado para destacar o comportamento das séries.

A figura mostra que o comportamento observado é muito próximo aos resultados obtidos nas análises anteriores, aproximando-se mais dos resultados obtidos utilizando surrogates do tipo 1. A Figura 6.22 mostra os resultados destas mesmas análises com os sinais simulados.

Os resultados com sinais simulados também são semelhantes aos obtidos com as surrogates do tipo 1. O comportamento de decrescimento suave e crescimento abrupto que surge com a formulação (5.7) ocorre para os mesmos três sinais: mapa logístico e mapa de Hénon, ambos em regime caótico, e ruído 1/f. Este tipo de surrogate analisada busca manter as características de distribuição e de potência espectral do sinal original, mas destruindo suas correlações temporais 

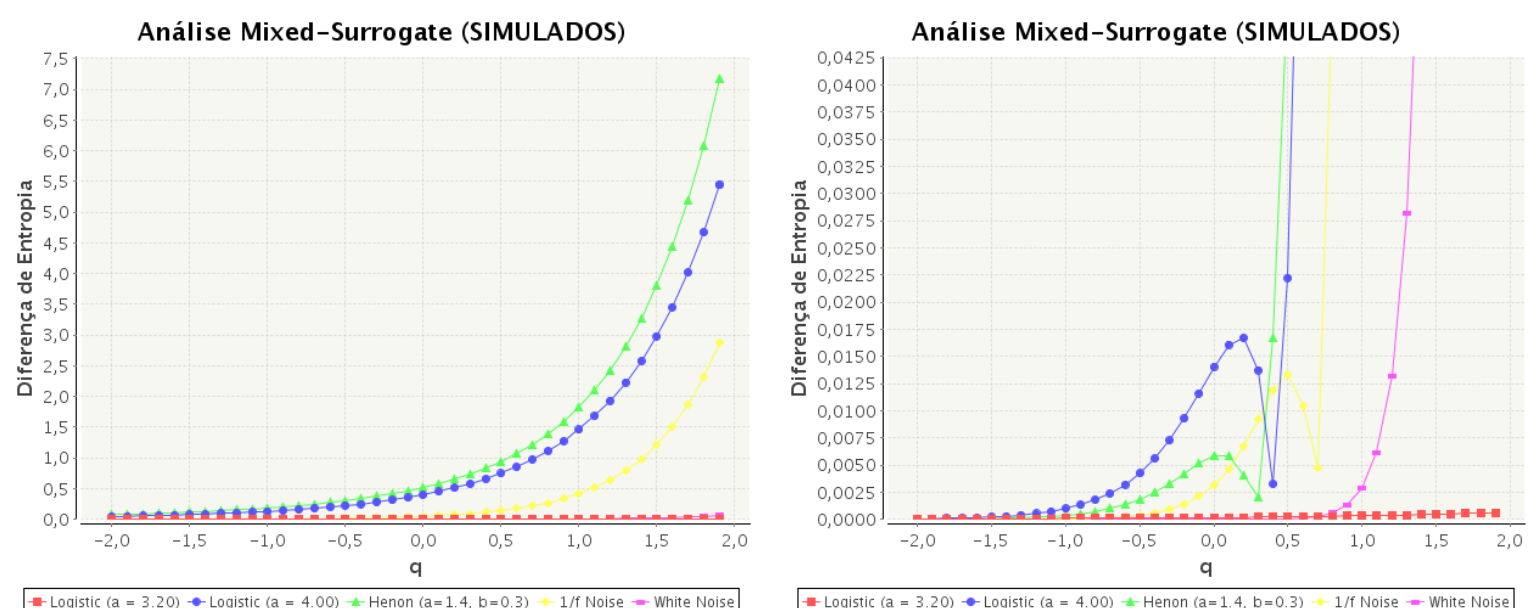

Figura 6.22: Análise dos sinais simulados utilizando surrogates tipo 3. O gráfico à esquerda mostra os resultados utilizando a generalização da entropia dada pela equação (5.5), e à direita utilizando a equação (5.7). O eixo vertical foi ampliado no gráfico à direita para destacar o comportamento das séries.

e do espaço de fases do seu espectro. Com isso, é possível observar que o ruído 1/f, apesar de possuir espectro próximo ao de suas séries surrogates, difere destas por possuir correlações temporais que foram destruídas. Isso também é perdido nos dois mapas caóticos analisados. No caso do ruído branco, os dados substitutos têm a mesma potência espectral e distribuição, e as correlações entre diferentes instantes são inexistents, portanto não são quebradas no processo de geração.

As Figuras 6.23, 6.24 e 6.25 mostram os diagramas de blocos com a classificação (ordem) das séries RR e sinais simulados nesta análise surrogate tipo 3. 

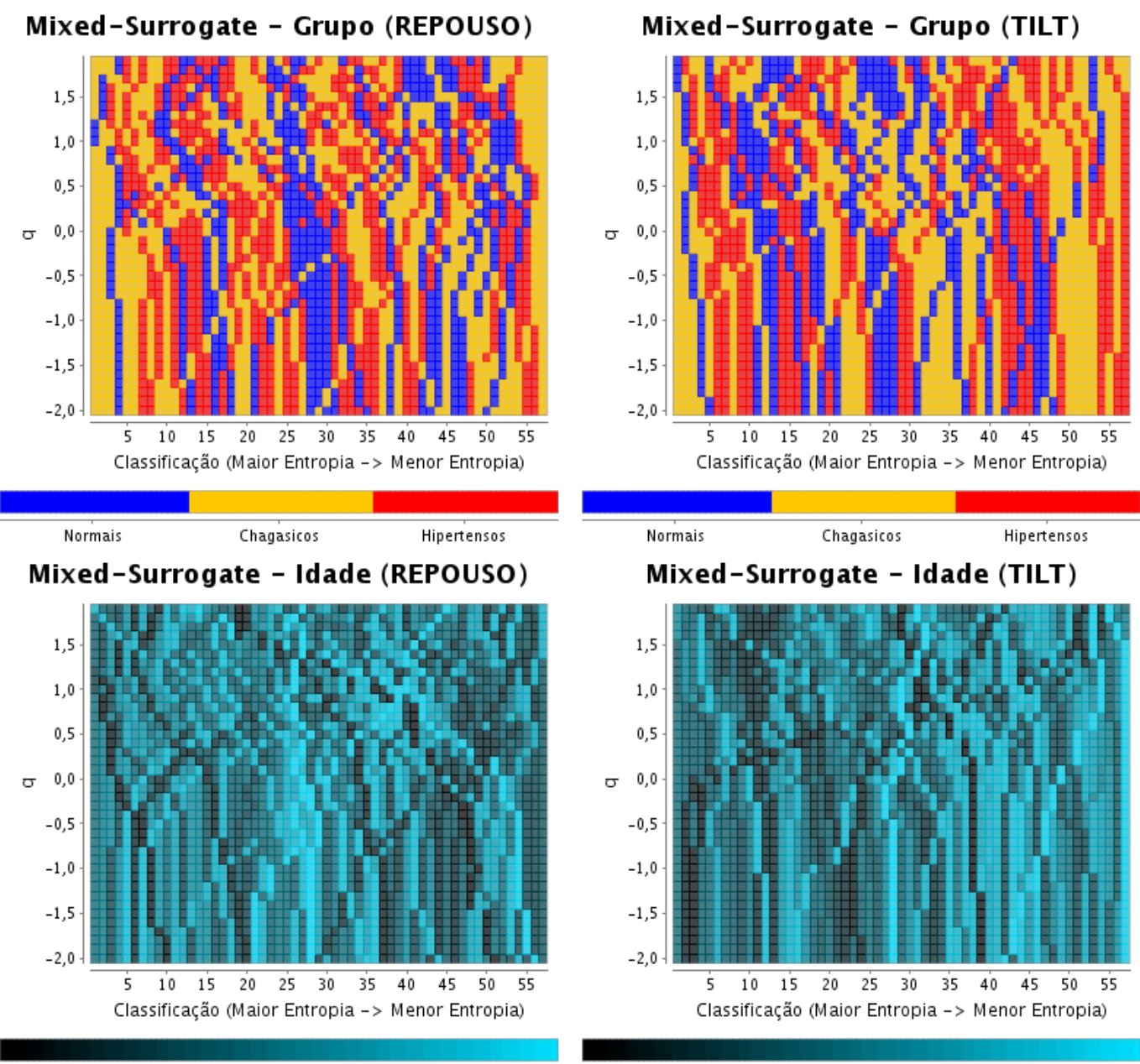

Mixed-Surrogate - Idade (TILT)
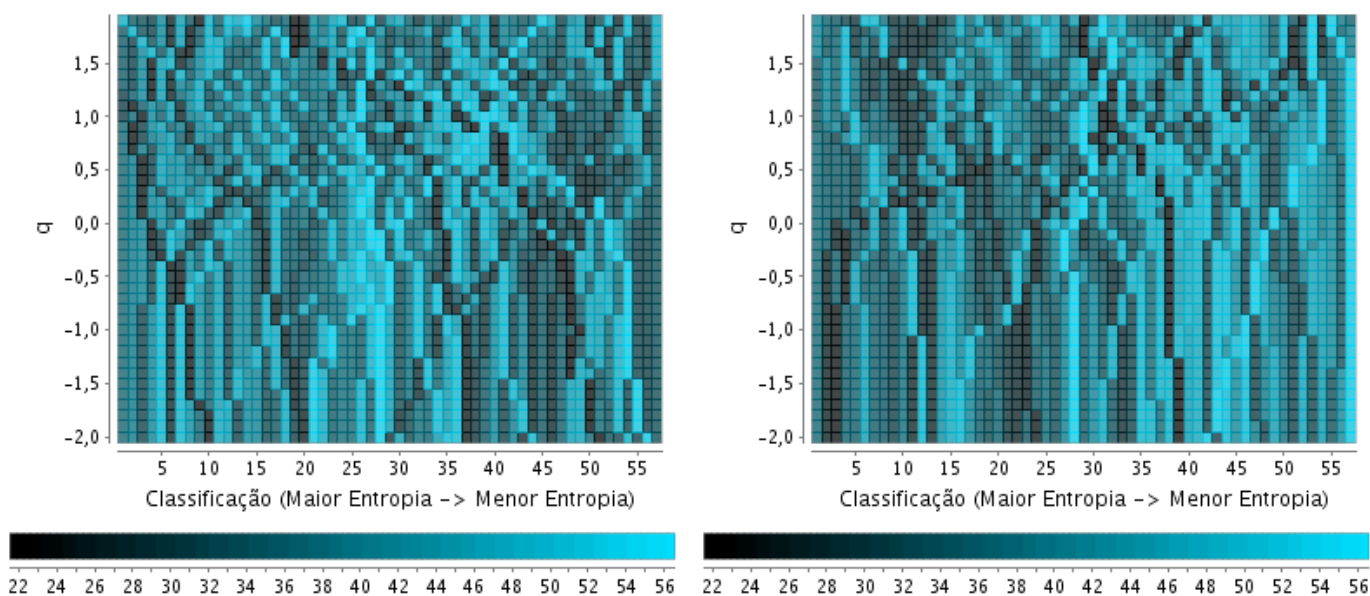

Mixed-Surrogate - Peso (REPOUSO)

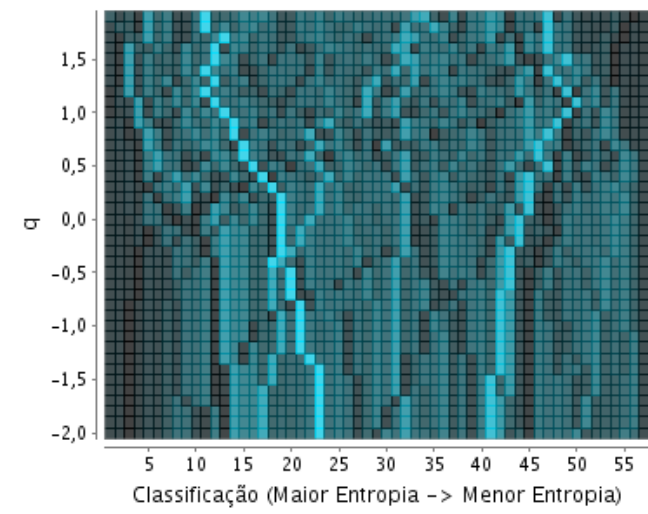

Mixed-Surrogate - Peso (TILT)

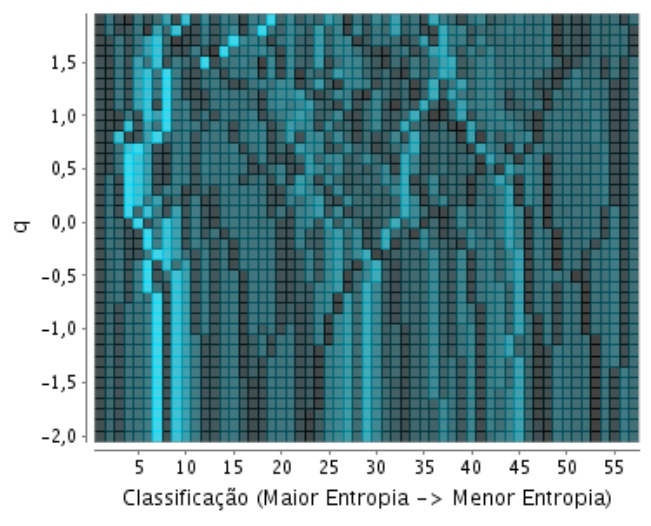

545760636669727578818487909396991031071111151191231271315457606366697275788184879093969910310711115119123127131

Figura 6.23: Diagrama de blocos com a classificação de cada série em relação à diferença de entropia entre a série original e a entropia média das séries surrogates tipo 3, utilizando a generalização da entropia dada pela equação (5.5). Em cor são destacadas a idade, peso e grupo de cada paciente. 

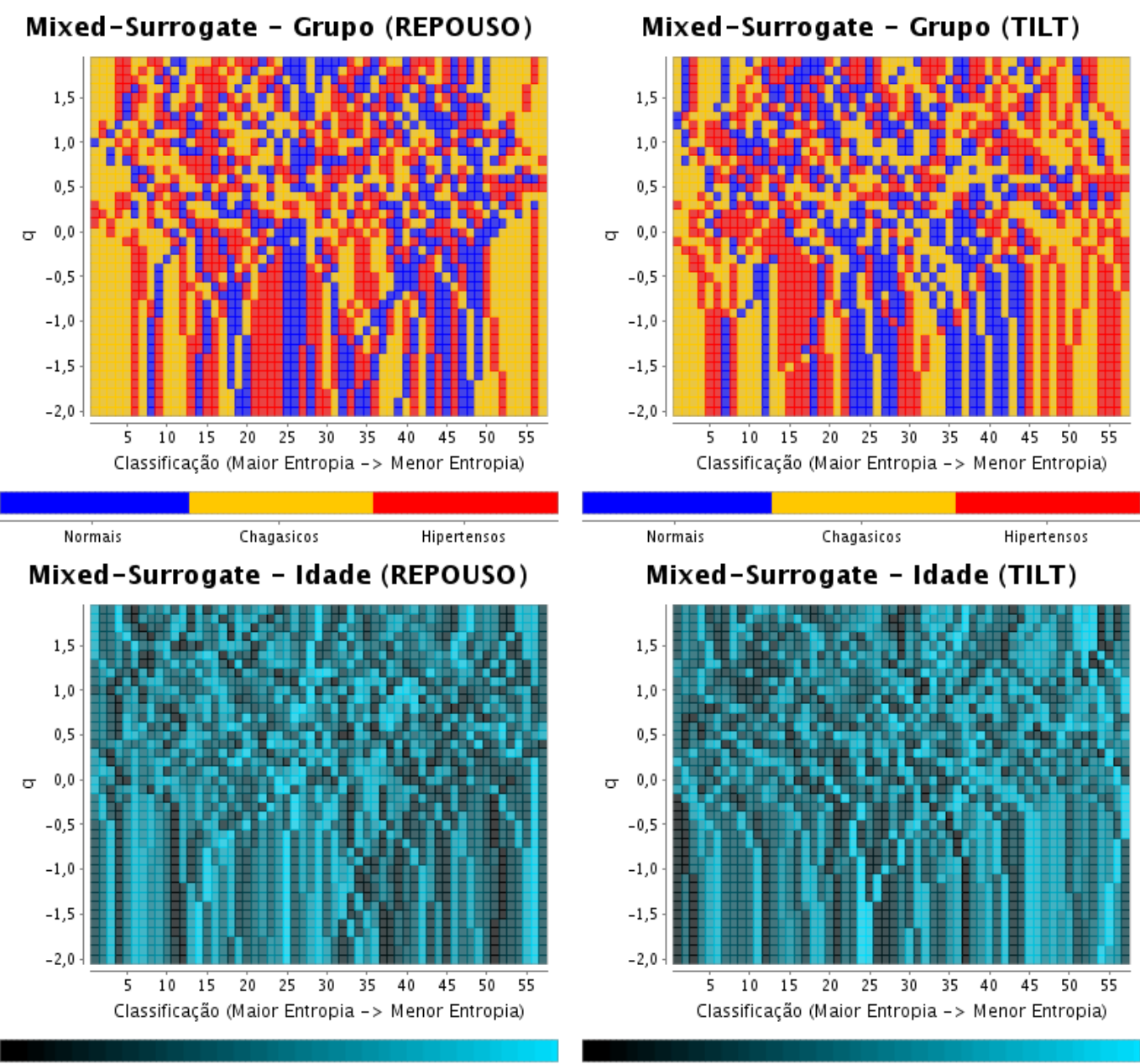

Mixed-Surrogate - Idade (TILT)
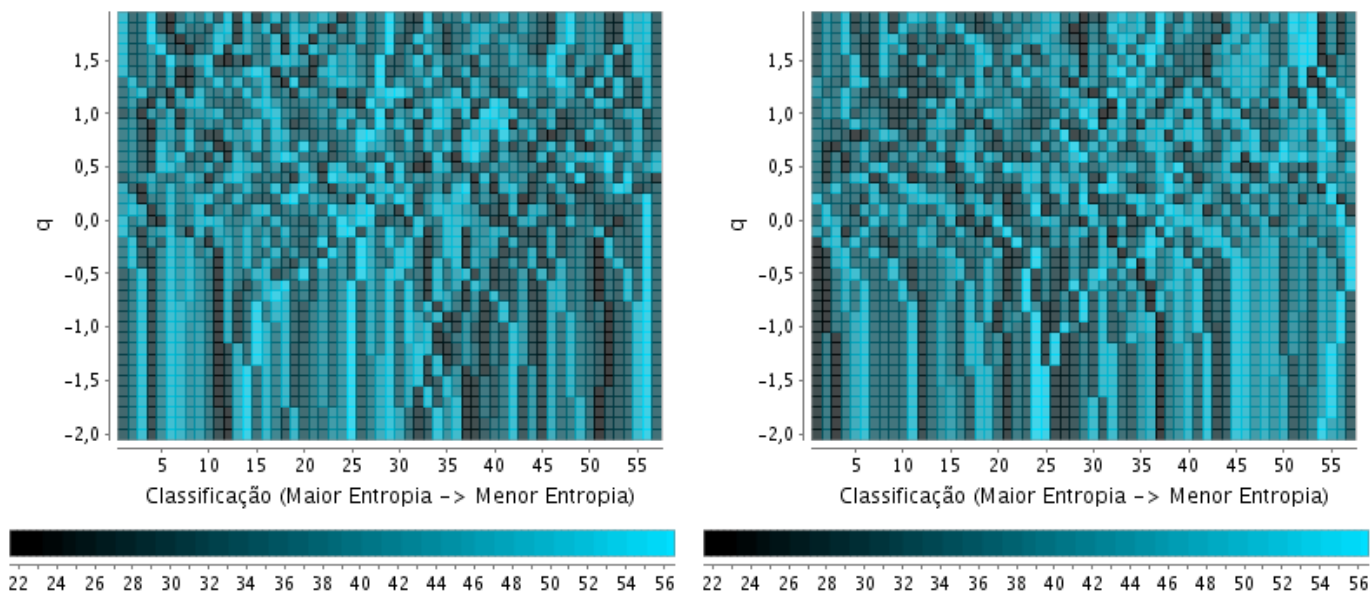

Mixed-Surrogate - Peso (REPOUSO)

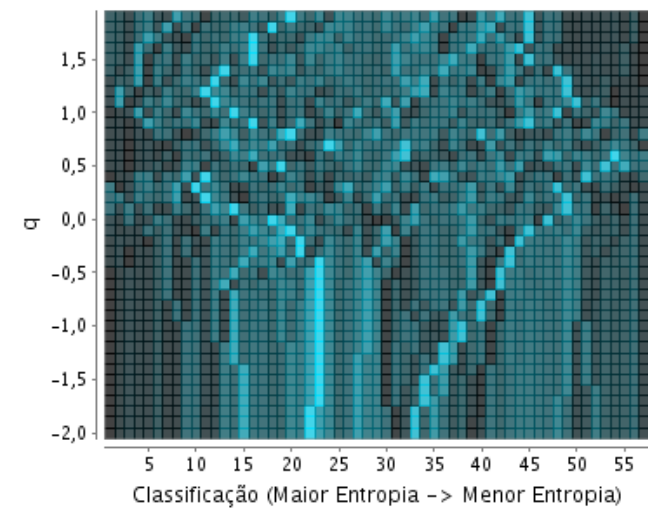

Mixed-Surrogate - Peso (TILT)

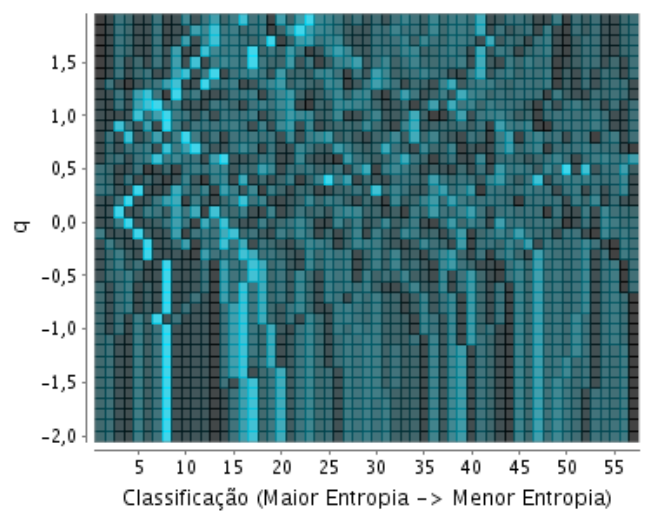

545760636669727578818487909396991031071111151191231271315457606366697275788184879093969910310711115119123127131

Figura 6.24: Diagrama de blocos com a classificação de cada série em relação à diferença de entropia entre a série original e a entropia média das séries surrogates tipo 3, utilizando a generalização da entropia dada pela equação (5.7). Em cor são destacadas a idade, peso e grupo de cada paciente. 

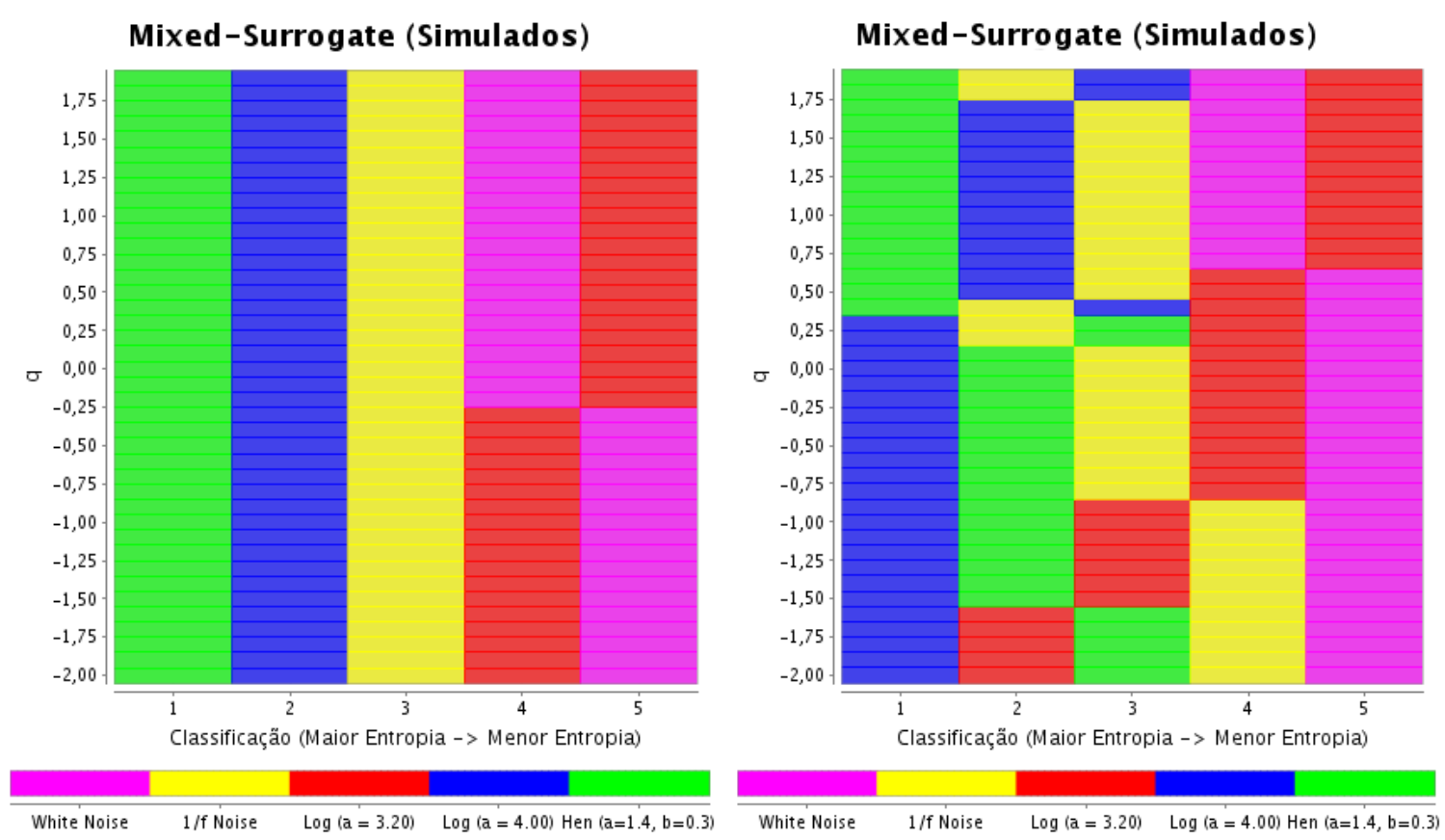

Figura 6.25: Diagrama de blocos com a classificação dos sinais simulados em relação à diferença de entropia entre a série original e a entropia média das séries surrogates tipo 3. O gráfico à esquerda mostra os resultados utilizando a generalização da entropia dada pela equação (5.5), e à direita utilizando a equação (5.7).

Pelos diagramas percebe-se novamente que não há uma perfeita discriminação das séries RR por nenhum dos parâmetros em destaque, considerando como critério de classificação os valores de diferença da entropia. No caso dos sinais simulados, os resultados são parecidos com os obtidos com as séries surrogates tipo 1, com a diferença de que agora, a série resultante do mapa logístico regular é praticamente nula para todo o intervalo de $q$ analisado.

\subsection{Sistema Computacional}

Como citado no Capítulo 5, todas as ferramentas computacionais implementadas neste projeto foram agrupadas em um sistema computacional de modo a facilitar os procedimentos de seleção dos sinais e métodos e visualização dos resultados. Inicialmente, a motivação para a criação deste sistema era apenas facilitar esses procedimentos de análise. Porém, com o tempo foi-se percebendo que um sistema com estas características poderia ser muito útil para outros pesquisadores, tanto na análise da variabilidade cardíaca como em outras análises envolvendo processamento de sinais (em especial dos sinais biológicos). Devido a isso, foi dispendido bastante esforço na sua implementação e aperfeiçoamento, paralelamente ao desenvolvimento do projeto. O aperfeiçoamento deste sistema contou fortemente com a participação do bolsista de treinamento técnico Juliano Jinzenji Duque, vinculado ao mesmo grupo de pesquisa deste 
projeto.

As principais características deste sistema são:

- Conexão com um sistema gerenciador de banco de dados (SGBD) PostgreSQL, no qual os dados de pacientes podem ser facilmente armazenados e recuperados. A estrutura de tabelas do banco de dados definida para essa funcionalidade é mostrada na Figura 6.26.

- Seleção de um sinal a partir de uma das fontes disponíveis:

- Banco de Dados;

- Gerador de Sinais, com os 4 tipos de sinais simulados descritos no capítulo anterior;

- Arquivo Texto, no formato ASCII;

- ICA (Independent Component Analysis). Neste caso, o que se oferece é a aplicação do algorítmo de ICA em um conjunto de séries, e ao final o usuário escolhe uma das séries resultantes para realizar as análises. A motivação para incorporar este método ao sistema são os dados de sinais multivariados que podem ser modelados como uma mistura linear de várias fontes de sinais independentes. Esta situação é bastante comum em sinais fisiológicos, como por exemplo a polissonografia e magnetocardiocrafia fetal.

- Seleção de uma ou mais ferramentas de análise ao mesmo tempo e visualização dos resultados em diferentes abas;

- Arquitetura aberta, o que significa que o sistema provê uma estrutura para que os usuários possam escrever seus próprios métodos, de uma maneira simplificada, e que o sistema reconhece esses métodos como plugins, permitindo a esses usuário utilizar a infraestrutura do sistema para avaliar seus métodos.

- Um detector de picos R foi incorporado ao sistema, permitindo aos usuários que disponham de ECGs converter esse sinal para uma séries RR antes da análise.

- Uma ferramenta simples de edição dos sinais é disponibilizada aos usuários para remover trechos indesejados dos sinais antes das análises.

Com estas características, este sistema pode ser bastante útil em diversas áreas de pesquisa envolvendo processamento de sinais biomédicos. A idéia é disponibilizar este sistema no futuro, como código aberto, para quem quiser utilizá-lo, modificá-lo ou aperfeiçoá-lo. Recentemente, 


\begin{tabular}{|c|c|c|c|c|}
\hline & & & Ex & am \\
\hline & & & • & $\operatorname{VARCHAR}(20)$ \\
\hline & & & •num exam & INTEGER \\
\hline • & $\operatorname{VARCHAR}(20)$ & $\mathrm{N}$ & opgroup & $\operatorname{VARCHAR}(30)$ \\
\hline `name & $\operatorname{VARCHAR}(40)$ & & 'weight & REAL \\
\hline 'birthdate & CHAR (10) & & oheight & REAL \\
\hline ogender & CHAR (1) & & oobs & TEXT \\
\hline & & & 'signal & TEXT \\
\hline & & & - samp le rate & INTEGER \\
\hline
\end{tabular}

Figura 6.26: Estrutura de tabelas definida para o banco de dados do sistema. O atributo id na tabela exam é chave extrangeira e indica que um exame está associado a um paciente; a ligação 1 para $\mathrm{N}$ indica que um paciente pode conter vários exames associados, o que é identificado pelo atributo num_exam da tabela exam.

um pequeno tutorial foi escrito, abordando suas principais características, bem como a estrutura de classes e as regras que envolvem a escrita dos plugins. A Figura 6.27 ilustra algumas interfaces gráficas do sistema.
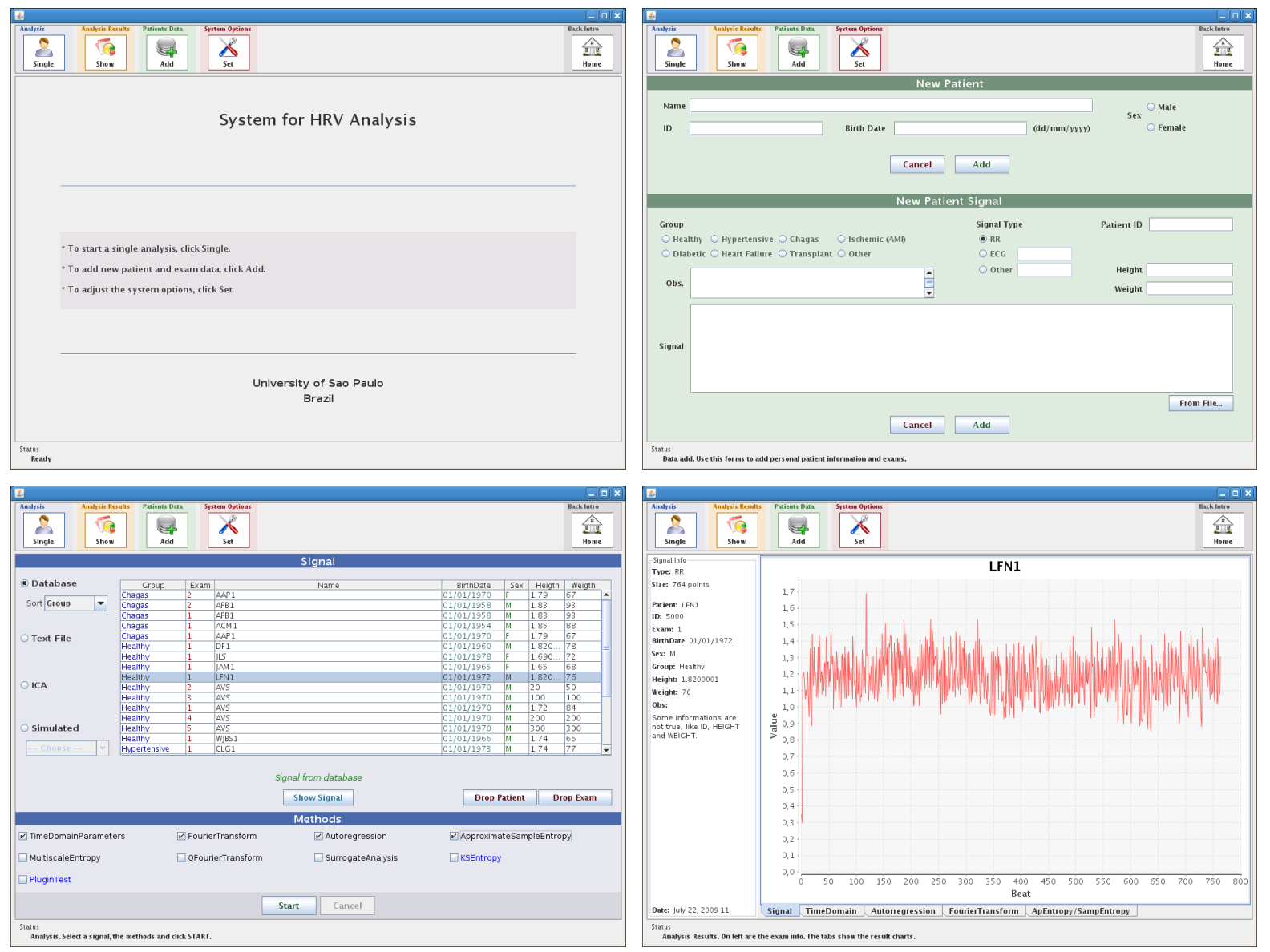

Figura 6.27: Screenshots de algumas telas da primeira versão do sistema. Acima é mostrada a tela de introdução do sistema (esq.) e a tela para inserção de novos registros no banco de dados (dir.). Abaixo é mostrada a tela de seleção do sinal e dos métodos de análise (esq.), sendo que os métodos implementados por usuários (plugins) aparecem em cor azul. À direita é mostrada a tela de resultados. Cada aba contém o resultado de um método diferente. 
Existem outros grupos de pesquisa em variabilidade cardíaca que também desenvolveram sistemas gratuitos de análise de séries RR que são bastante interessantes, como é o caso do sistema Kubios HRV [42], um sistema simples mas muito útil, desenvolvido por um grupo de pesquisadores da Finlândia. O sistema desenvolvido neste projeto possui algumas características diferentes do Kubios HRV, e o intuito com ele não é competir com os outros sistemas. Pelo contrário, espera-se acrescentar com esta ferramenta, tendo em mente que disponibilizando tal sistema com plataforma aberta podemos contribuir para a melhoria de todos os envolvidos nas pesquisas, sendo este nosso principal objetivo.

Um segunda versão do sistema está em fase de finalização. Sua principal diferença para a primeira versão é a reformulação das interfaces gráfica e a possibilidade de seleção de múltiplos sinais. Isso torna as análises mais consistentes, principalmente quando o intuito é comparar resultados entre grupos de sinais. Outras facilidades implementadas com esta nova versão são:

- todos resultados de análises ficam disponíveis para visualização, podendo serem salvos e recuperados pelo sistema.

- correção manual da detecção de picos, permitindo a inclusão e remoção de picos detectados automaticamente;

- inversão de polaridade de sinais;

- inclusão de novas fontes de seleção de sinais;

- todos os gráficos possuem parâmetros de visualização que podem ser definidos pelo usuário (escala e passo de cada eixo do sinal). 


\section{Conclusões e Perspectivas}

Os resultados obtidos com as entropias aproximada e amostral mostraram que a generalização utilizando a equação (5.5) não traz informações adicionais em relação às suas formulações clássicas, pois o comportamento das séries resultantes, neste caso, é regido diretamente pela função logarítmo generalizada ( $q$-logarítmo). Por outro lado, a generalização da equação (5.5) altera a percepção da entropia, resultando em séries com características diferentes, variando a ordem de classificação das séries com o valor de $q$. Neste caso as as séries se cruzam, e isso ocorre com maior intensidade no intervalo de $q$ entre 0 e 1.5 .

Nas avaliações utilizando séries surrogates, os resultados ressaltaram o potencial do parâmetro $q$ na entropia amostral, distinguindo as diferentes situações de complexidade dos sinais simulados e fornecendo algumas idéias quanto à interpretação dos resultados com séries RR. Os resultados também revelaram algumas características que necessitam ser mais exploradas para serem compreendidas. Com os diagramas de blocos foi possível observar que, nestas avaliações que levaram em conta a diferença de entropia, as maiores variações de classificação das séries ocorreram para $q>0$, sendo que o intervalo de 0 a 1 é onde ocorrem os fenômenos observados com a generalização da equação (5.7). Contudo, estes diagramas mostraram também que não houve, em nenhum momento, uma boa separação das séries RR quanto ao grupo, idade ou peso.

Os resultados obtidos com a entropia multiescala e com a transformada de Fourier ainda não foram concludentes e precisam ser melhor explorados. Em ambos os casos, a adição do parâmetro $q$ de não extensividade aumentou o número de graus de liberdade destas ferramentas, e consequentemente o domínio de avaliação delas. Em suas formulações clássicas, o resultado de cada uma é uma série de valores. Com a generalização, para cada valor de $q$ irá existir uma série resultante diferente, o que exige mais tempo e preparo para uma avaliação adequada. Apesar disto, os resultados obtidos neste trabalho demonstraram potencial desta generalização, incentivando uma maior exploração destas duas ferramentas.

De uma maneira geral, neste trabalho podemos concluir que o paradigma não extensivo mostrou-se útil aplicado na formulação de entropia aproximada/amostral. As duas formas de 
generalização avaliadas (equações 5.5 e 5.7) geraram diferentes resultados. A formulação da equação (5.5) mostrou-se útil apenas nas análises utilizando séries surrogates, enquanto que a formulação (5.7) já diferencia a percepção da entropia em sua aplicação direta; utilizada na análise surrogate, esta última formulação ainda apresentou um comportamento intrigante, que aparentemente carrega informações importantes da série, mas que precisa ser melhor compreendido. Para cada série, este comportamento de decrescimento lento e crescimento abrupto revela diferentes valores de mínimo, máximo e inclinação, valores que podem conter informação importantes sobre a série.

Com todos esses resultados observado até aqui, acredita-se que as séries RR carreguem consigo muitas informações importantes a respeito do estado fisiológico de um indivíduo, e que estas informações são provenientes dos mais variados mecanismos e sistemas regulatórios presentes no organismo humano, que interagem-se mutuamente a todo instante. Com isso, dentro de um mesmo grupo (por exemplo, de pacientes chagásicos ou com mesma idade) poderia existir uma grande variedade de estados fisiológicos, único em cada organismo, e isto pode ser refletido na dinâmica da série de intervalos de batimentos cardíacos, consideração que nos parece razoável uma vez que o sistema cardíaco utiliza-se de informações de todo o organismo na sua regulação. Com isto, a detecção de complexidade através da entropia leva em conta este estado fisiológico, sendo talvez uma explicação para as variações que ocorrem dentro de um mesmo grupo de pacientes.

A continuação deste trabalho está sendo planejado e consistirá do estudo aprofundado das generalizações da entropia multiescala e da transformada de Fourier. Pretende-se explorar com detalhes o comportamento da entropia amostral de um sinal nas suas diferentes escalas de visualização, bem como outras características da transformada de Fourier generalizada, como por exemplo o espetro de fases e sua representação em partes real e imaginária para diversos outros sinais simulados, buscando uma validação destas ferramentas para análise e interpretação com sinais reais de variabilidade cardíaca. 


\section{Referências Bibliográficas}

[1] GUYTON, A. C.; HALL, J. E. Textbook of Medical Physiology. 9. ed. [S.1.]: Elsevier, 1996.

[2] SöRNMO, L.; LAGUNA, P. Bioelectrical Signal Processing in Cardiac and Neurological Applications. [S.1.]: Elsevier, 2005.

[3] NAKAZATO, K. C. A Entropia Aproximada como Ferramenta Metodológica no Estudo da Variabilidade da Frequência Cardíaca em Pacientes com Hipertensão Arterial Primária e Doença de Chagas. Dissertação (Mestrado) — Departamento de Clínica Médica, Faculdade de Medicina de Ribeirão Preto, Universidade de São Paulo.

[4] PAGANI, M. et al. Power spectral analysis of heart rate and arterial pressure variabilities as a marker of sympatho-vagal interaction in man and conscious dog. Circ Res, v. 59, n. 2, p. 178-193, 1986.

[5] MALLIANI, A. et al. Cardiovascular neural regulation explored in the frequency domain. Circulation, v. 84, n. 2, p. 482-492, 1991.

[6] MONTANO, N. et al. Power spectrum analysis of heart rate variability to assess the changes in sympathovagal balance during graded orthostatic tilt. Circulation, v. 90, n. 4, p. 18261831, 1994.

[7] CARDIOLOGY, E. S. of; PACING, N. A. S. of; ELETROPHYSIOLOGY. Heart rate variability: Standards of measurement, physiological interpretation, and clinical use. Circulation, v. 93, n. 5, p. 1043-1065, 1996.

[8] BANNISTER, S. R. The diagnosis and treatment of autonomic failure. Journal of Autonomic Nervous System, v. 30, p. 519-524, 1990.

[9] THOMSON, P. D.; MELMON, K. L. Clinical assessment of autonomic function. Anesthesiology, v. 29, n. 4, p. 724-731, 1968.

[10] CLAYTON, R. et al. Comparison of autoregressive and fourier transform based techniques for estimating rr interval spectra. In: Computers in Cardiology 1997. [S.1.: s.n.], 1997. p. 379-382. ISSN 0276-6547.

[11] PORTA, A. et al. Progressive decrease of heart period variability entropy-based complexity during graded head-up tilt. J Appl Physiol, v. 103, n. 4, p. 1143-1149, 2007.

[12] AKAY, M. (Ed.). Nonlinear Biomedical Signal Processing. [S.1.]: IEEE Press, 2001.

[13] FREITAS, A. A. F. de. Sistema nervoso autônomo e aparelho cardiovascular: um paradigma de auto-organização, complexidade e caos. Rev. Port. Cardiol., v. 19, p. 161-191, 2000 . 
[14] PORTA, A. et al. Addressing the complexity of cardiovascular regulation. Philosophical Transactions of the Royal Society A: Mathematical, Physical and Engineering Sciences, v. 367, n. 1892, p. 1215-1218, 2009.

[15] SAVI, M. A. Dinâmica Não-linear e Caos. [S.1.]: E-Papers, 2006.

[16] BAKER, G. L.; GOLLUB, J. P. Chaotic Dynamics: an Introduction. Second. [S.1.]: Cambridge University Press, 1996.

[17] FIEDLER-FERRARA, N.; PRADO, C. P. C. Caos - Uma Introdução. [S.1.]: Edgard Blücher Ltda, 1995.

[18] SMITH, S. W. The Scientist and Engineer's Guide to Digital Signal Processing. California Technical Publishing, 1997. Disponível em: <http://www.dspguide.com>.

[19] BORGES, E. P. Irreversibilidade, desordem e incerteza: Três visões da generalização do conceito de entropia. Revista Brasileira de Ensino de Física, v. 21, n. 4, 1999.

[20] WILLIAMS, G. P. Chaos Theory Tamed. [S.1.]: Joseph Henry Press, 1997.

[21] TSALLIS, C. Computational applications of nonextensive statistical mechanics. Journal of Computational and Applied Mathematics, v. 227, n. 1, p. 51-58, maio 2009. ISSN 03770427.

[22] SPROTT, J. C. Chaos and Time-Series Analysis. [S.1.]: Oxford University Press, 2003.

[23] SHANNON, C. E.; WEAVER, W. The mathematical theory of communication. [S.1.]: University of Illinois Press, 1949.

[24] PINCUS, S. M. Approximate entropy as a measure of system complexity. Proceedings of the National Academy of Sciences of the United States of America, v. 88, n. 6, p. 2297-2301, 1991.

[25] GRASSBERGER, P.; PROCACCIA, I. Estimation of the kolmogorov entropy from a chaotic signal. Phys. Rev. A, American Physical Society, v. 28, n. 4, p. 2591-2593, Oct 1983.

[26] ECKMANN, J. P.; RUELLE, D. Ergodic theory of chaos and strange attractors. Rev. Mod. Phys., American Physical Society, v. 57, n. 3, p. 617-656, Jul 1985.

[27] COSTA, M.; GOLDBERGER, A. L.; PENG, C.-K. Multiscale entropy analysis of biological signals. Physical Review E (Statistical, Nonlinear, and Soft Matter Physics), APS, v. 71, n. 2, p. 021906, 2005.

[28] LAKE, D. E. et al. Sample entropy analysis of neonatal heart rate variability. Am J Physiol Regul Integr Comp Physiol, v. 283, n. 3, p. R789-797, 2002.

[29] RICHMAN, J. S.; MOORMAN, J. R. Physiological time-series analysis using approximate entropy and sample entropy. Am J Physiol Heart Circ Physiol, v. 278, n. 6, p. H20392049, 2000.

[30] COSTA, M.; GOLDBERGER, A. L.; PENG, C.-K. Multiscale entropy analysis of complex physiologic time series. Phys. Rev. Lett., American Physical Society, v. 89, n. 6, p. 068102-, jul. 2002. 
[31] BORGES, E. P. Na sutil fronteira entre a ordem e o caos. Ciencia Hoje, v. 38, n. 233, p. 43-47, jan/fev 2006.

[32] BORGES, E. P. A possible deformed algebra and calculus inspired in nonextensive thermostatistics. Physica A: Statistical Mechanics and its Applications, v. 340, n. 1-3, p. 95 101, 2004. ISSN 0378-4371. News and Expectations in Thermostatistics.

[33] MAY, R. M. Simple mathematical models with very complicated dynamics. Nature, v. 261, p. 459-467, jun. 1976.

[34] HéNON, M. A two-dimensional mapping with a strange attractor. Communications in Mathematical Physics, v. 50, p. 69-77, fev. 1976.

[35] UMAROV, S.; TSALLIS, C.; STEINBERG, S. A generalization of the central limit theorem consistent with nonextensive statistical mechanics. 2006.

[36] UMAROV, S.; TSALLIS, C.; STEINBERG, S. On a q-central limit theorem consistent with nonextensive statistical mechanics. Milan Journal of Mathematics, v. 76, n. 1, p. 307328, dez. 2008.

[37] BORGES, E. P. et al. Mother wavelet functions generalized through q -exponentials. Journal of Physics A: Mathematical and General, v. 37, n. 39, p. 9125, 2004.

[38] UMAROV, S.; TSALLIS, C. On a representation of the inverse fq-transform. Physics Letters A, v. 372, n. 29, p. 4874-4876, jul. 2008. ISSN 0375-9601.

[39] THEILER, J. et al. Testing for nonlinearity in time series: the method of surrogate data. Physica D Nonlinear Phenomena, v. 58, p. 77-94, set. 1992.

[40] SCHREIBER, T.; SCHMITZ, A. Improved surrogate data for nonlinearity tests. Phys. Rev. Lett., American Physical Society, v. 77, n. 4, p. 635-, jul. 1996.

[41] SHIAVI, R. Random signal modeling and parametric spectral estimation. In: Introduction to Applied Statistical Signal Analysis. Third edition. Burlington: Academic Press, 2007. p. 287 - 330. ISBN 978-0-12-088581-7.

[42] TARVAINEN, M. P. et al. Kubios HRV - A Software for Advanced Heart Rate Variability Analysis. 2009. 1022-1025 p. Disponível em: <http://kubios.uku.fi >. 